\title{
Preparation and anisotropic properties of textured structural ceramics: A review
}

\author{
Zhuo ZHANG ${ }^{a, b}$, Xiaoming DUAN ${ }^{a, b, c, *}$, Baofu QIU ${ }^{a, b}$, Zhihua YANG $^{a, b, c}$, \\ Delong $\mathrm{CAI}^{a, b}$, Peigang $\mathrm{HE}^{a, b}$, Dechang JIA ${ }^{a, b, c, *}$, Yu ZHOU ${ }^{a, b}$ \\ ${ }^{a}$ Key Laboratory of Advanced Structural-Functional Integration Materials \& Green \\ Manufacturing Technology, Harbin Institute of Technology, Harbin 150001, China \\ ${ }^{b}$ Institute for Advanced Ceramics, School of Materials Science and Engineering, \\ Harbin Institute of Technology, Harbin 150001, China \\ ${ }^{c}$ State Key Laboratory of Advanced Welding and Joining, Harbin Institute of \\ Technology, Harbin Institute of Technology, Harbin 150001, China
}

Received: November 23, 2018; Revised: March 16, 2019; Accepted: March 22, 2019

(c) The Author(s) 2019.

\begin{abstract}
Ceramics are usually composed of randomly oriented grains and intergranular phases, so their properties are the statistical average along each direction and show isotropy corresponding to the uniform microstructures. Some methods have been developed to achieve directional grain arrangement and preferred orientation growth during ceramic preparation, and then textured ceramics with anisotropic properties are obtained. Texture microstructures give particular properties to ceramics along specific directions, which can effectively expand their application fields. In this review, typical texturing techniques suitable for ceramic materials, such as hot working, magnetic alignment, and templated grain growth (TGG), are discussed. Several typical textured structural ceramics including $\alpha-\mathrm{Al}_{2} \mathrm{O}_{3}$ and related nacre bioinspired ceramics, $\mathrm{Si}_{3} \mathrm{~N}_{4}$ and $\mathrm{SiAlON}, \mathrm{h}-\mathrm{BN}, \mathrm{MB}_{2}$ matrix ultra-high temperature ceramics, MAX phases and their anisotropic properties are presented.
\end{abstract}

Keywords: texture; structural ceramics; anisotropic properties; strengthening and toughening mechanisms

\section{Introduction}

Since the periodicity and density of the atoms in single crystals are not identical along different directions, the physical and chemical properties of single crystals along different directions are various. But most materials, either metals or ceramics, are polycrystalline materials composed of unoriented grains, resulting in their isotropic

*Corresponding authors.

E-mail: X. Duan, duanxiaoming@hit.edu.cn,dxmhit@126.com; D. Jia,dcjia@hit.edu.cn properties. When some external conditions, such as stress fields, electromagnetic fields, and temperature fields, are applied during the process of material preparation, grains can be preferentially aligned along specific crystallographic directions, forming texture microstructures [1-3]. Performances of materials along preferred crystal lattice orientation can be enhanced by texturing so that they can be applied to more harsh service environments [4-6].

For many metallic materials, their slip systems can be activated at suitable temperature, and then grains can be easily oriented by deformation, such as rolling 
and extrusion [7-12]. Subsequent heat treatment of deformed metal can result in oriented nucleation of recrystallization and preferred orientation growth [1317]. By appropriate deformation and heat treatment, texture degree and grain size of metals can be adjusted, and the required anisotropic properties can be obtained [18-21]. Unlike metals, atoms in ceramics are mainly interconnected by covalent and ionic bonds, which are strong enough to prevent plastic deformation. So deformation techniques are not suitable for texture formation of ceramics. Specific techniques, such as hot working, magnetic alignment, and templated grain growth (TGG), have been invented, which can effectively promote the preferred orientation of ceramic grains $[2,22,23]$.

Textured ceramics have many superior properties compared with ceramics composed of randomly oriented grains. As for functional ceramics, texture microstructures can increase the critical current density of superconductors [24-26], increase the electrical conductivity of ionic conductors $[27,28]$, heighten the magnetic anisotropy of hexaferrite ceramics [29-31], and improve the electromechanical coupling coefficient of piezoelectric ceramics [32-35]. As for structural ceramics, fracture toughness along specific directions increases with the incorporation of oriented grains, which favor the mechanisms of crack deflection, crack bridging, and grain pull-out [36-39]. Figure 1 shows the schematic diagram of the microstructure of a lamellar textured porous $\alpha$-alumina $\left(\alpha-\mathrm{Al}_{2} \mathrm{O}_{3}\right)$ specimen prepared by hotpressing (HP) and its anisotropic mechanical properties and thermal conductivities [40]. Due to the texture microstructure, it possesses higher thermal conductivity

\section{Pressing direction during fabrication}

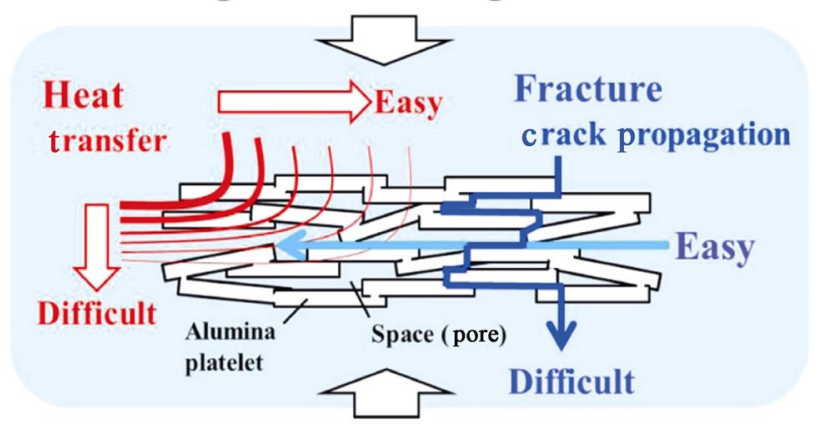

Fig. 1 Schematic diagram of the microstructure and anisotropic mechanical properties and thermal conductivities of a lamellar textured porous $\alpha-\mathrm{Al}_{2} \mathrm{O}_{3}$ specimen prepared by HP. Reproduced with permission from Ref. [40], (C) Elsevier Ltd and Techna Group S.r.1. 2015. along the lamella and better mechanical properties perpendicular to the lamella.

There are many examples of textured materials with excellent performances in natural creatures. Natural materials, such as nacre, bone, and bamboo, usually combine stiff and soft components and possess hierarchical structures [41]. For example, many skeletal tissues consist of organic fibrils and mineral particles $[42,43]$. In the exoskeleton of Homarus americanus, the organic matrix consists of $\alpha$-chitin fibrils and some noncrystalline proteins. Most of the $\alpha$-chitin lattice cells are oriented with the long crystallographic axis towards the surface of the exoskeleton to provide mechanical support for the body [44]. Another typical example is that many mollusks protect themselves from predators by their hard external shells consisting of a brittle external calcite layer and a tough internal nacre layer. The nacre layer is composed of aragonite, chitin, and proteins, and possesses the brick-and-mortar structure employing a variety of toughening mechanisms such as crack deflection and microbuckling to induce a gradual "graceful failure" [45]. Inspired by specific structures of natural creatures, much research has been put into textured materials possessing hierarchical structures [46-58].

There have already been some reviews about textured metals and functional ceramics [32,59-63]. But there are few summaries about textured structural ceramics. In this review, an overview of preparation methods of textured structural ceramics is given. In addition, the state of the art of several typical textured structural ceramics and their anisotropic properties are discussed. The aim of this review is to give a brief introduction of textured structural ceramics for new researchers in this field and to provide some useful references for them.

\section{Characterization of texture}

Texture can be divided into morphological texture where anisometric grains are oriented and crystallographic texture where grains have preferred crystal lattice orientation. These axis orientations (the $c$-axis orientation, the $a, b$-axis orientation, etc.) in the remainder of this review all refer to the crystallographic axes system. Morphological texture and crystallographic texture usually coexist for textured structural ceramics. Morphological texture can be characterized by microscopes such as optical microscope $(\mathrm{OM})$, scanning electron microscope 
(SEM), transmission electron microscope (TEM), etc. Crystallographic texture can be characterized by pole figures and inverse pole figures obtained with X-ray diffraction (XRD) and electron back scattering diffraction (EBSD) using SEM, Euler maps obtained with EBSD using SEM, etc. The diffraction intensities of special crystal planes obtained by XRD and neutron diffraction (ND) can also be used to characterize crystallographic texture. ND is very useful to analyze large bulk materials as neutrons have the highest penetration among neutrons, electrons, and X-ray [64], and it can also be used for in situ observation of texture development due to its low absorption [65-67]. As the characterization methods of texture are usually used in the following parts of this review, they are discussed here firstly.

\section{1 Characterization of morphological texture}

$\mathrm{OM}$ and SEM can provide visualized morphology information of textured materials. TEM can be used to observe morphological microstructure and determine grain orientation in a small area of several micrometers. Figure 2 shows the polished surface morphology of textured alumina observed by $\mathrm{OM}$, indicating that plate-like alumina grains were oriented perpendicular to the magnetic field that applied during slip casting [68]. But in most cases, especially for the ceramics with fine grain sizes, SEM is used more frequently due to its higher resolution than OM. Figure 3 shows the fracture morphology of textured alumina ceramics [69]. Although the grain size is only about $1-5 \mu \mathrm{m}$, texture characteristics can be observed clearly. And the relationship between magnetic field and grain preferred orientation is the same as that in Fig. 2. Figure 4 shows the TEM images of textured h-BN-MAS composites prepared from $\mathrm{h}-\mathrm{BN}$ powders with different sizes, where grain size and morphology are clearly seen [70]. The grain orientation is more obvious for textured specimen prepared using h-BN powders with large size.

For textured ceramics mainly containing elongated grains, orientation factor $f_{0}$ can be calculated from SEM morphology images to quantitively characterize morphological texture degree, which is defined as Eq. (1) [71]:

$$
f_{0}=\frac{2}{N} \sum_{i=1}^{N} \cos ^{2} \theta_{i}-1
$$

where $N$ is the number of elongated grains, and $\theta_{i}$ is the tilt angle between the real grain orientation and the
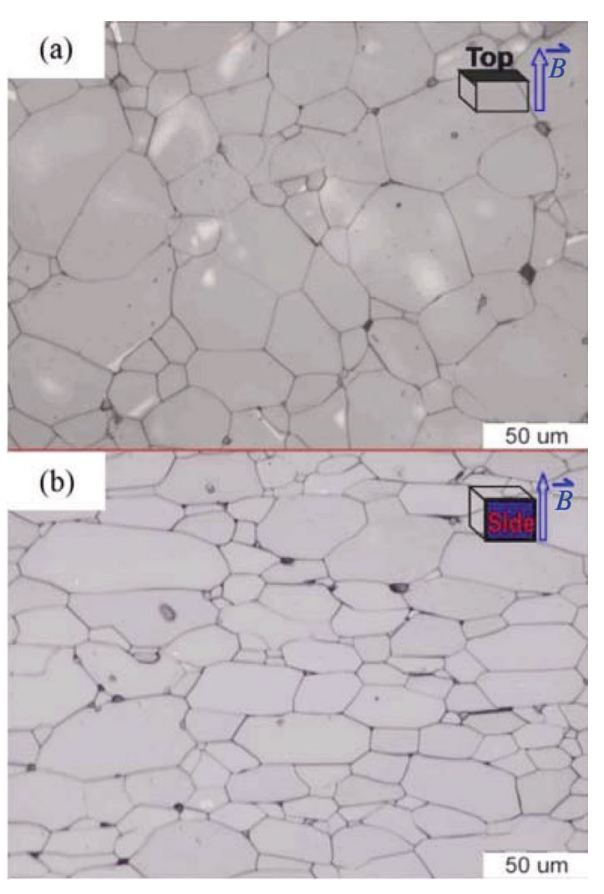

Fig. 2 OM thermal etched surfaces of textured alumina ceramics: (a) perpendicular to the magnetic field direction; (b) parallel to the magnetic field direction. Reproduced with permission from Ref. [68], (C) Elsevier Ltd and Techna Group S.r.1. 2012.
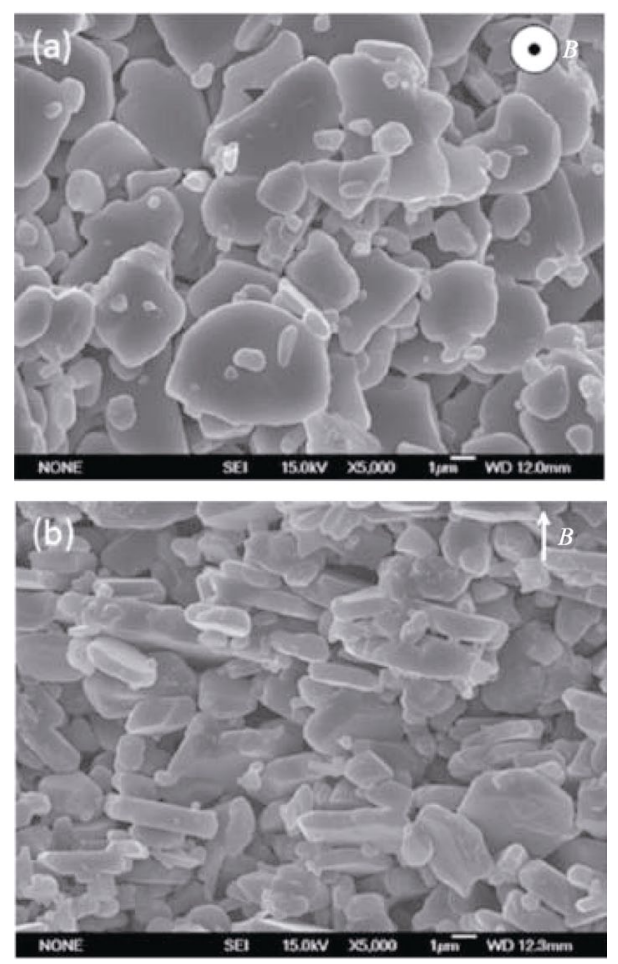

Fig. 3 SEM fracture morphologies of textured alumina ceramics: (a) perpendicular to the magnetic field direction; (b) parallel to the magnetic field direction. Reproduced with permission from Ref. [69], C WILEY - VCH Verlag $\mathrm{GmbH} \&$ Co. KGaA, Weinheim 2015. 


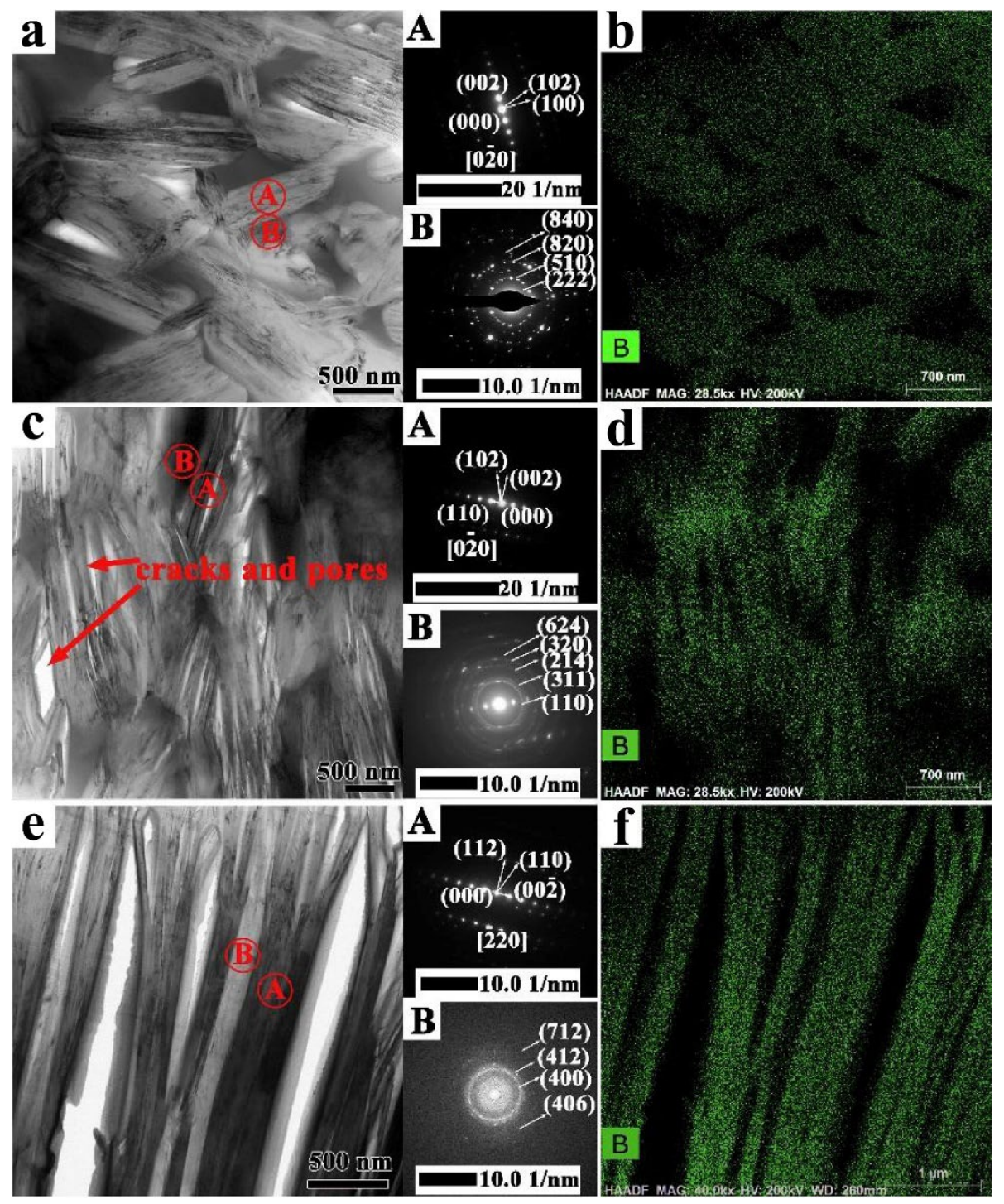

Fig. 4 Bright field TEM images, corresponding SAED patterns, and elemental distributions of boron for textured h-BN-MAS composites prepared from h-BN powders with different sizes: (a, b) $0.5 \mu \mathrm{m}$; (c, d) $5.0 \mu \mathrm{m}$; (e, f) $11.0 \mu \mathrm{m}$. Reproduced with permission from Ref. [70], (C) Elsevier Ltd. 2018.

ideal texture orientation. $N$ and $\theta_{i}$ can be obtained by image analysis software. For a sample with randomly oriented grains, $f_{0}=0$. For samples with perfect texture parallel and perpendicular to the ideal texture orientation, $f_{0}=1$ and -1 , respectively.

\section{2 Characterization of crystallographic texture}

\subsubsection{Pole figures, inverse pole figures, and Euler maps}

EBSD device attached to SEM can provide Kikuchi patterns and further give orientation maps (Euler maps) [72-75]. The schematic diagram of EBSD is shown in Fig. 5, where the two diffraction cones (Kossel cones) of two sides of one crystal plane form the Kikuchi band on the screen [76].

EBSD and XRD can both provide pole figures and inverse pole figures, which can provide the orientation information on one sample surface. Pole figures show the projection of the crystal orientation in the sample coordinate system, and inverse pole figures show the projection of the sample orientation in the crystal coordinate system [77]. To obtain the $\{h k l\}$ pole figure of one polycrystalline sample by XRD, the $2 \theta$ angle determined by Bragg's law should be fixed and the sample should be rotated in the coordinate system so that diffraction can occur at all $\{h \mathrm{kl}\}$ crystal planes in every crystal [78]. EBSD can provide pole figures by indexing Kikuchi patterns. EBSD possesses a much 


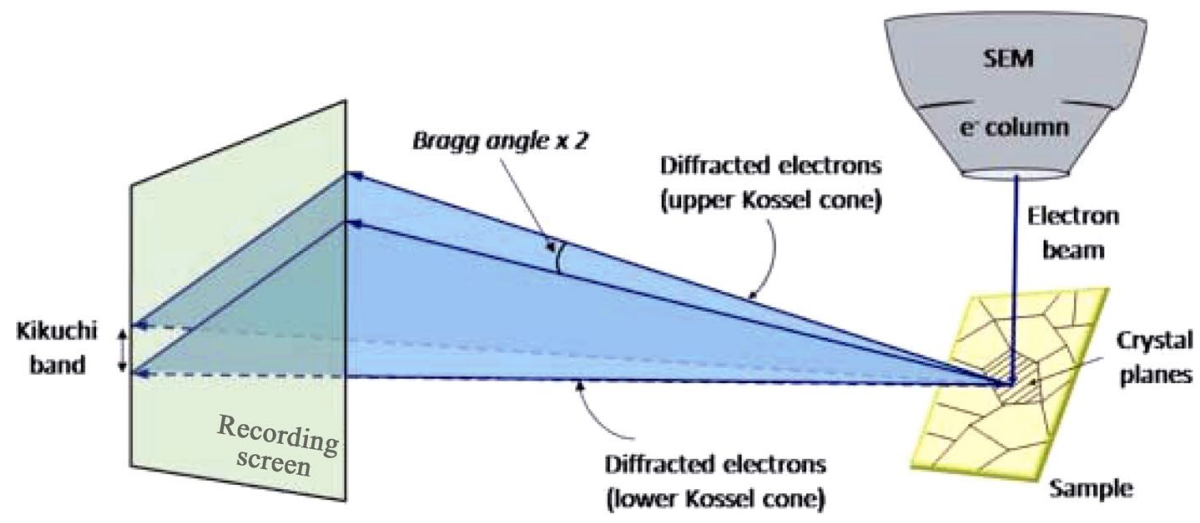

Fig. 5 Schematic of Kikuchi patterns obtained by EBSD. Reproduced with permission from Ref. [76], (c) Elsevier B.V. 2015.

higher spatial resolution than XRD as the electron beam can be focused.

Ni et al. [79] prepared textured h-BN matrix ceramics by slip casting and SPS using irregularly shaped and platelike h-BN powders as raw materials, respectively. Figures 6(a) and 6(b) give h-BN (002) pole figures on the surfaces perpendicular to the casting direction of slip casting green bodies obtained by XRD. The pole figure of the green body prepared using plate-like powders possesses stronger intensity in the center than the other, indicating that plate-like powders are more favorable to texture formation than irregular shaped powders. Figures 6(c) and 6(d) show fracture morphologies of the surfaces parallel to the casting direction of sintered specimens, where the specimen prepared using platelike powders is composed of plate-like grains with strong orientation, while that prepared using irregularly shaped powders mainly contains irregular shaped grains without orientation.

The numbers in pole figures of Fig. 6 are the multiples of a random distribution (MRD) defined as the volume fraction of the grains with certain orientation in the textured specimen divided by that in the homogeneous specimen, which can reflect texture degree. $M R D=1$ and $>1$ represent random orientation and preferred orientation, respectively. Higher $M R D$ values represent
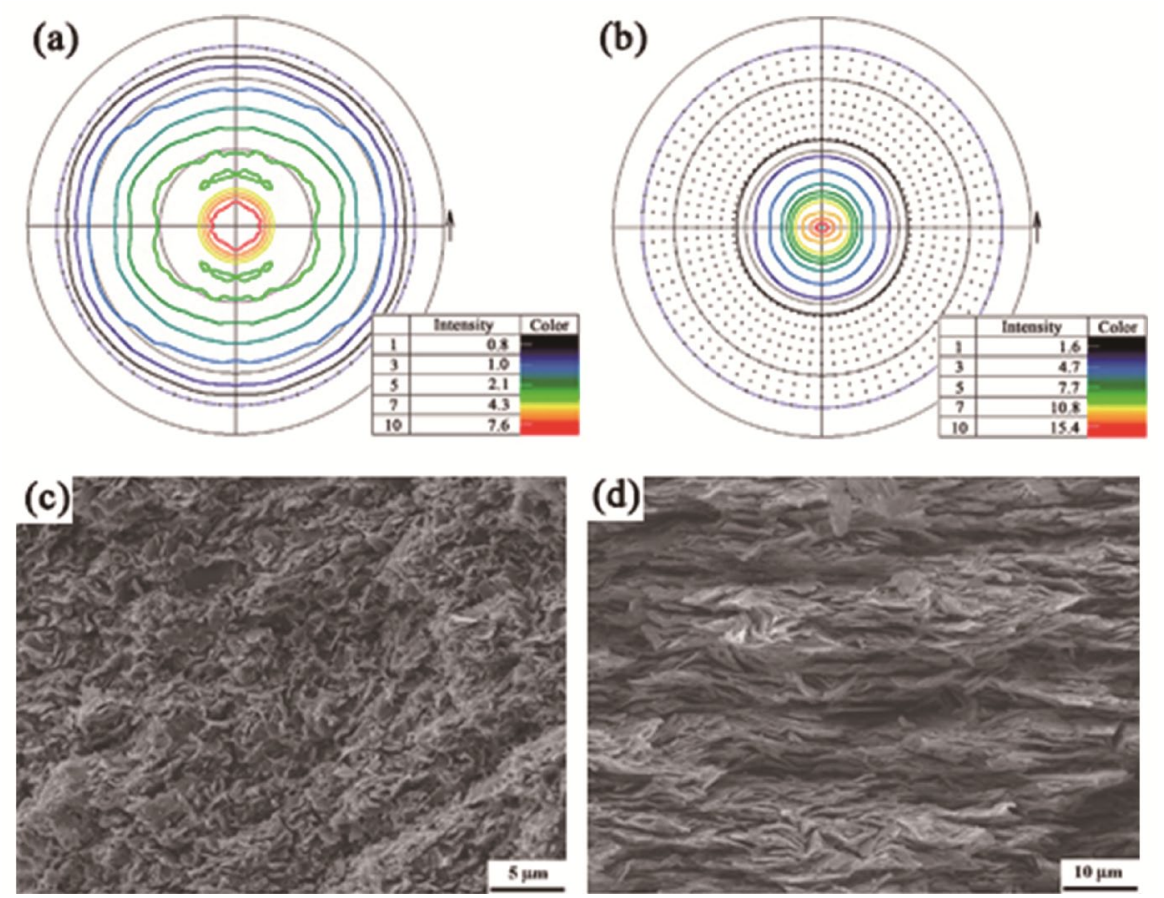

Fig. 6 h-BN (002) pole figures of surfaces perpendicular to the casting direction of green bodies and fracture morphologies of surfaces parallel to the casting direction of sintered specimens prepared using: (a, c) irregular shaped powders; (b, d) plate-like powders. Reproduced with permission from Ref. [79], (C) The American Ceramic Society 2011. 
higher texture degree.

As the volume fraction of grains with a given orientation is proportional to the relative intensity of specific XRD peak, $M R D$ values are usually obtained with XRD [79,80]. MRD values can be calculated by the March-Dollase function expressed as Eq. (2) [81-83]:

$$
P_{r}(\eta)=\left(r^{2} \cos ^{2} \eta+r^{-1} \sin ^{2} \eta\right)^{-3 / 2}
$$

where $r$ is the orientation parameter, which was defined as the ratio of the final specimen thickness after compaction to the initial specimen thickness in the original model. $r=1$ for a homogeneous specimen and $r \rightarrow 0$ for a perfectly textured specimen. $\eta$ is the tilt angle between the preferred orientation axis and the scattering vector. For the slip casting h-BN green bodies, the preferred orientation of the $c$-axis is parallel to the casting direction. If the green body possesses perfect texture microstructure, $r \rightarrow 0, P_{r}(\eta) \rightarrow \infty$ at $\eta=0$ and $P_{r}(\eta) \rightarrow 0$ at $\eta=\pi / 2$. So $M R D$ values are the highest at the pole figure center in Fig. 6.

Figure 7 shows the Euler maps and inverse pole figure of textured $\alpha-\mathrm{Al}_{2} \mathrm{O}_{3}$ ceramics prepared by magnetic alignment and pressureless sintering [84]. The orientation of each grain in Euler maps is represented by its color. The corresponding orientations of different colors are shown in Fig. 7(c). The inverse pole figure shows the orientation information on the cross-section perpendicular to the magnetic field direction. Combining Figs. 7(a), 7(b), and 7(c). (0 $\overline{1} 10),(0 \overline{2} 10)$, and (0 $\overline{1} 00)$ crystal planes are mainly distributed on the surface parallel to the magnetic field direction, while (0001) plane is mainly distributed on the cross-section perpendicular to the magnetic field direction. The intensity around (0001) plane is the highest in Fig. 7(d), also indicating that (0001) plane is oriented perpendicular to the magnetic field direction, i.e., the $c$-axis is oriented parallel to the magnetic field direction.

\subsubsection{Orientation factors calculated from XRD patterns}

The formation of crystallographic texture in materials will correspond to the changing of relative intensities of XRD peaks, which are different from the standard data of the JCPDS card obtained from the powders of the specific material. Now several methods have been developed to calculate the orientation factors to quantitively evaluate the texture degree, but we should determine the most suitable method according to the specific material.

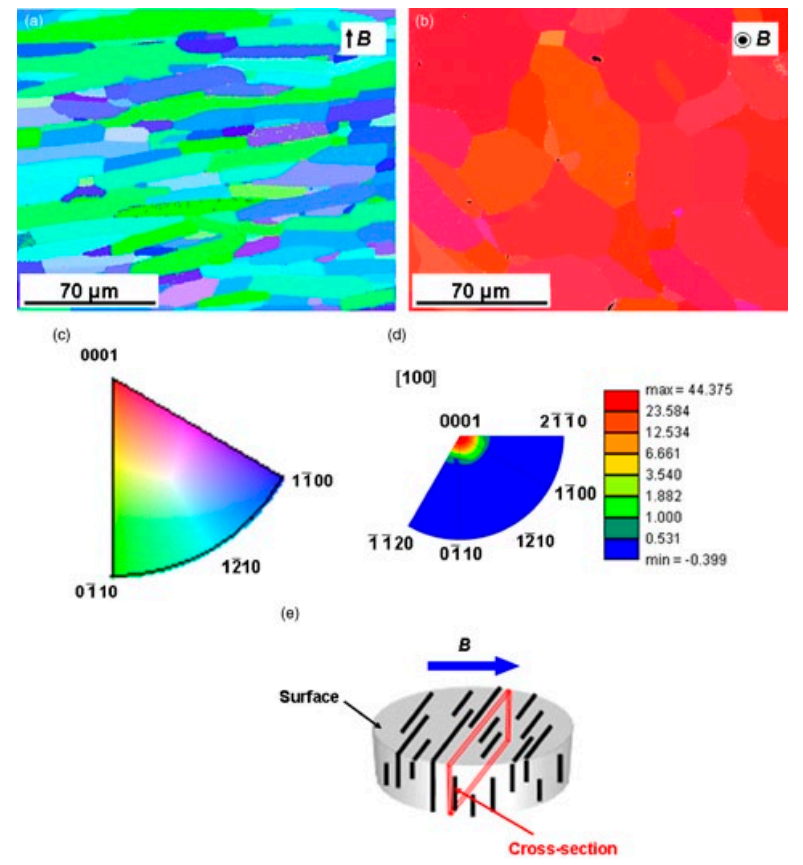

Fig. 7 Euler maps and inverse pole figure of textured $\alpha-\mathrm{Al}_{2} \mathrm{O}_{3}$ ceramics prepared by magnetic alignment and pressureless sintering: $(\mathrm{a}, \mathrm{b})$ Euler maps of the surface and the cross-section of textured $\alpha-\mathrm{Al}_{2} \mathrm{O}_{3}$ ceramics; (c) color map indicating the orientation in (a) and (b); (d) inverse pole figure for (b); (e) schematic diagram of the surface and the cross-section of textured $\alpha-\mathrm{Al}_{2} \mathrm{O}_{3}$ ceramics. Reproduced with permission from Ref. [84], (C) The American Ceramic Society 2010.

\section{(1) Lotgering factor $f$}

The most widely used factor quantitively characterizing texture degree is Lotgering factor $f$, which can be calculated according to Eq. (3) [40]:

$$
f=\frac{P-P_{0}}{1-P_{0}}
$$

where $P$ is the ratio of the diffraction peak intensity of the preferred orientation to all the diffraction peaks on the surface of textured sample, and $P_{0}$ represents that of the standard data. Obviously, $P \leqslant 1$. For the sample totally composed of randomly oriented grains, $P=P_{0}$ and $f=0$. For one sample completely textured, that is, composed of grains with perfectly preferred orientation, $P=1$, and $f=1$. Lotgering factor reflects the fraction of the area with a specific prefered orientation. As for materials belonging to the hexagonal crystal lattice such as $\alpha-\mathrm{Al}_{2} \mathrm{O}_{3}, \mathrm{Si}_{3} \mathrm{~N}_{4}, \mathrm{~h}-\mathrm{BN}$, and MAX phases, $(00 l)$ peaks are the main diffraction peaks on the textured sample surface perpendicular to the preferred orientation of the $c$-axis, so $P=\sum I_{00 l} / \sum I_{h k l}$, and the Lotgering factor is $f_{00 l}$. If one sample belonging to 
the hexagonal crystal lattice is totally textured, $f_{00 l}$ on that surface is 1 . If the sample is totally composed of randomly oriented grains, $f_{00 l}$ on all surfaces of the sample is 0 [40]. Besides $(00 l)$ planes, there are also some other planes can be used to calculate the Lotgering factor. For example, Zhang et al. [84] prepared textured $\alpha-\mathrm{Al}_{2} \mathrm{O}_{3}$ by slip casting in a strong magnetic field parallel to the horizon, and the $c$-axis of $\alpha-\mathrm{Al}_{2} \mathrm{O}_{3}$ was preferentially oriented parallel to the magnetic field. On the top surface of the sample, not $(00 l)$ but (110) and (300) were the strong diffraction peaks, so $P=\left(I_{110}+I_{300}\right) / \sum I_{h k l}$.

(2) Index of orientation preference

Index of orientation preference (IOP) is another indicator that is usually used to characterize the texture degree of HPed h-BN ceramics. IOP values are calculated by Eq. (4) [1]:

$$
\begin{aligned}
& I O P= \\
& \left\{\begin{array}{l}
\frac{\left(I_{100} / I_{002}\right)_{\mathrm{perp}}}{\left(I_{100}^{\prime} / I_{002}^{\prime}\right)_{\mathrm{par}}},\left(I_{100} / I_{002}\right)_{\mathrm{perp}}>\left(I_{100}^{\prime} / I_{002}^{\prime}\right)_{\mathrm{par}} \\
-\frac{\left(I_{100}^{\prime} / I_{002}^{\prime}\right)_{\mathrm{par}}}{\left(I_{100} / I_{002}\right)_{\mathrm{perp}}},\left(I_{100} / I_{002}\right)_{\mathrm{perp}}<\left(I_{100}^{\prime} / I_{002}^{\prime}\right)_{\mathrm{par}}
\end{array}\right.
\end{aligned}
$$

where $I$ and $I^{\prime}$ are the corresponding diffraction intensities on the sample surface perpendicular and parallel to the external pressure, respectively. If the sample is composed of randomly oriented grains, $I O P= \pm 1$. If the $c$-axis of the sample is preferentially oriented parallel to the pressure direction, $I O P<-1$. If the $c$-axis of the sample is preferentially oriented prependicular to the pressure, $I O P>1$. Obviously, the larger absolute value of $I O P$ indicates the more significant preferred orientation.

(3) Orientation factor $P$

Orientation factor $P$ has been developed to characterize texture degree of $\alpha-\mathrm{Al}_{2} \mathrm{O}_{3}$. On the textured $\alpha-\mathrm{Al}_{2} \mathrm{O}_{3}$ sample surface perpendicular to the $c$-axis orientation, the texture degree can be calculated by Eq. (5) [69]:

$$
P=I_{006} /\left(I_{006}+I_{110}\right)
$$

For the standard $\alpha-\mathrm{Al}_{2} \mathrm{O}_{3}$ powders, $P$ is about 0.02 [85]. $P$ can reach 1 for the perfectly textured $\alpha-\mathrm{Al}_{2} \mathrm{O}_{3}$. The more closer $P$ to 1 indicates the more significant texture of the sample.

\section{Preparation of textured ceramics}

In this part, three texturing techniques (hot working, magnetic alignment, and TGG) commonly used for ceramic materials are reviewed. Their key technological parameters (the pressure for hot working, the magnetic intensity for magnetic alignment, the amount and morphology of template grains for TGG, etc.) influencing texture formation and properties of ceramics are analyzed.

Although there are some other methods, such as slip casting [79,86,87], extrusion [88-92], tape casting [9398], can also be used to form texture microstructures in ceramics, they are usually used as aids to other techniques and not aimed at texture formation. For example, slip casting is usually conducted in magnetic fields to orientate ceramic grains with magnetic anisotropy [81,99-110], extrusion, and tape casting are usually used to align template grains for TGG [111-114]. So they are not discussed solely here.

\section{1 Texturing techniques}

\subsubsection{Hot working}

Hot working is to apply uniaxial pressure to align grains and form texture microstructures during high temperature sintering or heat treatment. As for metals, the external uniaxial pressure on the specimen can lead to grain boundary slip and dislocation movement inside grains $[115,116]$. As for ceramics, the uniaxial pressure can result in grain rotation and preferred orientation growth, forming texture microstructures [38,117]. External pressure can also promote densification of ceramic materials and reduce sintering temperature to a certain extent [118-121].

For ceramic materials belonging to the hexagonal crystal lattice, grains usually present plate-like or rod-like morphologies. It is easy for them to form texture by grain rotation during hot working. $\alpha-\mathrm{Al}_{2} \mathrm{O}_{3}$, hexagonal boron nitride (h-BN), and MAX phases tend to grow along the $a, b$-axis, forming plate-like grains rotated with the $c$-axis parallel to the pressure direction (the $c$-axis oriented texture) $[1,122,123] . \mathrm{Si}_{3} \mathrm{~N}_{4}$ and $\mathrm{SiAlON}$ incline to grow along the $c$-axis, forming rod-like grains rotated with the $c$-axis perpendicular to the pressure direction (the $a, b$-axis oriented texture), that is, rod-like grains tend to be arbitrarily oriented in the plane perpendicular to the pressure direction $[6,124]$. Besides these structural ceramics belonging to the hexagonal crystal lattice, hot working can also be used to prepare some textured piezoelectric ceramics with bismuth layered structure $[125,126]$. 
Hot working can be divided into hot-pressing (HP), hot-forging (HF), and sinter-forging (SF). $\mathrm{HP}$ is to sinter ceramics under uniaxial pressure. Spark plasma sintering (SPS), also called pulsed electric current sintering (PECS), also belongs to HP, and there is not only uniaxial pressure but also electric current applied to the specimen during SPS [40,126]. Figure 8 shows preparation and fracture morphologies of textured h-BN matrix ceramics by HP [127]. Plate-like h-BN grains can be rotated with the $c$-axis parallel to the pressure direction. Figure 8(a) shows the schematic diagram of the preparation process, where two plate-like specimens with their normals parallel and perpendicular to the HP direction and the crystal structure of h-BN are also shown. Figures 8(b) and 8(c) display fracture morphologies perpendicular and parallel to the HP direction of textured h-BN matrix ceramics, respectively, where plate-like h-BN grains are oriented perpendicular to the pressure direction. HF is a superplastic deformation technique to forge the sintered specimen by applying uniaxial pressure at high temperature. Figure 9 shows the preparation and fracture morphologies of textured $\mathrm{Si}_{3} \mathrm{~N}_{4}$ matrix ceramics by hot working [23,128]. Figures 9(a) and 9(b) show two superplastic deformation techniques under simple compression (SC) and plane-strain compression (PSC). SC can generate the $a, b$-axis oriented texture, which is the most common texture of $\mathrm{Si}_{3} \mathrm{~N}_{4}$ ceramics containing rod-like grains. Xie et al. [129] prepared $\mathrm{Si}_{3} \mathrm{~N}_{4}-\mathrm{Si}_{2} \mathrm{~N}_{2} \mathrm{O}$ ceramics possessing the $c$-axis oriented texture with rod-like grains oriented in one direction by forging the specimen in a graphite channel die, that is, superplastic deformation under PSC. SF combines sintering and HF into one step $[23,124,127,130]$. Figure 9(c) shows the photographs of the $\mathrm{Si}_{3} \mathrm{~N}_{4}$ green body after cold isostatic pressing (CIP) and the as-sintered $\mathrm{Si}_{3} \mathrm{~N}_{4}$ specimen prepared by CIP and SF. Figures 9(d) and 9(e) show fracture morphologies of $\mathrm{Si}_{3} \mathrm{~N}_{4}$ specimens prepared by $\mathrm{HP}$ and $\mathrm{SF}$ at $1900{ }^{\circ} \mathrm{C}$ for $3 \mathrm{~h}$ under $30 \mathrm{MPa}$, respectively. The SFed specimen possesses more significant texture microstructure than the HPed specimen, indicating SF is more favorable to texture formation than HP.

\subsubsection{Magnetic alignment}

Some materials possess magnetic anisotropy, i.e., the magnetic susceptibilities vary along different crystallographic directions, so they can be highly oriented by slip casting or gelcasting in magnetic fields $[2,131]$. For materials belonging to the hexagonal crystal lattice, such as $\alpha-\mathrm{Al}_{2} \mathrm{O}_{3}, \mathrm{Si}_{3} \mathrm{~N}_{4}$, and MAX phases, the anisotropy of magnetic susceptibilities $\Delta \chi$ can be expressed as Eq. (6) [132,133]:

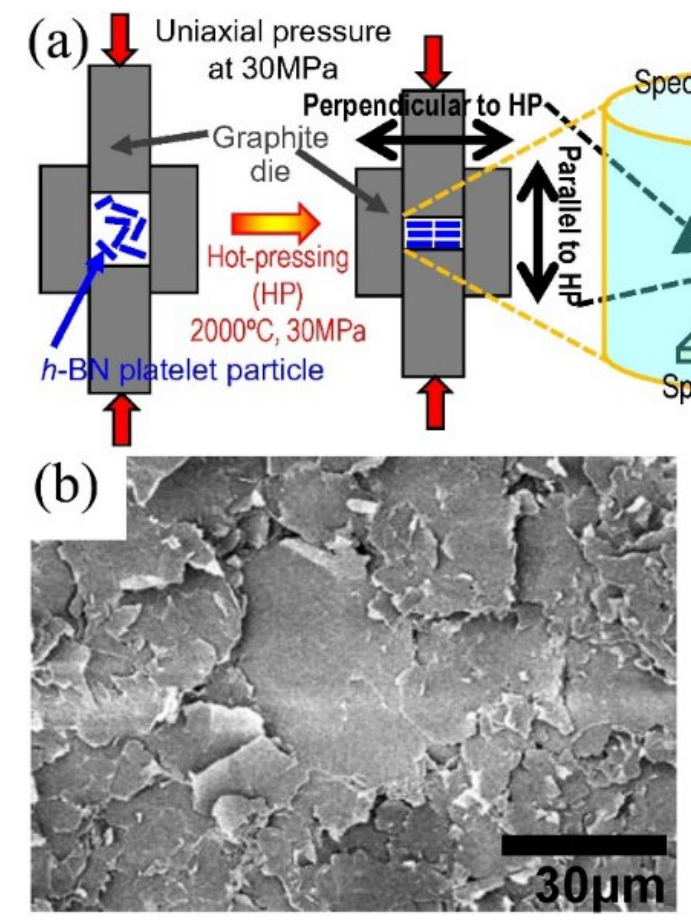

Fig. 8 Preparation and fracture morphologies of textured h-BN matrix ceramics prepared by HP: (a) schematic diagram of the preparation process; $(b, c)$ fracture morphologies perpendicular and parallel to HP direction of textured h-BN ceramics sintered with 15 vol\% $\mathrm{Yb}_{2} \mathrm{O}_{3}-\mathrm{MgO}$ additive, respectively. Reproduced with permission from Ref. [127], (C) Acta Materialia Inc. 2016. 


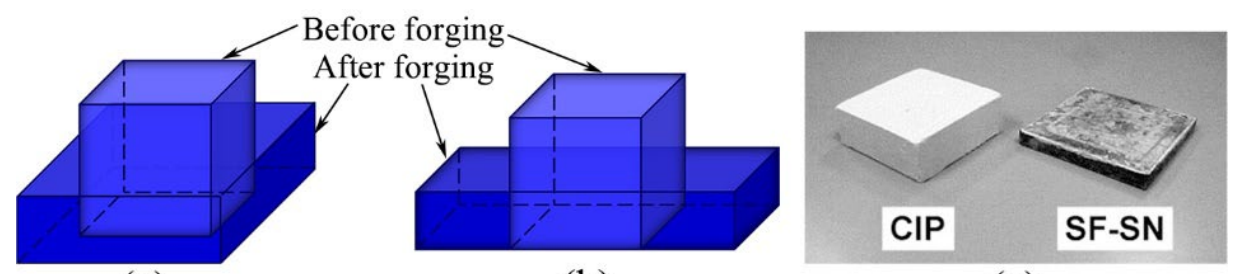

(a)

(b)

(c)

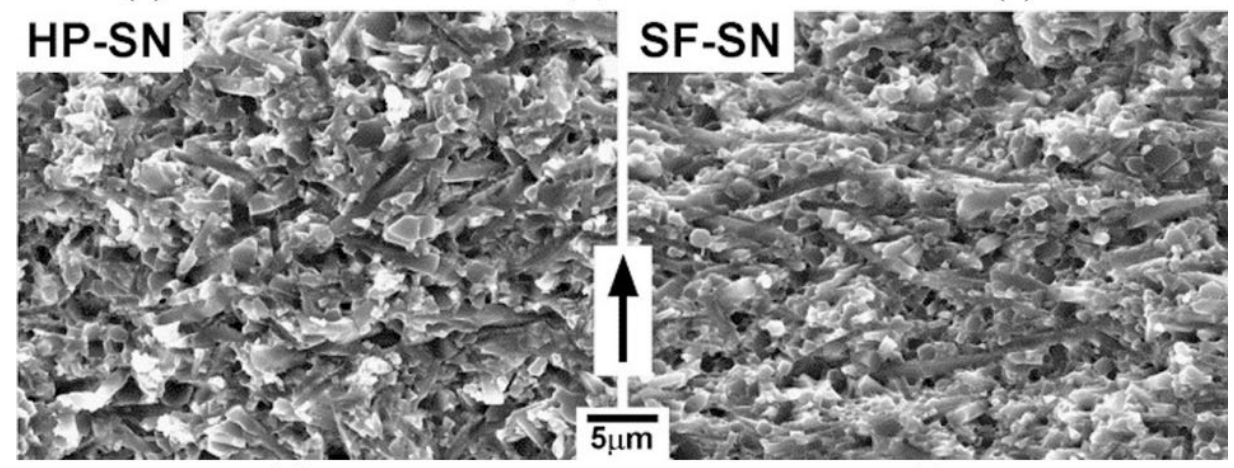

(d)

(e)

Fig. 9 Preparation and fracture morphologies of textured $\mathrm{Si}_{3} \mathrm{~N}_{4}$ matrix ceramics prepared by hot working: (a, b) schematic diagram of superplastic deformation under $\mathrm{SC}$ and PSC, respectively; (c) CIPed $\mathrm{Si}_{3} \mathrm{~N}_{4}$ green body (left) and $\mathrm{SFed}_{\mathrm{Si}} \mathrm{N}_{4}$ specimen (right); (d, e) fracture morphologies of $\mathrm{Si}_{3} \mathrm{~N}_{4}$ specimens prepared by HP and SF, respectively. The arrow indicates crack propagation directions. Uniaxial pressure was applied vertically. Reproduced with permission from Ref. [128], (C) Elsevier Science Ltd. 2002.

$$
\Delta \chi=\chi_{c}-\chi_{a, b}
$$

where $\chi_{c}$ and $\chi_{a, b}$ are the magnetic susceptibilities along the $c$-axis and the $a, b$-axis, respectively.

When the material suspension is placed in a magnetic field, material particles tend to be rotated with the crystallographic axis possessing higher $\chi$ parallel to the magnetic field. The driving energy $\Delta E$ of rotation is given by Eq. (7) $[132,133]$ :

$$
\Delta E=\Delta \chi V B^{2} /\left(2 \mu_{0}\right)
$$

where $V$ is the volume of the material particle, $B$ is the magnetic flux density, and $\mu_{0}$ is the permeability in vacuum. The particle's thermal motion energy $U$ can be described as Eq. (8) [134]:

$$
U=3 n N_{0} k_{\mathrm{B}} T
$$

where $n$ is the mole number of the material particle, $N_{0}$ is Avogadro constant, $k_{\mathrm{B}}$ is Boltzmann constant, and $T$ is the temperature. When $\Delta E$ is higher than $U$, the particle can be rotated by the magnetic field. Figure 10 shows the schematic diagram of the effect of a magnetic field on the alignment of rod-like particles belonging to the hexagonal crystal lattice [2]. If the $c$-axis possesses higher $\chi$, rod-like particles will be aligned parallel to the magnetic field. If the $c$-axis possessing lower $\chi$, rod-like particles will be aligned
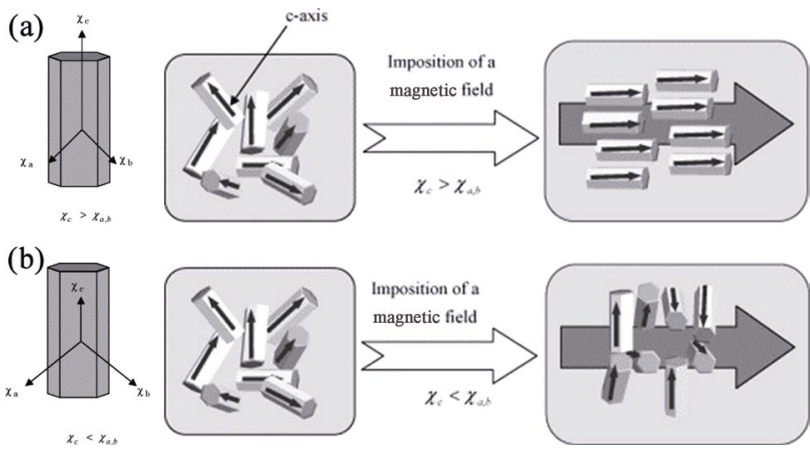

Fig. 10 Schematic diagram of the effect of a magnetic field on the alignment of rod-like particles belonging to the hexagonal crystal lattice: (a) $\chi_{c}>\chi_{a, b}$; (b) $\chi_{c}<$ $\chi_{a, b}$. Reproduced with permission from Ref. [2], (C) Elsevier B.V. 2006.

perpendicular to the magnetic field. Obviously, the former case is more favorable to texture formation.

\subsubsection{Templated grain growth}

TGG is an effective technique to prepare textured ceramics by adding some template grains into matrix grains to promote preferred orientation growth. Grains with anisometric shape, such as plate-like and rod-like grains, are called template grains (or seeds). Grains with equiaxed shape are called matrix grains [32]. 
Firstly, template grains are dispersed into matrix grains. Then the green body is formed by tape casting or extrusion, where template grains are oriented and homogeneously distributed in matrix grains [23]. Figure 11 shows the schematic diagrams of preparing $\mathrm{Si}_{3} \mathrm{~N}_{4}$ green body containing oriented $\beta-\mathrm{Si}_{3} \mathrm{~N}_{4}$ seeds by extrusion and tape casting [23]. During subsequent liquid phase sintering (usually pressureless), materials of matrix grains are transported to template grains, leading to the preferred orientation growth of template grains, and finally textured ceramics can be obtained $[3,32,135]$.

TGG has been widely used in the fabrication of textured piezoelectric ceramics with perovskite structure [136-140], because this kind of materials possesses very low crystallographic anisotropy $\left(\mathrm{BaTiO}_{3}\right.$ of the tetragonal crystal lattice has a small $c: a$ lattice constant ratio of about 1.007) and are very hard to be textured by hot working or magnetic alignment [141]. Based on TGG, reactive-templated grain growth (RTGG) was developed for these piezoelectric ceramics with high crystallographic symmetry. The difference between TGG and RTGG is that the target compound's precursors possessing anisometric shape are used and chemical reactions happen during RTGG [32,142-145]. Besides piezoelectric ceramics, TGG can also be applied to the texture formation of some structural ceramics, such as

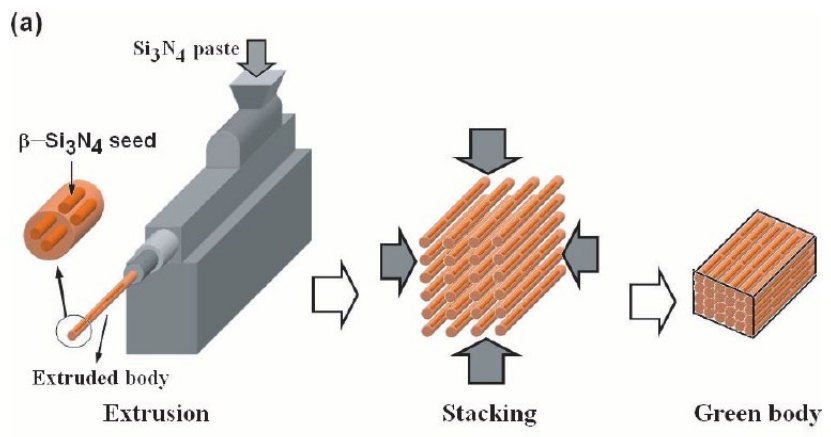

(b)

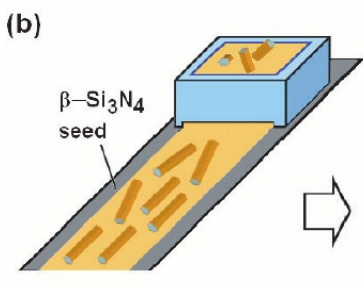

Tape casting
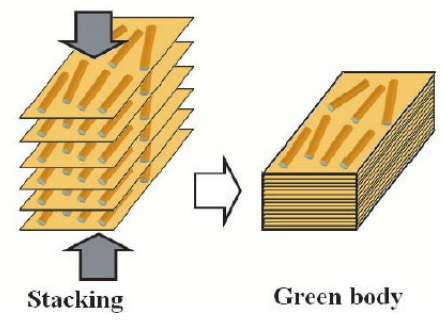

Fig. 11 Schematic diagrams of preparing $\mathrm{Si}_{3} \mathrm{~N}_{4}$ green bodies containing oriented $\beta-\mathrm{Si}_{3} \mathrm{~N}_{4}$ seeds by (a) extrusion and (b) tape casting. Reproduced with permission from Ref. [23], (c) National Institute for Materials Science 2008.
$\alpha-\mathrm{Al}_{2} \mathrm{O}_{3}$ and $\mathrm{Si}_{3} \mathrm{~N}_{4}[3,146]$. But it has seldom been used to prepare textured h-BN ceramics which are hard to be sintered without external pressure [147].

Although TGG is a very effective technique to prepare textured ceramics, densification is suppressed compared with using only equiaxed grains [3]. The hindrance of densification can be more serious for piezoelectric ceramics as the structure and chemical composition of template grains are usually different from that of matrix grains [148]. The above problems should be given prior consideration.

\subsubsection{Other texturing techniques}

In addition to these usual techniques discussed in Sections 2.1.1-2.1.3, some other techniques have also been developed to form texture microstructures in ceramics, such as freeze-casting which is usually used to prepare nacre bioinspired ceramics, as shown in Fig. 12 [53]. The general procedure is as follows. The starting colloids containing inorganic grains are frozen unidirectionally under the controlled temperature gradient. These inorganic grains grow between concentrated colloids. Then the solvent crystals are removed by sublimation, forming a layered porous scaffold composed of inorganic grains, where these pores are the replica of solvent crystals. The architecture of the scaffold can be adjusted by controlling the freezing kinetics of the solvent. Dense textured ceramics can be prepared by subsequent pressing and sintering. When the solvent is water, this method is also called ice-templating [53, $54,149,150]$.

Laser rapid solidification has been developed to form texture microstructures on material surfaces or prepare textured specimens of a few grams within several minutes [151]. Harimkar and Dahotre [152] prepared surface modified $\alpha-\mathrm{Al}_{2} \mathrm{O}_{3}$ ceramics by laser rapid solidification with the laser fluence ranging from 458 to $726 \mathrm{~J} / \mathrm{cm}^{2}$. Faceted grains with $\{110\}$ and $\{211\}$ planes as surfaces are formed at the laser fluence of $573 \mathrm{~J} / \mathrm{cm}^{2}$. Besides, the grain size of the modified surface increases as the laser fluence increases. Zhang et al. [151,153] conducted such research on texture formation of some ferroelectric ceramics including $\mathrm{SrBi}_{2} \mathrm{Nb}_{2} \mathrm{O}_{9}$ and $\mathrm{BaTi}_{2} \mathrm{O}_{5}$. Both of them tend to grow preferentially along $<010>$ directions as their $\{010\}$ planes have the lowest atom density, forming the $b$-axis oriented ceramics composed of plate-like grains parallel to the laser incident direction.

Some additives are also favorable to texture formation 


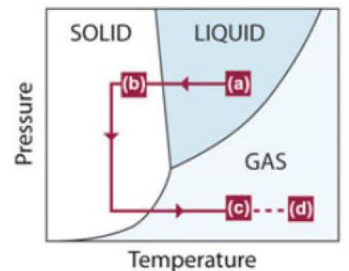

Temperature

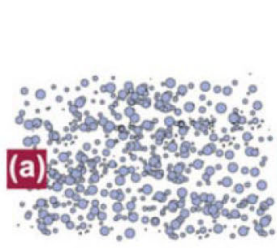

Starting colloids

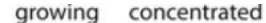

crystals colloids

(b)

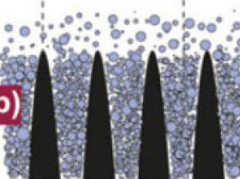

Freezing

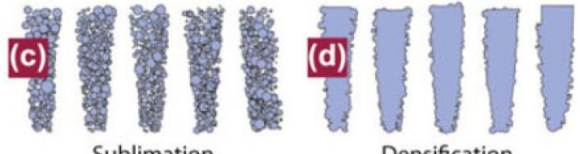

Densification

Fig. 12 Schematic diagram of freeze-casting. Reproduced with permission from Ref. [53], (c) Materials Research Society 2013.

of ceramics. Rutkowski et al. [154] prepared $\mathrm{Si}_{3} \mathrm{~N}_{4-}$ graphene composites by HP. As the graphene addition increases from 0.5 to $10 \mathrm{wt} \%$, the velocity anisotropy of longitudinal ultrasonic wave of the composites increases from $3 \%$ to $30 \%$. Hubáček et al. [155] prepared textured $\mathrm{BN}-\mathrm{Cu}$ composites by HP. The ultradispersed $\mathrm{Cu}$ in $\mathrm{BN}$ grains promotes the formation of donor-acceptor complexes between $\mathrm{Cu}$ electrons and $\pi$ electrons of $\mathrm{BN}$, activating lateral facets of $\mathrm{BN}$ and making them exposed to the uniaxial pressure, forming texture microstructure where the $c$-axis is oriented perpendicular to the pressure direction. But this effect is only remarkable when the $\mathrm{Cu}$ content is $1.5 \%-2.0 \%$, where the index of orientation preference $(I O P)$ reaches above 50 .

\section{2 Factors influencing texture formation}

\subsubsection{Raw materials}

(1) Grain size of raw powders

Compared with coarse powders, fine powders are more easily to be rotated under uniaxial pressure or magnetic fields. Zhang et al. [84] prepared textured $\alpha-\mathrm{Al}_{2} \mathrm{O}_{3}$ ceramics by slip casting in a horizontal magnetic field of $9.4 \mathrm{~T}$ using spherical raw powders with different sizes. The surface morphologies of these textured $\alpha-\mathrm{Al}_{2} \mathrm{O}_{3}$ specimens are shown in Fig. 13. The specimen prepared using the finest powders possesses the highest Lotgering factor, indicating it has the highest texture degree. That prepared by the coarsest powders has the lowest texture degree. Although that prepared using mixture of coarse and fine powders possesses grains with the highest aspect ratio, its Lotgering factor is not as high as that prepared by fine powders.

(2) Morphology of raw powders

Compared with equiaxed powders, anisometric powders are more easily to be oriented under uniaxial pressure. The SPSed $\mathrm{Cr}_{2} \mathrm{AlC}$ specimen prepared by Duan et al. [123] using coarse equiaxed raw powders is composed of unoriented grains, while that prepared using as-milled fine plate-like powders is composed of oriented grains
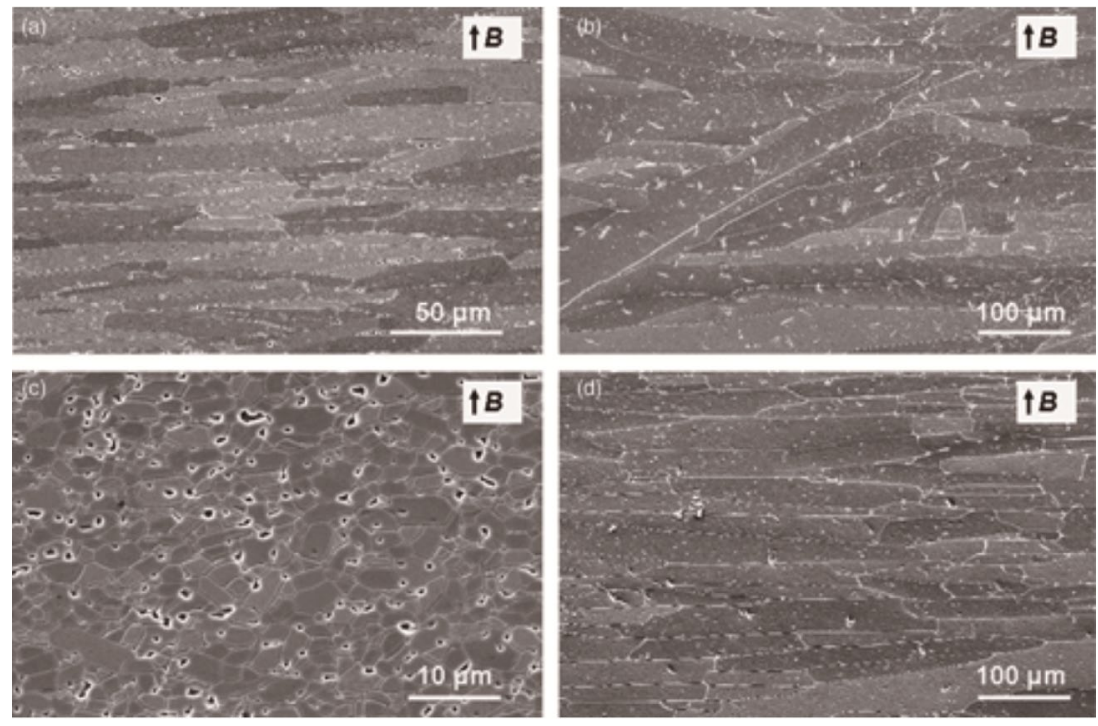

Fig. 13 Surface morphologies of textured $\alpha-\mathrm{Al}_{2} \mathrm{O}_{3}$ specimens prepared using raw powders with different grain sizes ( $\left.\mu \mathrm{m}\right)$ : (a) 0.37 ; (b) 0.77 ; (c) 1.89 ; (d) 0.37 and 1.89 (7:3). The grain aspect ratios of each specimen are 4.52, 4.30, 1.86, and 5.45, respectively. The Lotgering factors $f_{110}+300$ of each specimen are $0.80,0.18,0.16$, and 0.34 , respectively. Reproduced with permission from Ref. [84], (C) The American Ceramic Society 2010. 
with the $c$-axis parallel to the pressure direction, as shown in Fig. 14(a). Figures 14(b) and 14(c) show the Euler maps (orientation maps) of untextured and textured $\mathrm{Cr}_{2} \mathrm{AlC}$ specimens obtained with EBSD using SEM, respectively. The grain color of the Euler map of the specimen sintered using fine plate-like powders is mostly green, and the grain size is very fine, indicating this specimen is composed of fine grains with strong orientation. While the specimen sintered using coarse equiaxed powders is composed of unoriented coarse grains. Figures $14(\mathrm{~d})$ and $14(\mathrm{e})$ show the $(0001)$ pole figure and inverse pole figure of the textured $\mathrm{Cr}_{2} \mathrm{AlC}$

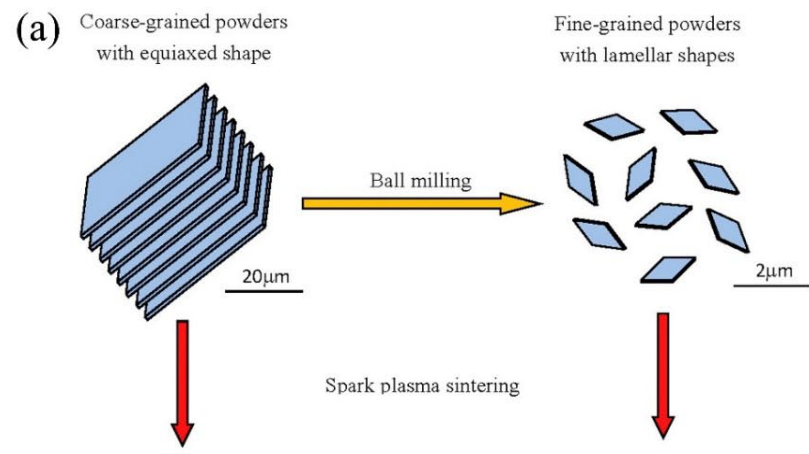

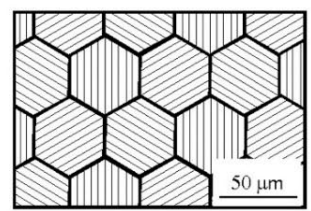

Coarse-grained $\mathrm{Cr}_{2} \mathrm{AlC}$ bulk ceramic

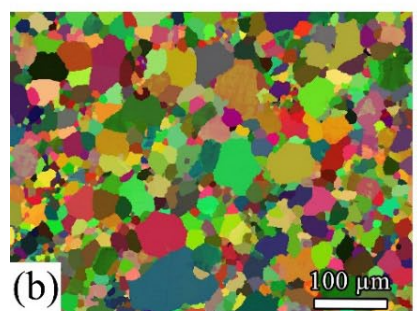

(b)

(d)

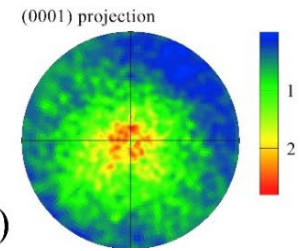

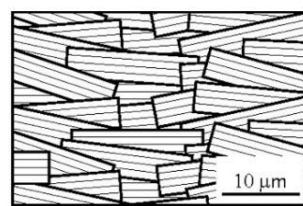

Fine-grained $\mathrm{Cr}_{2} \mathrm{AlC}$ bulk ceramic with texture

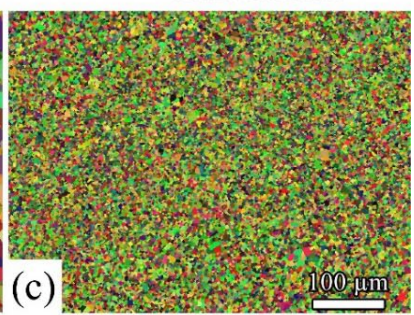

(e)

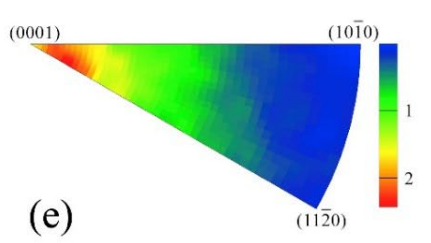

Fig. 14 Preparation and characterization of coarsegrained $\mathrm{Cr}_{2} \mathrm{AlC}$ ceramic without texture and fine-grained $\mathrm{Cr}_{2} \mathrm{AlC}$ ceramic with texture: (a) schematic diagrams of preparation; $(b, c)$ Euler maps of untextured and textured specimens, respectively; (d, e) (0001) pole figure and inverse pole figure of textured $\mathrm{Cr}_{2} \mathrm{AlC}$ specimen surface perpendicular to the sintering pressure, respectively. Reproduced with permission from Ref. [123], C Elsevier Ltd. 2014. specimen surface perpendicular to the pressure direction obtained with EBSD using SEM. The intensity in the pole figure center is the highest, and the intensity around (0001) in the inverse pole figure is also the highest, indicating that $\mathrm{Cr}_{2} \mathrm{AlC}$ grains are oriented with the $c$-axis parallel to the pressure direction.

(3) Morphology, size, and amount of template grains

As for TGG, the most important factor influencing texture formation is the characteristics of template grains. Takatori et al. [3] studied the effect of seeds on the texture formation of $\alpha-\mathrm{Al}_{2} \mathrm{O}_{3}$ ceramics prepared by tape casting and sintering. The results are shown in Table 1, where S, M, and $\mathrm{L}$ represent plate-like seeds of small, middle, and large size, respectively. Their average diameters are $0.51,2.11$, and $4.62 \mu \mathrm{m}$, and aspect ratios are 10,25 , and 25 , respectively. The numbers following $\mathrm{S}, \mathrm{M}$, and $\mathrm{L}$ are the mass fraction of seeds. Euler maps of these specimens obtained by EBSD are shown in Fig. 15, where Tref indicates the specimen sintered with only equiaxed powders. Red grains in Euler maps indicate that the $c$-axis is oriented within $20^{\circ}$ from the vertical direction. Table 1 reflects that finer powders are better to densification as they possess higher specific surface area favorable to sinterability. When the mass fraction of seeds is fixed at $5 \%$, the M5 specimen possesses the highest Lotgering factor, which is consistent with Euler maps in Fig. 15, where the Euler map of the M5 specimen possesses more red grains than that of S5 and L5 specimens. M seeds have higher aspect ratio than $\mathrm{S}$ seeds and finer size than L seeds. Seeds with higher aspect ratio are more favorable to texture formation. Besides, when the mass fraction is fixed, $\mathrm{M}$ seeds are more favorable to texture formation than $\mathrm{L}$ seeds as there are more $\mathrm{M}$ seeds in the matrix grains of unit volume than L seeds, resulting in more effective preferred orientation growth. The M30 specimen possesses the highest Lotgering factor and the best $c$-axis oriented texture among M5, M30, and M60. Within a certain range, the more seeds added

Table 1 Effect of morphology, size, and amount of template grains on the texture degree of $\alpha-\mathrm{Al}_{2} \mathrm{O}_{3}$ ceramics [3]

\begin{tabular}{ccc}
\hline Seed & Density $\left(\mathrm{g} / \mathrm{cm}^{3}\right)$ & Lotgering factor $f_{006+1010}$ \\
\hline S5 & 3.95 & 0.22 \\
M5 & 3.89 & 0.42 \\
M30 & 3.89 & 0.69 \\
M60 & 3.89 & 0.18 \\
L5 & 3.87 & 0.22 \\
\hline
\end{tabular}




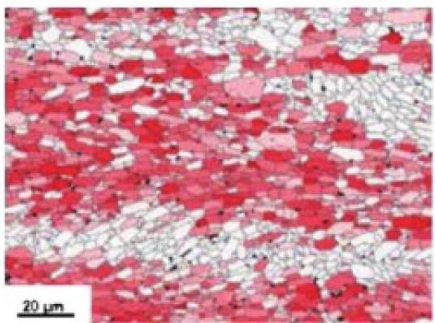

(a) M60

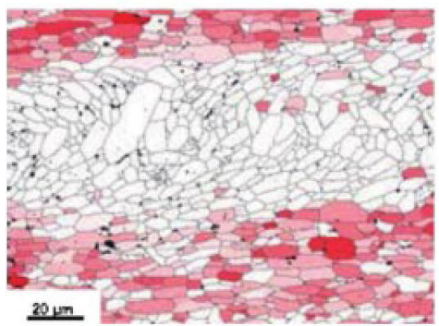

(d) L5

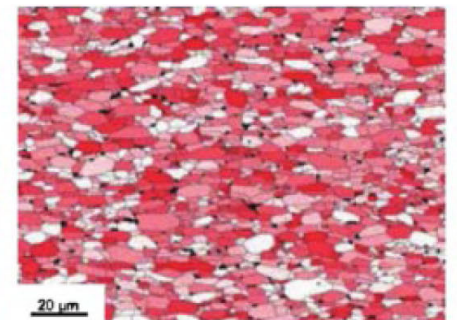

(b) $\mathrm{M} 30$

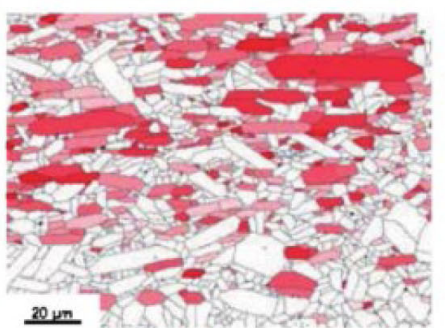

(e) $\mathrm{S} 5$

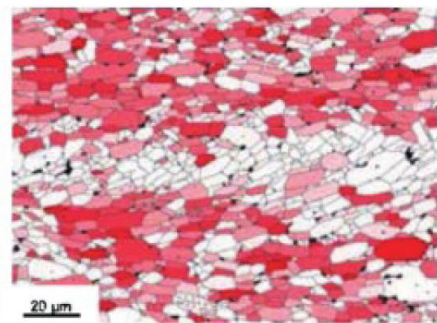

(c) M5

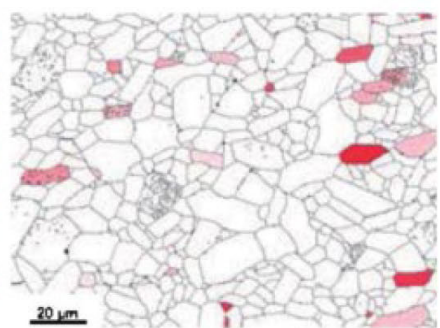

(f) Tref

Fig. 15 Euler maps of $\alpha-\mathrm{Al}_{2} \mathrm{O}_{3}$ specimens prepared using different seeds of different amount (the vertical direction in the maps corresponds to the stacking direction of plate-like seeds). Reproduced with permission from Ref. [3], (C) The Ceramic Society of Japan 2016.

into the matrix, the more significant texture can be formed. But when the amount surpasses a certain value, it will be unfavorable to texture formation. Because too many seeds mean the reduction of matrix grains that can be consumed to form anisometric grains and the decrease of distance between seeds, which tend to result in the formation of fine grains with low aspect ratio [22].

Template grains are usually aligned by the shearing force during tape casting or extrusion. So the alignment process is also important to texture formation. Taking tape casting as an example, besides higher solid content, higher carrier speed can also cause higher shear force. But if the speed is too high, template grains won't have enough time to be aligned [156]. Besides, the torque aligning template grains can be increased dramatically by dividing the flow into more flows during tape casting [157].

(4) Liquid phase sintering additives

Liquid phase sintering is a common method for preparation of ceramic materials. Liquid phase can provide a fast material diffusion path, so liquid phase sintering is more favorable to densification than solid state sintering [158-161]. Liquid phase can also provide an environment for grain rotation under uniaxial pressure, which is favorable to texture formation [129].

Seabaugh et al. [162] studied the amount of $\mathrm{CaO}-$ $\mathrm{SiO}_{2}$ liquid phase sintering additive on the texture formation of $\alpha-\mathrm{Al}_{2} \mathrm{O}_{3}$ matrix ceramics. Morphologies of these specimens are shown in Fig. 16. The specimen prepared using $5 \mathrm{wt} \%$ liquid phase sintering additive has the most significant texture microstructure, because more liquid phase provides a faster material diffusion path for preferred orientation growth [147,163]. But the anisotropic grain growth results in a rigid network, causing grain interlocking, which is unfavorable to densification, as shown in Fig. 16 [162,164].

The wettability of liquid phase sintering additives to the matrix grains is also important to texture formation. It was demonstrated by Suzuki et al. [165] that $\mathrm{TiO}_{2}$ and $\mathrm{MgO}$ are favorable to the sinterability and texture formation of $\alpha-\mathrm{Al}_{2} \mathrm{O}_{3}$, while $\mathrm{Y}_{2} \mathrm{O}_{3}$ stabilized $\mathrm{ZrO}_{2}$ is not. Kusunose and Sekino [127] proved that the composite additives of a rare-earth oxide and an alkaline-earth oxide exhibit better wettability to h-BN grains and are better to texture formation and directional thermal conduction performance of HPed h-BN matrix ceramics than the simple additive of an alkaline-earth oxide. So appropriate additives should be chosen for specific materials.

(5) Suspension viscosity

Magnetic alignment is usually combined with slip casting, gelcasting, or electrophoretic deposition, so the suspension viscosity can significantly affect grain rotation in the magnetic field. Low suspension viscosity benefits its flowability, thus has a positive 

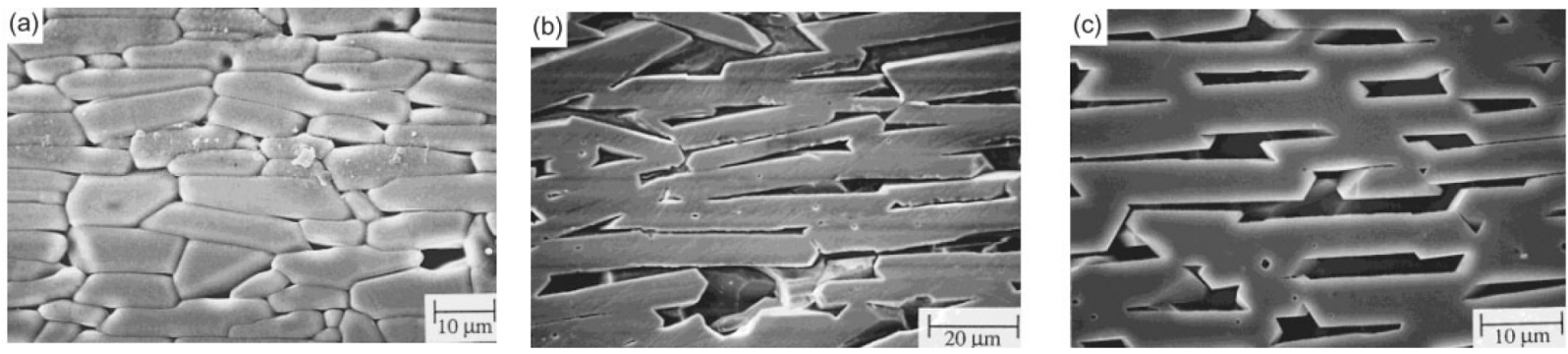

Fig. 16 Morphologies of liquid phase sintered $\alpha-\mathrm{Al}_{2} \mathrm{O}_{3}$ specimens using $4 \mathrm{wt} \%$ oriented template grains and different amount of $\mathrm{CaO}-\mathrm{SiO}_{2}$ additive: (a) $0.5 \mathrm{wt} \%$, (b) $1 \mathrm{wt} \%$, (c) $5 \mathrm{wt} \%$. Reproduced with permission from Ref. [162], (C) John Wiley and Sons 2005.

effect on the alignment of particles. Low viscosity is also good for densification [132]. Suzuki et al. [166] conducted such research on textured $\alpha-\mathrm{Al}_{2} \mathrm{O}_{3}$ ceramics prepared by slip casting in a magnetic field of $10 \mathrm{~T}$ and sintering at $1600{ }^{\circ} \mathrm{C}$ for $2 \mathrm{~h}$. The results are shown in Table 2. Moderate dispersant amount and low solid content result in low suspension viscosity and high texture degree.

However, gelcasting seems to be more effective for suspension with high solid content, which was proposed by Szudarska et al. [167]. After gelcasting in a magnetic field of $12 \mathrm{~T}$ and subsequent sintering at $1600{ }^{\circ} \mathrm{C}$ for $2 \mathrm{~h}$, the textured $\alpha-\mathrm{Al}_{2} \mathrm{O}_{3}$ specimen prepared from suspension with $45 \mathrm{vol} \%$ solid possesses higher texture degree than that prepared from suspension with 40 and 50 vol\% solid, though its viscosity is in the medium of the three. Besides, high solid content is favorable to the quality of the green body. So the solid content should be decided by considering both the viscosity and the quality of the green body [168].

\subsubsection{Preparation process factors}

(1) Sintering temperature

High sintering temperature is generally beneficial to

Table 2 Effect of dispersant amount and solid content on the viscosity of suspensions and texture degree of sintered $\alpha-\mathrm{Al}_{2} \mathrm{O}_{3}$ specimens [166]

\begin{tabular}{cccc}
\hline $\begin{array}{c}\text { Solid content } \\
\text { (vol\%) }\end{array}$ & $\begin{array}{c}\text { Dispersant } \\
\text { amount (wt\%) }\end{array}$ & $\begin{array}{c}\text { Viscosity (mPa.s, } \\
\text { measured at a shear } \\
\left.\text { rate of } 100 \mathrm{~s}^{-1}\right)\end{array}$ & $\begin{array}{c}\text { Orientation } \\
\text { factor } P\end{array}$ \\
\hline \multirow{3}{*}{30} & 0.44 & 60.07 & 0.04 \\
& 0.50 & 14.31 & 0.98 \\
30 & 0.58 & 10.38 & 0.99 \\
40 & 1.20 & 17.45 & 0.93 \\
45 & - & 28.59 & 0.94 \\
& - & 200.51 & 0.91 \\
\end{tabular}

densification and texture formation of ceramics. Uchikoshi et al. [169] prepared textured $\alpha-\mathrm{Al}_{2} \mathrm{O}_{3}$ ceramics by electrophoretic deposition in a magnetic field of $10 \mathrm{~T}$ and subsequent sintering. As the sintering temperature increases from 800 to $1600{ }^{\circ} \mathrm{C}$, the orientation factor $I_{006} /\left(I_{006}+I_{110}\right)$ increases from 0.08 to 0.96 . Meanwhile, the relative density also increases from $59 \%$ to $97 \%$.

Takatori et al. [3] studied the effect of sintering temperature on texture formation of $\alpha-\mathrm{Al}_{2} \mathrm{O}_{3}$ ceramics prepared by TGG. Fracture morphologies of $\alpha-\mathrm{Al}_{2} \mathrm{O}_{3}$ specimens sintered at different temperatures using 30 and $100 \mathrm{wt} \%$ seeds with average diameter of $2.11 \mu \mathrm{m}$ and aspect ratio of 25 (marked as M30 and M100) are shown in Fig. 17. When the sintering temperature is 1400,1600 , and $1700{ }^{\circ} \mathrm{C}$, the Lotgering factors $f_{006}$ of $\mathrm{M} 30$ are $0.36,0.55$, and 0.69 , respectively, and that of M100 are $0.26,0.41$, and 0.15 , respectively. For M30, the preferred orientation growth and densification are both promoted by high sintering temperature. For M100, too high sintering temperature may be not favorable to texture formation.

(2) Sintering pressure

Duan et al. [1] and Xue et al. [170] studied the effect of sintering pressure on the texture degree of h-BN matrix ceramics prepared by HP, as shown in Table 3. For plate-like h-BN powders, as the pressure increases, they are more easily to be rotated with the $c$-axis parallel to the pressure direction, causing higher texture degree $(I O P<0)$. But when h-BN raw powders possess irregular shape, the uniaxial pressure is not very high, and there is no liquid phase sintering additive used, the pressure can promote grain contact, causing the preferred orientation growth of plate-like grains along the pressure direction $(I O P>0)$.

The HPed h-BN (002) pole figures of textured h-BNmullite composites prepared under different sintering pressure are shown in Figs. 18(a), 18(c), and 18(e). As 
(a) M100_1400'C_4h

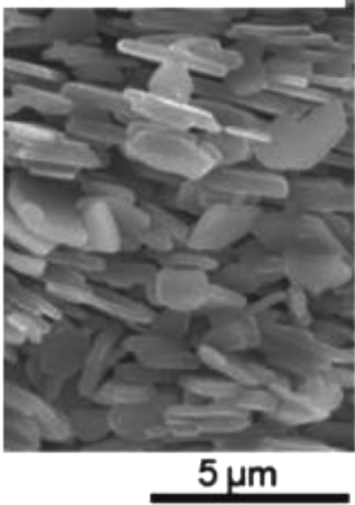

(d) M30_1400 $\mathrm{C} \quad 4 \mathrm{~h}$

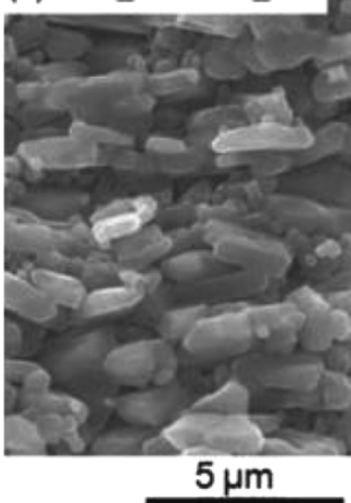

(b) M100_1600'C_4h

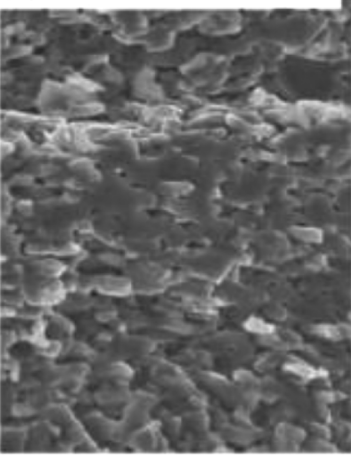

$10 \mu \mathrm{m}$
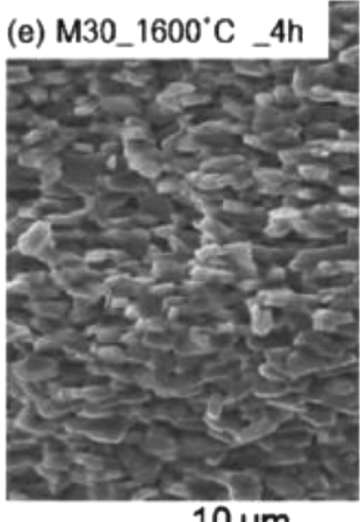

$10 \mu \mathrm{m}$

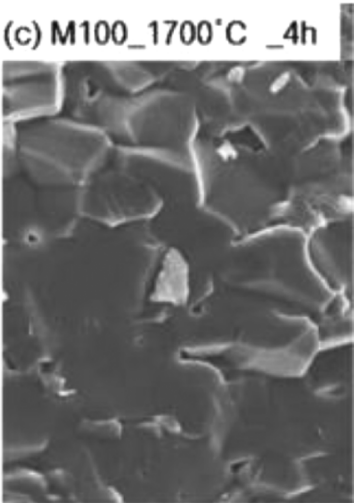

$10 \mu \mathrm{m}$

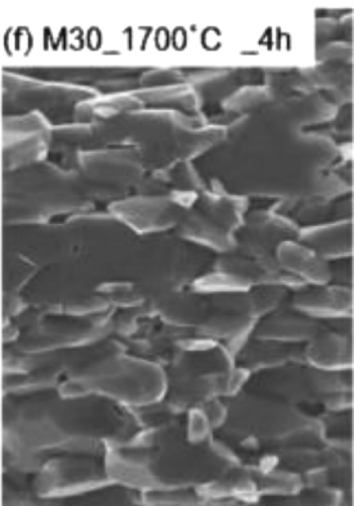

$10 \mu \mathrm{m}$

Fig. 17 Fracture morphologies of textured $\alpha-\mathrm{Al}_{2} \mathrm{O}_{3}$ specimens with different amount of seeds sintered at different temperatures for $4 \mathrm{~h}$ in air. Reproduced with permission from Ref. [3], (c) The Ceramic Society of Japan 2016.

Table 3 Effect of sintering pressure on the texture degree of HPed h-BN matrix ceramics

\begin{tabular}{lccc}
\hline Researchers & Raw materials & Sintering pressure & IOP value \\
\hline & $15 \mathrm{MPa}$ & 11.5 \\
& $30 \mathrm{MPa}$ & 27.2 \\
Xue et al. [170] Irregular shaped h-BN & $45 \mathrm{MPa}$ & 20.6 \\
& $60 \mathrm{MPa}$ & 10.9 \\
\hline \multirow{4}{*}{ Duan et al. [1]] } & Plate-like h-BN + 20 & $10 \mathrm{MPa}$ & -178 \\
& wt\% mullite & $20 \mathrm{MPa}$ & -350 \\
& & $30 \mathrm{MPa}$ & -2160 \\
\hline
\end{tabular}

the sintering pressure increases, the intensity at the center of the pole figure increases, indicating that stronger texture has been formed by higher pressure. Figures 18(b), 18(d), and 18(f) show the relative volume fraction distribution of $\mathrm{h}-\mathrm{BN}$ grains in textured composites along the $(0, \phi, 5)$ direction obtained from orientation distribution function (ODF), where $\phi$ represents the deviation angle of the $c$-axis from the ideal orientation (the pressure direction). As the sintering pressure increases, more h-BN grains are oriented with smaller deviation angles, also demonstrating the positive effect of sintering pressure on texture formation.

(3) Magnetic intensity

According to Eq. (7), for these materials possessing anisotropic magnetic susceptibility, the stronger the applied magnetic field is, the higher energy materials possess to be rotated to the easy magnetization direction. Uchikoshi et al. [132] studied the effect of magnetic intensity on the texture degree of $\alpha-\mathrm{Al}_{2} \mathrm{O}_{3}$ ceramics prepared by magnetic alignment and sintering. The texture degree increases with the increase of magnetic field intensity, as shown in Fig. 19.

Terada et al. [67] studied texture development of $\alpha-\mathrm{Al}_{2} \mathrm{O}_{3}$ suspension in a changing magnetic field by in situ ND. The schematic diagram of the experimental apparatus is shown in Fig. 20(a). The magnetic field dependence of diffraction intensities of different crystal planes of $\alpha-\mathrm{Al}_{2} \mathrm{O}_{3}$ is shown in Fig. 20(b). As the magnetic intensity increases, the diffraction intensity of (006) decreases, indicating that $\alpha-\mathrm{Al}_{2} \mathrm{O}_{3}$ particles tend to be aligned with the $c$-axis parallel to the magnetic 


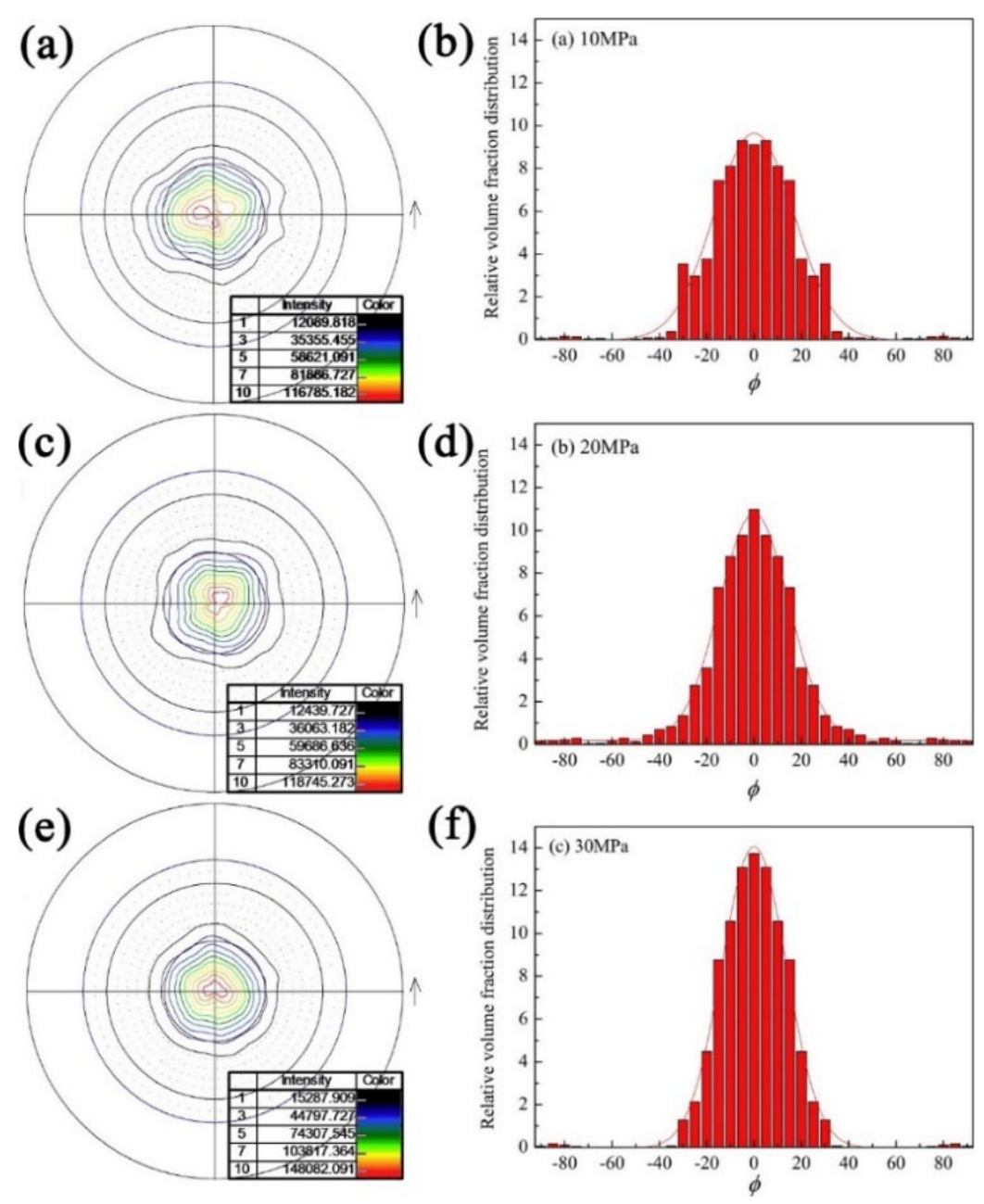

Fig. 18 (002) pole figures and relative volume fraction distribution of h-BN grains in textured h-BN matrix ceramics prepared under different sintering pressure: (a, b) $10 \mathrm{MPa}$; (c, d) $20 \mathrm{MPa}$; (e, f) $30 \mathrm{MPa}$. Reproduced with permission from Ref. [1], (C) Acta Materialia Inc. 2012.

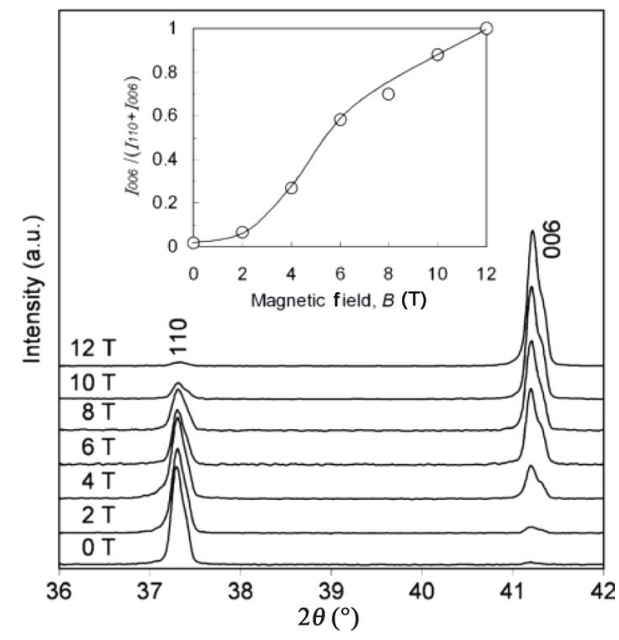

Fig. 19 Effect of magnetic intensity on (110) and (006) diffraction peak intensities and orientation factors of $\alpha-\mathrm{Al}_{2} \mathrm{O}_{3}$ specimen surfaces perpendicular to the magnetic field. Reproduced with permission from Ref. [132], (C) Springer Science+Business Media, LLC 2006. field. Then the magnetic intensity and sintering temperature dependence of the orientation parameter $r$ of the sintered $\alpha-\mathrm{Al}_{2} \mathrm{O}_{3}$ ceramics is also studied [64]. Figure 21(a) shows the measuring apparatus, where the double arrow indicates the magnetic field direction parallel to the scattering vector. The specimen holder was horizontally rotated, and the scattering angle, $2 \theta$, was changed to measure diffraction intensities of different crystal planes. The measuring result is shown in Fig. 21(b). As the magnetic intensity and sintering temperature increase, the orientation parameter $r$ of the sintered $\alpha-\mathrm{Al}_{2} \mathrm{O}_{3}$ specimen is more close to 0 , indicating the formation of stronger texture.

As for gelcasting in magnetic fields, the magnetic field exposure time and the idle time between the moment of adding the initiator into the suspension and the moment when viscosity increases rapidly due to the polymerisation can also influence texture formation. It 
(a)

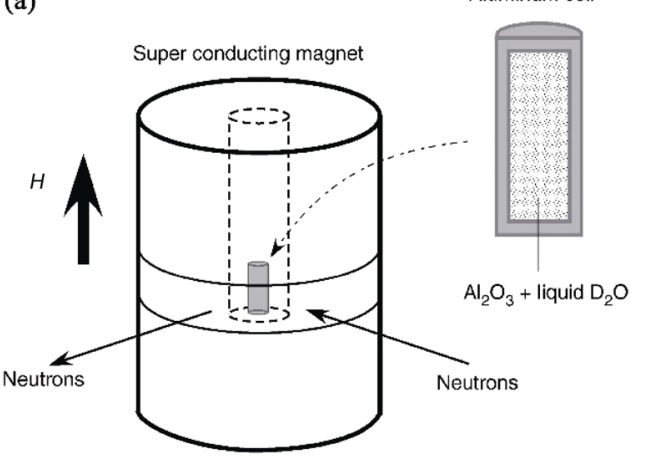

(b)

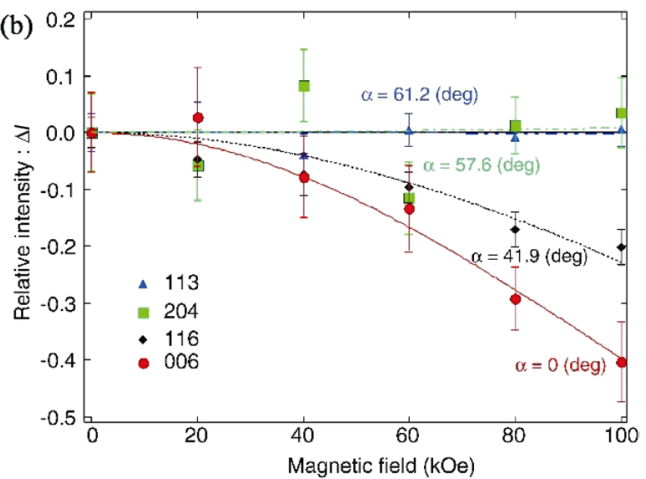

Fig. 20 Characterization of texture development of $\alpha-\mathrm{Al}_{2} \mathrm{O}_{3}$ suspension in a changing magnetic field: (a) schematic diagram of the experimental apparatus; (b) magnetic field dependence of diffraction intensities of different crystal planes of $\alpha-\mathrm{Al}_{2} \mathrm{O}_{3}$. Reproduced with permission from Ref. [67], (C) American Institute of Physics 2008.

(a)

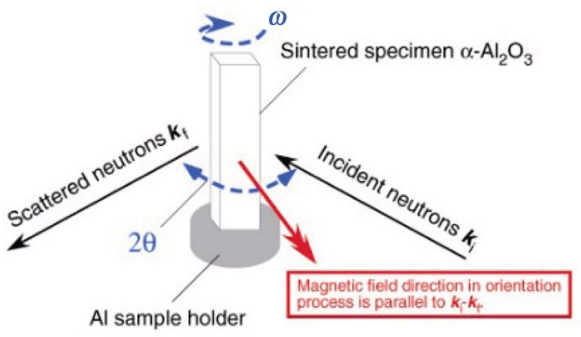

(b)

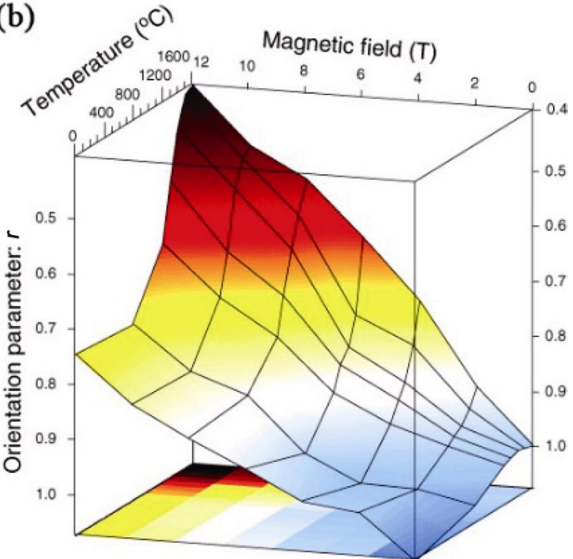

Fig. 21 Magnetic intensity and sintering temperature dependence of the orientation parameter $r$ of the sintered $\alpha-\mathrm{Al}_{2} \mathrm{O}_{3}$ : (a) schematic diagram of the experimental apparatus; (b) measuring result. Reproduced with permission from Ref. [64], (C) IOP Publishing Ltd. 2009.

has been confirmed that short idle time and long magnetic field exposure time are favorable to the orientation of particles during gelcasting. The idle time can be controlled by adjusting the amount of catalyst and initiator [167,171].

\section{3 Comparisons of texturing techniques}

Each texturing technique has its own advantages and disadvantages. Hot working is usually used to prepare textured ceramics with anisometric grains, but it is not useful to prepare textured materials with equiaxed grains. Magnetic alignment can align all materials possessing crystal magnetic anisotropy, but many ceramic materials belong to weak magnetic substances. So strong magnetic fields up to $10 \mathrm{~T}$ are needed to texture them. TGG is low-cost and can form significant texture microstructures. But TGG green bodies usually need to go through pressureless sintering, so it is hard to densify some materials hard to be sintered such as
h-BN. The difference between template grains and matrix grains can also suppress densification. The characteristics of these techniques are listed in Table 4.

\section{Typical textured structural ceramics and their anisotropy}

Mechanical properties along specific directions of structural ceramics can be significantly improved by texturing so that they can be applied to more harsh service environments. In this part, several typical textured structural ceramics including $\alpha-\mathrm{Al}_{2} \mathrm{O}_{3}$ and $\alpha-\mathrm{Al}_{2} \mathrm{O}_{3}$ related nacre bioinspired ceramics, $\mathrm{Si}_{3} \mathrm{~N}_{4}$ and SiAlON, h-BN, $\mathrm{MB}_{2}$ matrix ultra-high temperature ceramics, MAX phases and some other ceramics and their anisotropic properties are discussed. $\alpha-\mathrm{Al}_{2} \mathrm{O}_{3}$ is one of the most common structural ceramics and has been widely used [172-177]. $\mathrm{Si}_{3} \mathrm{~N}_{4}$ and $\mathrm{SiAlON}$ are 
Table 4 Comparisons of texturing techniques

\begin{tabular}{|c|c|c|c|c|}
\hline Techniques & Advantages & Disadvantages & Materials requirements & Typical materials \\
\hline Hot working & $\begin{array}{l}\text { Accelerate mass transfer } \\
\text { process and densification }\end{array}$ & $\begin{array}{c}\text { High cost } \\
\text { High energy consumption }\end{array}$ & $\begin{array}{l}\text { Materials with anisometric } \\
\text { crystal structure }\end{array}$ & $\begin{array}{c}\alpha-\mathrm{Al}_{2} \mathrm{O}_{3} \\
\text { h-BN } \\
\mathrm{Si}_{3} \mathrm{~N}_{4} \\
\text { MAX phases }\end{array}$ \\
\hline Magnetic alignment & All grains can be aligned & $\begin{array}{l}\text { Strong magnetic fields } \\
\text { are needed }\end{array}$ & $\begin{array}{l}\text { Materials possessing } \\
\text { magnetic anisotropy }\end{array}$ & $\begin{array}{c}\alpha-\mathrm{Al}_{2} \mathrm{O}_{3} \\
\mathrm{Si}_{3} \mathrm{~N}_{4} \\
\text { MAX phases }\end{array}$ \\
\hline TGG & $\begin{array}{l}\text { Simple process } \\
\text { Low-cost }\end{array}$ & Densification is hard & Materials easy to be sintered & $\begin{array}{c}\alpha-\mathrm{Al}_{2} \mathrm{O}_{3} \\
\mathrm{Si}_{3} \mathrm{~N}_{4} \\
\text { Piezoelectric ceramics }\end{array}$ \\
\hline
\end{tabular}

usually used to fabricate whisker-reinforced ceramics due to their excellent mechanical properties $[178,179]$. The lamellar structure of $\mathrm{h}-\mathrm{BN}$ enables it to be used as directional thermal conductive materials $[147,180$ 182]. $\mathrm{MB}_{2}$ matrix ultra-high temperature ceramics have extreme high temperature that allows them to be used in extreme environments $[183,184]$. MAX phases have been widely studied recently due to their excellent properties combining that of metals and ceramics $[180$, 185-189].

\section{4. $1 \alpha-\mathrm{Al}_{2} \mathrm{O}_{3}$ and $\alpha-\mathrm{Al}_{2} \mathrm{O}_{3}$ related nacre bioinspired ceramics}

\subsection{1 $\alpha-\mathrm{Al}_{2} \mathrm{O}_{3}$}

Alumina is present in nature with a variety of phases, in which $\alpha-\mathrm{Al}_{2} \mathrm{O}_{3}$ also called corundum belongs to the hexagonal crystal lattice $[190,191] . \alpha-\mathrm{Al}_{2} \mathrm{O}_{3}$ is thermodynamically stable and has many excellent properties such as high strength and hardness, low dielectric loss, good insulation performance, good resistance to oxidation at high temperature, outstanding biocompatibility, etc. It has been widely used in electronical, mechanical, biomedical, chemical, optical, and refractory fields [172-177].

$\alpha-\mathrm{Al}_{2} \mathrm{O}_{3}$ possesses a slight crystal magnetic anisotropy,
$\Delta \chi=\chi_{c}-\chi_{a, b}=7.1 \times 10^{-8} \mathrm{emu} \cdot \mathrm{mol}^{-1}$, so the $c$-axis of $\alpha-\mathrm{Al}_{2} \mathrm{O}_{3}$ can be aligned parallel to the magnetic field direction. But the $\Delta \chi$ is so low that strong magnetic fields are needed to form preferred grain orientation [64]. Figure 22 shows the polished surfaces of $\alpha-\mathrm{Al}_{2} \mathrm{O}_{3}$ ceramics prepared with and without the magnetic field [69]. Plate-like $\alpha-\mathrm{Al}_{2} \mathrm{O}_{3}$ grains are oriented with the $c$-axis parallel to the magnetic field. Due to the anisometric shape of $\alpha-\mathrm{Al}_{2} \mathrm{O}_{3}$ grains, hot working and TGG can also be used to prepared textured $\alpha-\mathrm{Al}_{2} \mathrm{O}_{3}$ ceramics [135,177].

During the preparation of textured $\alpha-\mathrm{Al}_{2} \mathrm{O}_{3}$ ceramics by TGG, the increase of seed amount can result in the decrease of grain size in the sintered specimen, which leads to the increase of flexural strength [192]. Fine seeds are more favorable to flexural strength than coarse seeds due to the same reason [193]. It is worth noting that high seed amount is not always favorable to texture formation of $\alpha-\mathrm{Al}_{2} \mathrm{O}_{3}$ ceramics, as discussed in Section 3.2.1.

Table 5 lists the mechanical and thermal properties of textured $\alpha-\mathrm{Al}_{2} \mathrm{O}_{3}$ matrix ceramics prepared by different methods. Textured $\alpha-\mathrm{Al}_{2} \mathrm{O}_{3}$ ceramics usually show better mechanical properties (flexural strength and fracture toughness) with the load parallel to the $c$-axis orientation than perpendicular to the $c$-axis
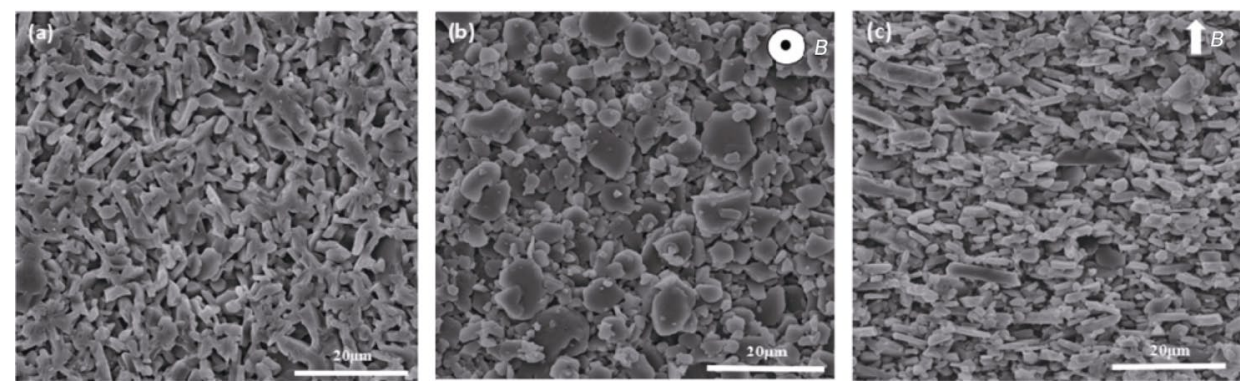

Fig. 22 Polished surfaces of untextured and textured $\alpha-\mathrm{Al}_{2} \mathrm{O}_{3}$ specimens: (a) untextured specimen; (b, c) textured specimen surfaces perpendicular and parallel to the magnetic field direction, respectively. Reproduced with permission from Ref. [69], (C) WILEY - VCH Verlag GmbH \& Co. KGaA, Weinheim 2015. 
Table 5 Properties of textured $\mathrm{Al}_{2} \mathrm{O}_{3}$ matrix ceramics

\begin{tabular}{|c|c|c|c|c|c|c|c|}
\hline Researchers & Raw materials & Preparation methods & $\begin{array}{c}\text { Relative } \\
\text { density }(\%)\end{array}$ & $\begin{array}{l}\text { Orientation } \\
\text { factor }\end{array}$ & $\begin{array}{l}\text { Flexural } \\
\text { strength } \\
(\mathrm{MPa})\end{array}$ & $\begin{array}{c}\text { Fracture } \\
\text { toughness } \\
\left(\mathrm{MPa} \cdot \mathrm{m}^{1 / 2}\right)\end{array}$ & $\begin{array}{c}\text { Thermal } \\
\text { conductivity } \\
(\mathrm{W} /(\mathrm{m} \cdot \mathrm{K}))\end{array}$ \\
\hline \multirow{4}{*}{$\begin{array}{l}\text { Yang et al. } \\
\text { [69] }\end{array}$} & \multirow{4}{*}{$\begin{array}{l}\text { Irregular shaped } \\
\alpha-\mathrm{Al}_{2} \mathrm{O}_{3}\end{array}$} & Pressureless sintering $\left(1600{ }^{\circ} \mathrm{C}\right)$ & 66.34 & $P=0.07$ & 55.41 & - & - \\
\hline & & $\begin{array}{l}\text { Magnetic alignment \& pressureless } \\
\text { sintering }\left(1500^{\circ} \mathrm{C}\right)\end{array}$ & 64.00 & $P=0.68$ & $\begin{array}{l}95.66(/ / c \text {-axis }) \\
80.21(\perp c \text {-axis })\end{array}$ & - & - \\
\hline & & $\begin{array}{l}\text { Magnetic alignment \& pressureless } \\
\text { sintering }\left(1550{ }^{\circ} \mathrm{C}\right)\end{array}$ & 64.11 & $P=0.68$ & $\begin{array}{l}97.65(/ / c \text {-axis }) \\
80.21(\perp c \text {-axis })\end{array}$ & - & - \\
\hline & & $\begin{array}{l}\text { Magnetic alignment \& pressureless } \\
\text { sintering }\left(1600{ }^{\circ} \mathrm{C}\right)\end{array}$ & 66.29 & $P=0.70$ & $\begin{array}{l}105.63(/ / c \text {-axis }) \\
85.96(\perp c \text {-axis })\end{array}$ & - & - \\
\hline \multirow{5}{*}{$\begin{array}{l}\text { Honda et al. } \\
\qquad[40]\end{array}$} & \multirow{5}{*}{ Plate-like $\alpha-\mathrm{Al}_{2} \mathrm{O}_{3}$} & $\operatorname{SPS}\left(1300{ }^{\circ} \mathrm{C}\right)$ & 67.56 & $f_{00 l}=0.31$ & $\begin{array}{l}155.17(/ / c \text {-axis }) \\
46.73(\perp c \text {-axis })\end{array}$ & - & $\begin{array}{c}3.4(/ / c \text {-axis }) \\
10.4(\perp c \text {-axis })\end{array}$ \\
\hline & & $\operatorname{SPS}\left(1400{ }^{\circ} \mathrm{C}\right)$ & 80.84 & $f_{00 l}=0.50$ & $\begin{array}{l}403.65(/ / c \text {-axis }) \\
217.84(\perp c \text {-axis })\end{array}$ & - & $\begin{array}{l}10.5(/ / c \text {-axis }) \\
22.3(\perp c \text {-axis })\end{array}$ \\
\hline & & $\operatorname{SPS}\left(1500{ }^{\circ} \mathrm{C}\right)$ & 90.47 & $f_{00 l}=0.51$ & $\begin{array}{l}373.68(/ / c \text {-axis }) \\
251.08(\perp c \text {-axis })\end{array}$ & - & $\begin{array}{l}11.0(/ / c \text {-axis }) \\
22.6(\perp c \text {-axis })\end{array}$ \\
\hline & & SPS $\left(1600{ }^{\circ} \mathrm{C}\right)$ & 95.06 & $f_{00 l}=0.71$ & $\begin{array}{l}416.91(/ / c \text {-axis }) \\
253.89(\perp c \text {-axis })\end{array}$ & - & $\begin{array}{l}30.4(/ / c \text {-axis }) \\
35.7(\perp c \text {-axis })\end{array}$ \\
\hline & & $\operatorname{SPS}\left(1650{ }^{\circ} \mathrm{C}\right)$ & 97.17 & $f_{00 l}=0.85$ & $\begin{array}{l}437.80(/ / c \text {-axis }) \\
256.16(\perp c \text {-axis })\end{array}$ & - & $\begin{array}{l}31.6(/ / c \text {-axis }) \\
35.3(\perp c \text {-axis })\end{array}$ \\
\hline $\begin{array}{l}\text { Nishimura et } \\
\text { al. }[122]\end{array}$ & $\begin{array}{l}\text { Platelike } \alpha-\mathrm{Al}_{2} \mathrm{O}_{3}+ \\
10 \text { wt } \% \text { fine } \alpha-\mathrm{Al}_{2} \mathrm{O}_{3}\end{array}$ & SPS & 95 & $f_{00 l}=0.34$ & $\begin{array}{l}338.46(/ / c \text {-axis }) \\
151.58(\perp c \text {-axis })\end{array}$ & $\begin{array}{l}4.2(/ / c \text {-axis }) \\
1.8(\perp c \text {-axis })\end{array}$ & $\begin{array}{l}36(/ / c \text {-axis }) \\
39(\perp c \text {-axis })\end{array}$ \\
\hline \multirow{5}{*}{$\begin{array}{c}\text { Carisey et al. } \\
\text { [192] }\end{array}$} & \multirow{5}{*}{$\begin{array}{c}\alpha-\mathrm{Al}_{2} \mathrm{O}_{3}+0-10 \text { wt } \% \\
\text { plate-like } \alpha-\mathrm{Al}_{2} \mathrm{O}_{3} \\
\text { seeds with size of } 3-7 \\
\mu \mathrm{m} \text { and } \\
10-15 \mu \mathrm{m}\end{array}$} & $\begin{array}{c}\text { TGG \& pressureless sintering } \\
\text { (0 wt } \% \text { seeds })\end{array}$ & - & - & $\begin{array}{l}383.62(/ / c \text {-axis }) \\
371.16(\perp c \text {-axis })\end{array}$ & $\begin{array}{l}6.47(/ / c \text {-axis }) \\
4.86(\perp c \text {-axis })\end{array}$ & - \\
\hline & & $\begin{array}{l}\text { TGG \& pressureless sintering } \\
\text { (5 wt } \% 3-7 \mu \mathrm{m} \text { seeds) }\end{array}$ & - & - & $\begin{array}{l}471.52(/ / c \text {-axis }) \\
402.96(\perp c \text {-axis })\end{array}$ & $\begin{array}{l}5.45(/ / c \text {-axis }) \\
5.28(\perp c \text {-axis })\end{array}$ & - \\
\hline & & $\begin{array}{l}\text { TGG \& pressureless sintering } \\
\quad(5 \mathrm{wt} \% 10-15 \mu \mathrm{m} \text { seeds) }\end{array}$ & - & - & $\begin{array}{l}432.90(/ / c \text {-axis }) \\
357.26(\perp c \text {-axis })\end{array}$ & $\begin{array}{l}4.57(/ / c \text {-axis }) \\
5.47(\perp c \text {-axis })\end{array}$ & - \\
\hline & & $\begin{array}{l}\text { TGG \& pressureless sintering } \\
\text { (10 wt } \% 3-7 \mu \mathrm{m} \text { seeds) }\end{array}$ & - & - & $\begin{array}{l}465.87(/ / c \text {-axis }) \\
444.60(\perp c \text {-axis })\end{array}$ & $\begin{array}{l}5.25(/ / c \text {-axis }) \\
4.89(\perp c \text {-axis })\end{array}$ & - \\
\hline & & $\begin{array}{l}\text { TGG \& pressureless sintering } \\
\text { (10 wt } \% 10-15 \mu \mathrm{m} \text { seeds) }\end{array}$ & - & - & $\begin{array}{l}436.67(/ / c \text {-axis }) \\
386.97(\perp c \text {-axis })\end{array}$ & $\begin{array}{l}5.15(/ / c \text {-axis }) \\
5.39(\perp c \text {-axis })\end{array}$ & - \\
\hline \multirow{4}{*}{$\begin{array}{c}\text { Pavlacka } \\
\text { and Messing } \\
{[193]}\end{array}$} & \multirow{4}{*}{$\begin{array}{c}\alpha-\mathrm{Al}_{2} \mathrm{O}_{3}+0.14 \mathrm{wt} \% \\
\left(\mathrm{CaO}+\mathrm{SiO}_{2}\right)+ \\
1-15 \mathrm{vol} \% \\
\text { plate-like } \alpha-\mathrm{Al}_{2} \mathrm{O}_{3}\end{array}$} & $\begin{array}{c}\text { TGG \& pressureless sintering } \\
\text { (1 vol\% seeds) }\end{array}$ & 98.20 & $r=0.13$ & $\begin{array}{l}305(/ / c \text {-axis }) \\
316(\perp c \text {-axis })\end{array}$ & $\begin{array}{l}3.05(/ / c \text {-axis }) \\
3.09(\perp c \text {-axis })\end{array}$ & - \\
\hline & & $\begin{array}{l}\text { TGG \& pressureless sintering } \\
\text { (5 vol } \% \text { seeds })\end{array}$ & 97.38 & $r=0.14$ & $\begin{array}{l}417(/ / c \text {-axis }) \\
421(\perp c \text {-axis })\end{array}$ & $\begin{array}{l}3.03(/ / c \text {-axis }) \\
3.93(\perp c \text {-axis })\end{array}$ & - \\
\hline & & $\begin{array}{l}\text { TGG \& pressureless sintering } \\
\text { (10 vol } \% \text { seeds })\end{array}$ & 94.49 & $r=0.16$ & $\begin{array}{l}420(/ / c \text {-axis }) \\
384(\perp c \text {-axis })\end{array}$ & $\begin{array}{l}3.11(/ / c \text {-axis }) \\
3.90(\perp c \text {-axis })\end{array}$ & - \\
\hline & & $\begin{array}{l}\text { TGG \& pressureless sintering } \\
\text { (15 vol } \% \text { seeds })\end{array}$ & 93.11 & $r=0.17$ & $\begin{array}{l}436(/ / c \text {-axis }) \\
511(\perp c \text {-axis })\end{array}$ & $\begin{array}{l}2.55(/ / c \text {-axis }) \\
4.58(\perp c \text {-axis })\end{array}$ & - \\
\hline
\end{tabular}

orientation. When the loading direction is parallel to the $c$-axis orientation, there are a large number of grains playing the role of load transfer, and the crack is transferred to the direction along the interfaces of these plate-like grains. So the crack needs to take longer paths to make fracture occur, and more energy needs to be consumed. When the external stress is perpendicular to the $c$-axis orientation, grains playing the role of load transfer are less, and the crack easily propagates along the interfaces of these plate-like grains, making the fracture occur easily than the former [40,194]. However, in the research of Pavlacka and Messing [193], the fracture toughness parallel to the $c$-axis orientation is surprisingly lower than that perpendicular to the $c$-axis orientation. Because the crack goes through the thickness parallel to the $c$-axis orientation (the smaller dimension of textured grains), which makes them more difficult to bridge effectively. So which direction possesses higher toughness is determined by whether crack deflection or bridging is the dominant toughening mechanism.

The thermal conductivity of textured $\alpha-\mathrm{Al}_{2} \mathrm{O}_{3}$ ceramics parallel to the $c$-axis orientation is lower than that perpendicular to the $c$-axis orientation $[40,122]$. There are more grain boundaries and defects along the $c$-axis 
orientation, so phonons are scattered more seriously, resulting in the lower thermal conductivity. $\alpha-\mathrm{Al}_{2} \mathrm{O}_{3}$ ceramics sintered at higher temperature have higher and more anisotropic flexural strength, because high sintering temperature is beneficial to densification and texture formation. But the anisotropy of thermal conductivities may not be promoted by high sintering temperature. Because the decrease of porosity combines grains more closely, thermal conductivities increase along both directions $[40,69]$.

Besides $\alpha-\mathrm{Al}_{2} \mathrm{O}_{3}$ bulk ceramics with the single texture microstructure, multilayered $\alpha-\mathrm{Al}_{2} \mathrm{O}_{3}$ ceramics with alternate orientations can be prepared by electrophoretic deposition in a magnetic field and alternately changing the included angle $\Phi_{B-E}$ between the electric field and the magnetic field. Figure 23 shows the preparation and microstructures of multilayered $\alpha-\mathrm{Al}_{2} \mathrm{O}_{3}$ ceramics by electrophoretic deposition in a magnetic field [195]. When the loading direction is perpendicular to the substrate, the crack propagates along grain boundaries, causing a complete intergranular fracture. When the loading direction is parallel to the substrate, the crack propagates through grains, causing an intragranular fracture. As a result, both the flexural strength and fracture toughness for the crack-propagation direction parallel to the substrate $\left(415 \mathrm{MPa}, 4.99 \mathrm{MPa} \cdot \mathrm{m}^{1 / 2}\right)$ are higher than that perpendicular to the substrate $(303 \mathrm{MPa}$, 3.65 $\left.\mathrm{MPa} \cdot \mathrm{m}^{1 / 2}\right)[195,196]$. The texture types of multilayered $\alpha-\mathrm{Al}_{2} \mathrm{O}_{3}$ ceramics can be adjusted by controlling the electric field and the magnetic field. For example, the multilayered $\alpha-\mathrm{Al}_{2} \mathrm{O}_{3}$ specimen with oriented and unoriented layers alternatively arranged can be prepared by alternate electrophoretic deposition in and out of a magnetic field [197].

\subsection{2 $\alpha-\mathrm{Al}_{2} \mathrm{O}_{3}$ related nacre bioinspired ceramics}

Mother-of-pearl (nacre) has excellent mechanical properties due to its specific brick-and-mortar structure. It is composed of $95 \mathrm{wt} \%$ plate-like aragonite whose chemical component is calcium carbonate and $5 \mathrm{wt} \%$ organic matrix whose components are proteins and polysaccharides. Polysaccharides are composed of cellulose and chitin $[45,46,198]$. Figure 24 shows the five scale levels of abalone nacre [46]. At level II, there are many nanoasperities on the surfaces of aragonite tiles. Although the ceramic content is very high, nacre possesses a fracture work 3000 times higher than aragonite. Its main toughening mechanisms are crack deflection at the interfaces between aragonite tiles and organic matrix, fiber pull-out of aragonite tiles, and crack bridging owing to organic fibers [199]. Besides, these organic layers can act as viscoelastic glue to prevent the deformation between aragonite platelets [57].

Much research has been carried out to prepare materials possessing the hierarchical structure similar to nacre by freeze-casting. Bouville et al. [55] prepared nacre-like $\alpha-\mathrm{Al}_{2} \mathrm{O}_{3}$ ceramics by ice-templating and subsequent pressing and sintering. The $\alpha-\mathrm{Al}_{2} \mathrm{O}_{3}$ specimen possesses a long-range ordered structure as shown in Fig. 25(a). It is composed of 98.5 vol $\% \alpha-\mathrm{Al}_{2} \mathrm{O}_{3}, 1.3$ vol\% silica, and $0.2 \mathrm{vol} \%$ calcia. The dimension of its closely packed ceramic platelets is identical to that of nacre. There are many nanoasperities on the surfaces

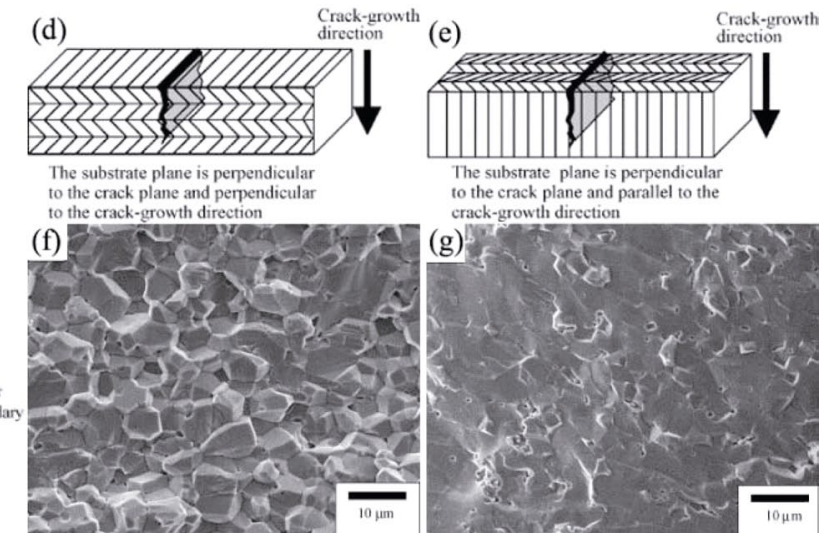

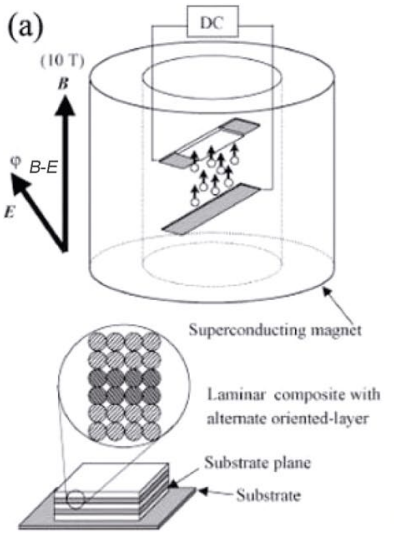
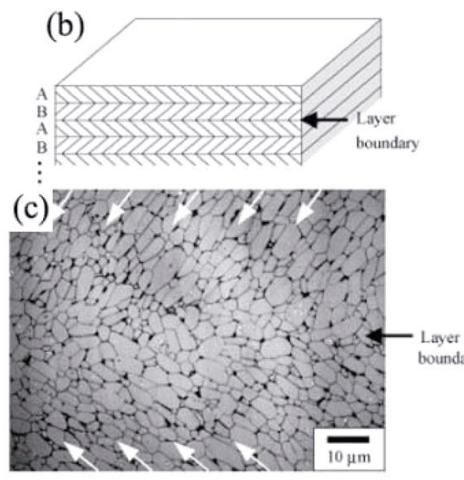

Fig. 23 Preparation and microstructures of multilayered $\alpha-\mathrm{Al}_{2} \mathrm{O}_{3}$ ceramics by electrophoretic deposition in a magnetic field: (a) schematic diagram of the experimental apparatus; $(b, c)$ microstructure of a multilayered $\alpha-\mathrm{Al}_{2} \mathrm{O}_{3}$ specimen prepared by alternately changing $\Phi_{B-E}= \pm 45^{\circ}$; (d, e) schematic diagrams of crack propagation perpendicular and parallel to the substrate, respectively; (f, g) fracture morphologies corresponding to (d) and (e), respectively. Reproduced with permission from Ref. [195], (C) Elsevier Ltd. 2005. 


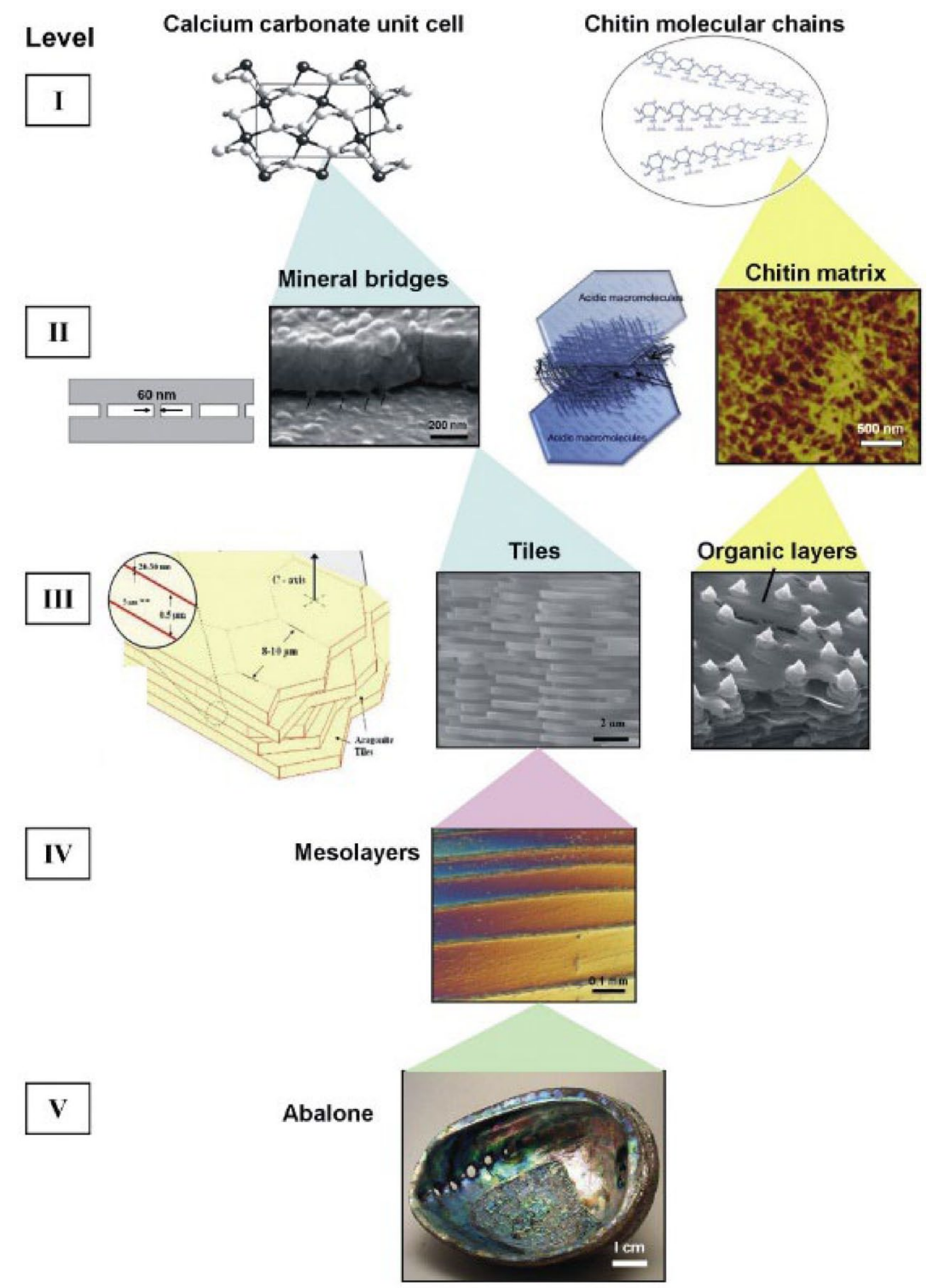

Fig. 24 Five levels of the hierarchical structure of the abalone nacre. (I) Molecular structures of calcium carbonates and chitins. (II) Mineral bridges possessing the sandwich structure. (III) Aragonite tiles and organic layers. (IV) Mesolayers with a thick organic layer separating tile assemblages. (V) The abalone. Reproduced with permission from Ref. [46], C Elsevier Ltd. 2010.

of these platelets, ceramic bonds (bridges) linking these platelets, and a secondary phase with low stiffness to ensure load redistribution, crack deflection, and delamination. This nacre-like $\alpha-\mathrm{Al}_{2} \mathrm{O}_{3}$ specimen possesses excellent mechanical properties with no anisotropy. It has a combination of high strength $(470 \mathrm{MPa})$, high toughness $\left(22 \mathrm{MPa} \cdot \mathrm{m}^{1 / 2}\right)$, and high stiffness (290 GPa). Figure 25(b) shows fracture toughness versus flexural strength of $\alpha-\mathrm{Al}_{2} \mathrm{O}_{3}$-based materials. There are usually conflicts between toughness and strength, because strength is the ability resisting non-recoverable (for example, plastic) deformation, while high toughness is usually related to good plasticity $[55,200]$. Nacre-like
$\alpha-\mathrm{Al}_{2} \mathrm{O}_{3}$ ceramics possess both high strength and toughness due to their hierarchical structure. Besides, they also have specific strength and specific toughness as high as engineering aluminium and magnesium alloys, as shown in Fig. 25(c).

\section{4. $2 \mathrm{Si}_{3} \mathrm{~N}_{4}$ and $\mathrm{SiAION}$}

Silicon nitride $\left(\mathrm{Si}_{3} \mathrm{~N}_{4}\right)$ belongs to the hexagonal crystal lattice and combines many outstanding properties such as high temperature strength, high thermal conductivity, low thermal expansion coefficient, good resistance to oxidation, excellent creep resistance, and good tribological properties [128,146,201-204]. It has been widely used 

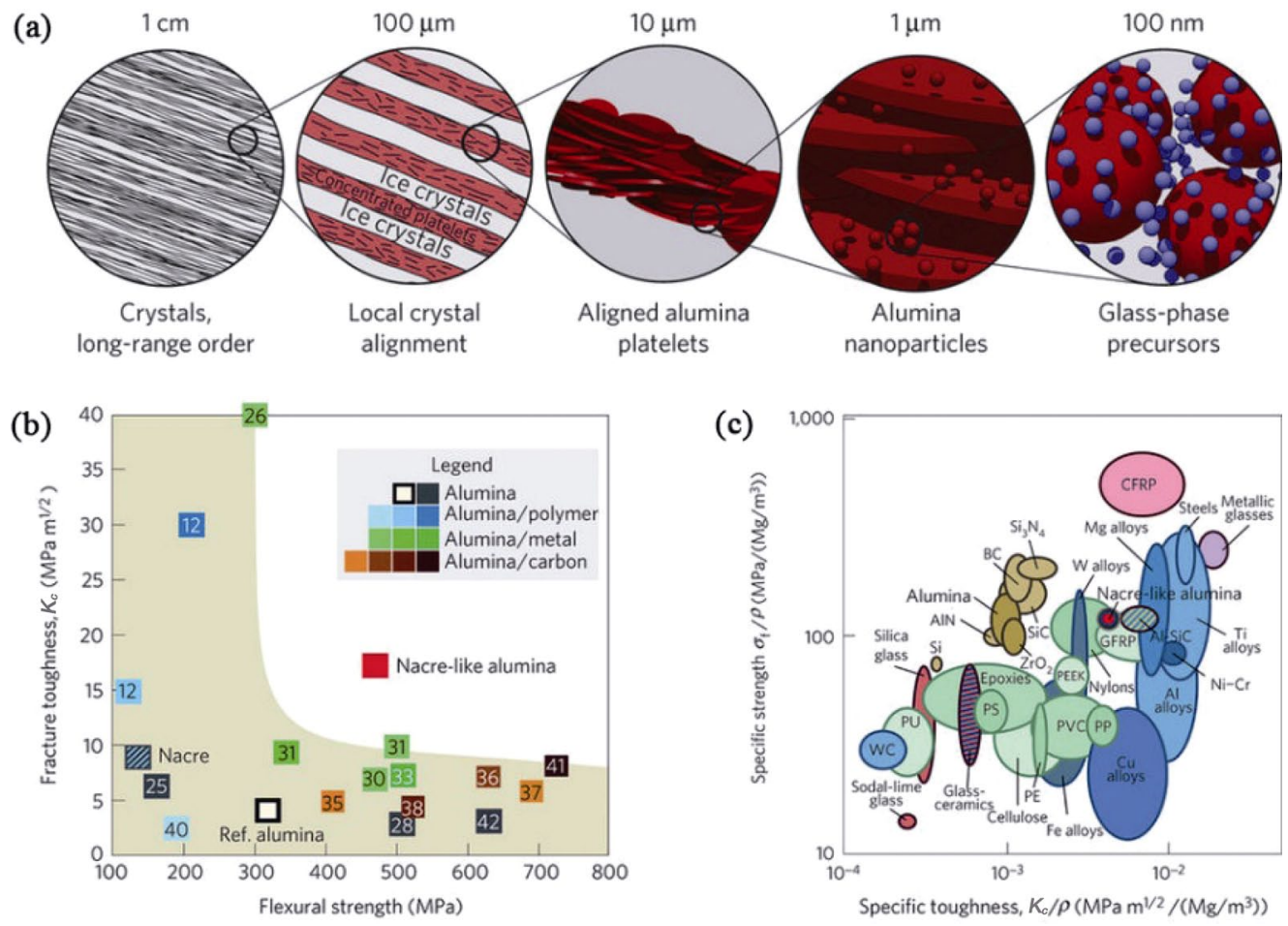

Fig. 25 Microstructure and properties of nacre-like $\alpha-\mathrm{Al}_{2} \mathrm{O}_{3}$ : (a) long-range ordered structure of nacre-like $\alpha$ - $\mathrm{Al}_{2} \mathrm{O}_{3}$; (b) fracture toughness versus flexural strength of $\alpha-\mathrm{Al}_{2} \mathrm{O}_{3}$-based materials (numbers in the figure are the reference numbers in Ref. [55]); (c) ashby diagram of specific strength versus specific toughness of a series of engineering and natural materials. Reproduced with permission from Ref. [55], (C) Springer Nature 2014.

as high temperature structural materials and has the potential to become the next-generation insulating substrate materials in high-power electronic devices [205,206].

Textured $\mathrm{Si}_{3} \mathrm{~N}_{4}$ ceramics can be prepared using $\alpha-\mathrm{Si}_{3} \mathrm{~N}_{4}$ powders and $\beta-\mathrm{Si}_{3} \mathrm{~N}_{4}$ seeds as main raw materials. $\alpha-\mathrm{Si}_{3} \mathrm{~N}_{4}$ can transfer into $\beta-\mathrm{Si}_{3} \mathrm{~N}_{4}$ when sintering at high temperature [207]. Some $\beta-\mathrm{Si}_{3} \mathrm{~N}_{4}$ seeds or rare earth oxides can decrease the activation energy of phase transformation from $\alpha-\mathrm{Si}_{3} \mathrm{~N}_{4}$ to $\beta-\mathrm{Si}_{3} \mathrm{~N}_{4}$, promoting phase transformation [208-212]. With some $\beta-\mathrm{Si}_{3} \mathrm{~N}_{4}$ seeds in $\alpha-\mathrm{Si}_{3} \mathrm{~N}_{4}$, the nucleation of $\beta-\mathrm{Si}_{3} \mathrm{~N}_{4}$ grains will take place easily at seed particle. Rod-like $\mathrm{Si}_{3} \mathrm{~N}_{4}$ seeds can grow preferentially along the length direction during sintering and result in a bimodal distribution of grain sizes, that is, a microstructure containing both large elongated grains and fine matrix grains can be obtained. These elongated grains act as the reinforced phase in matrix grains $[178,213,214]$. In textured $\mathrm{Si}_{3} \mathrm{~N}_{4}$ ceramics containing elongated grains, crack deflection and bridging can be more employed perpendicular to the $c$-axis orientation, which can significantly improve their mechanical properties [23]. Within a certain range, more $\beta-\mathrm{Si}_{3} \mathrm{~N}_{4}$ seeds are favorable to preferred orientation growth and texture formation in $\mathrm{Si}_{3} \mathrm{~N}_{4}$ ceramics [215]. But the preferred orientation growth of $\mathrm{Si}_{3} \mathrm{~N}_{4}$ grains usually happens with the phase transformation from $\alpha-\mathrm{Si}_{3} \mathrm{~N}_{4}$ to $\beta-\mathrm{Si}_{3} \mathrm{~N}_{4}$, so high $\alpha / \beta$ ratio can accelerate the preferred orientation growth of $\mathrm{Si}_{3} \mathrm{~N}_{4}$ grains and improve the mechanical properties [194,216-218].

$\mathrm{Si}_{3} \mathrm{~N}_{4}$ grains can be aligned with the $a, b$-axis parallel to the magnetic field as $\chi_{c}<\chi_{a, b}$. So the $c$-axis will be arbitrarily arranged in the plane perpendicular to the magnetic field [2]. But if the $\mathrm{Si}_{3} \mathrm{~N}_{4}$ suspension mold is rotated in a magnetic field whose direction is parallel to the horizon, $\mathrm{Si}_{3} \mathrm{~N}_{4}$ grains can be aligned parallel to the gravity direction, forming the $c$-axis oriented texture, as shown in Fig. 26 [133].

When sintered with uniaxial pressure, rod-like $\mathrm{Si}_{3} \mathrm{~N}_{4}$ grains can be rotated to the direction perpendicular to the pressure direction, forming the $a, b$-axis oriented texture [6]. HF of SC and PSC can result in the $a, b$-axis oriented texture and the $c$-axis oriented texture, respectively, as discussed in Section 3.1.1. Figure 27 shows the microstructures and XRD patterns of $\beta-\mathrm{Si}_{3} \mathrm{~N}_{4}$ specimens possessing the $a, b$-axis and $c$-axis oriented texture. For both the two kinds of textured $\beta-\mathrm{Si}_{3} \mathrm{~N}_{4}$ ceramics, the (002) diffraction intensities on the specimen 


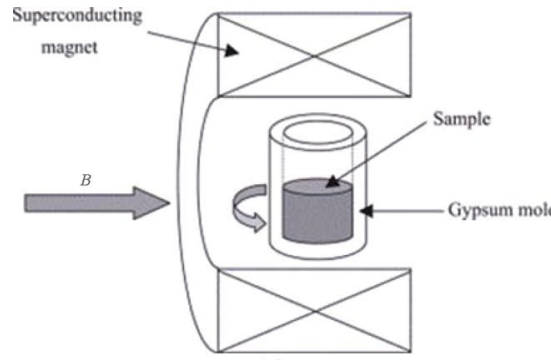

(a)

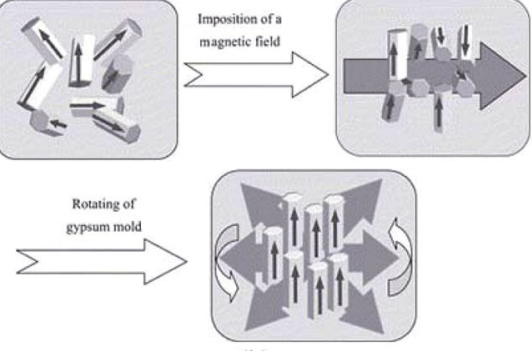

(b)

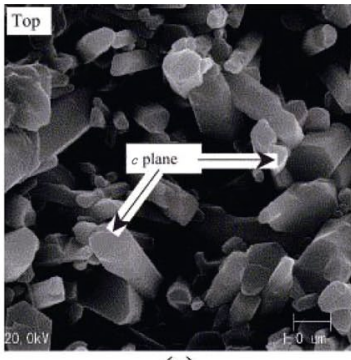

(c)

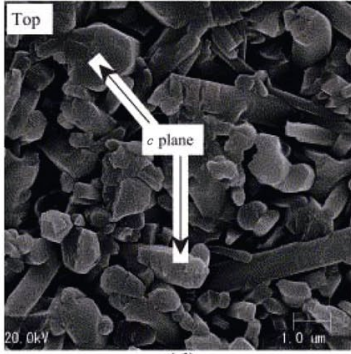

(d)

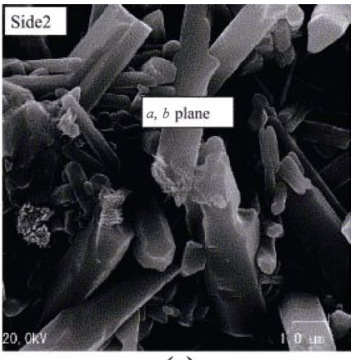

(e)

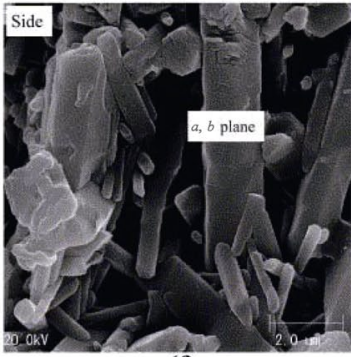

(f)

Fig. 26 Preparation and microstructures of textured $\mathrm{Si}_{3} \mathrm{~N}_{4}$ specimens by slip casting in a magnetic field: (a) schematic diagram of the experimental apparatus; (b) effect of the magnetic field and mold rotation on the orientation of rodlike $\mathrm{Si}_{3} \mathrm{~N}_{4}$ grains; $_{(\mathrm{c}, \text { e) }}$ top and side surfaces of textured $\mathrm{Si}_{3} \mathrm{~N}_{4}$ specimens prepared without mold rotation during slip casting, respectively; (d, f) top and side surfaces of textured $\mathrm{Si}_{3} \mathrm{~N}_{4}$ specimens prepared in the magnetic field with mold rotation during slip casting, respectively. Reproduced with permission from Ref. [133], @ Elsevier B.V. 2004.

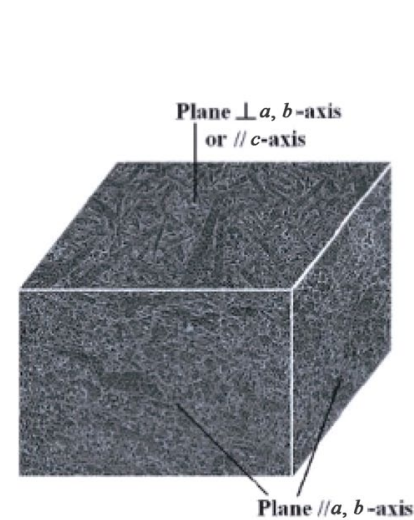

(a)

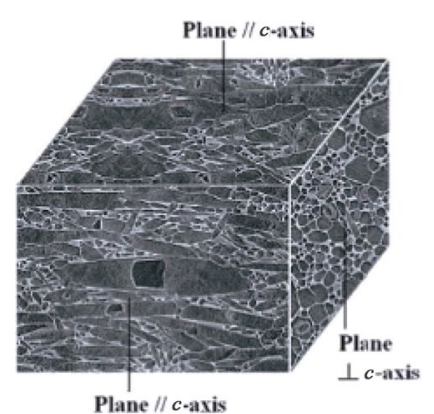

(d)

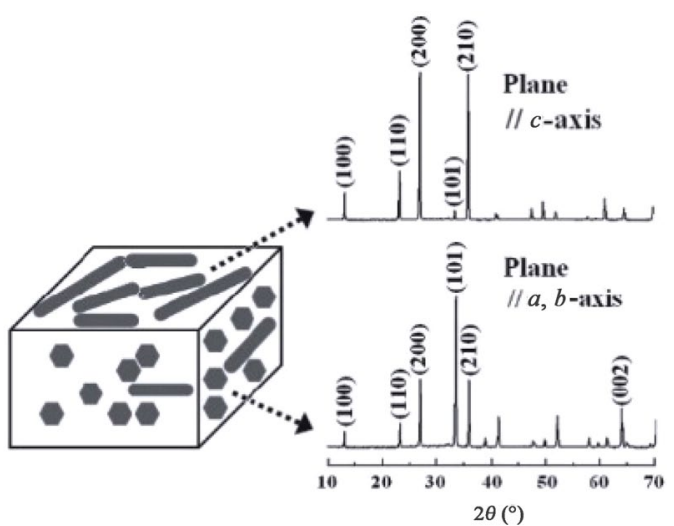

(b)

(c)

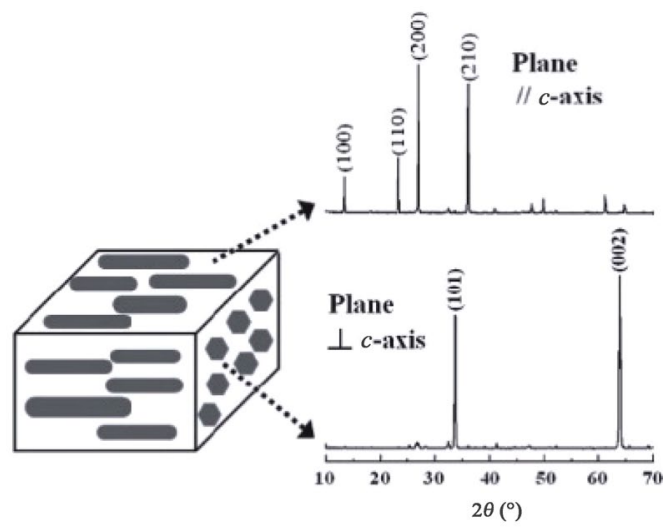

(e)

Fig. 27 Microstructures and XRD patterns of the $a, b$-axis oriented and $c$-axis oriented $\beta-\mathrm{Si}_{3} \mathrm{~N}_{4}$ specimens: (a, d) actual microstructures; (b, e) schematic diagrams; (c, f) XRD patterns. Reproduced with permission from Ref. [23], (C) National Institute for Materials Science 2008. 
surfaces parallel to the $a, b$-axis orientation are higher than that parallel to the $c$-axis orientation. But the $c$-axis oriented $\beta-\mathrm{Si}_{3} \mathrm{~N}_{4}$ specimen shows a much higher (002) diffraction intensity on the specimen surface parallel to the $a, b$-axis orientation than the $a, b$-axis oriented $\beta-\mathrm{Si}_{3} \mathrm{~N}_{4}$ specimen [23].

Table 6 shows the anisotropic properties of textured $\mathrm{Si}_{3} \mathrm{~N}_{4}$ matrix ceramics. Generally, $\beta-\mathrm{Si}_{3} \mathrm{~N}_{4}$ seeds with finer size and higher aspect ratio are more favorable to texture formation. Textured $\mathrm{Si}_{3} \mathrm{~N}_{4}$ ceramics with elongated $\beta-\mathrm{Si}_{3} \mathrm{~N}_{4}$ grains also possess more significantly anisotropic mechanical properties. When the loading direction is perpendicular to the $c$-axis orientation, the grain pullout mechanism can play a better role strengthening and toughening, resulting in higher mechanical properties $[71,213]$. However, when the seed amount is enough and the sintering time is very long, the microstructure might be not different from that prepared using nearequiaxed seeds. Because the steric hindrance during prolonged sintering limits the preferred orientation growth. Figure 28 shows the surface morphologies of textured $\mathrm{Si}_{3} \mathrm{~N}_{4}$ ceramics prepared using near-equiaxed and rodlike $\beta-\mathrm{Si}_{3} \mathrm{~N}_{4}$ seeds [219]. Due to the rotation of mold in their experiment, $\mathrm{Si}_{3} \mathrm{~N}_{4}$ specimens have the $c$-axis oriented texture. Grain size and morphology are similar for the two specimens. While equiaxed seeds are better to densification and thermal conduction than rod-like seeds.

The thermal conductivity of textured $\mathrm{Si}_{3} \mathrm{~N}_{4}$ ceramics also has strong relationship with grain size. The larger the grain size is, the larger the average free path of phonons is, and the higher thermal conductivity is. The prolonging of holding time, the high temperature annealing after sintering can both promote grain growth [6,220]. The hot-isostatic pressing (HIP) treatment can also lead to further increase of grain size and densification. Watari et al. [221] studied the effect of HIP on the thermal conductivity of textured $\mathrm{Si}_{3} \mathrm{~N}_{4}$ ceramics prepared by TGG and HP. Figure 29 shows the surface morphologies and thermal conductivities of textured $\mathrm{Si}_{3} \mathrm{~N}_{4}$ specimens without and with HIP. The HIPed specimen possesses elongated grains with the average diameter of $10 \mu \mathrm{m}$ and the average length of $200 \mu \mathrm{m}$, higher than 1.8 and $10 \mu \mathrm{m}$ of the specimen without HIP. Thus the HIPed specimen possesses the thermal conductivity of $155 \mathrm{~W} /(\mathrm{m} \cdot \mathrm{K})$ along the grain alignment

Table 6 Properties of textured $\mathrm{Si}_{3} \mathrm{~N}_{4}$ matrix ceramics

\begin{tabular}{|c|c|c|c|c|c|c|c|c|}
\hline Researchers & Raw materials & Seed morphology & $\begin{array}{l}\text { Preparation } \\
\text { methods }\end{array}$ & $\begin{array}{c}\text { Relative } \\
\text { density/bulk } \\
\text { density }\end{array}$ & $\begin{array}{l}\text { Orientation } \\
\text { factor }\end{array}$ & $\begin{array}{c}\text { Flexural } \\
\text { strength }(\mathrm{MPa})\end{array}$ & $\begin{array}{c}\text { Fracture } \\
\text { toughness } \\
\left(\mathrm{MPa} \cdot \mathrm{m}^{1 / 2}\right)\end{array}$ & $\begin{array}{l}\text { Thermal } \\
\text { conductivity } \\
(\mathrm{W} /(\mathrm{m} \cdot \mathrm{K}))\end{array}$ \\
\hline \multirow{2}{*}{$\begin{array}{l}\text { Imamura } \\
\text { et al. }[71]\end{array}$} & \multirow{2}{*}{$\begin{array}{c}\beta-\mathrm{Si}_{3} \mathrm{~N}_{4}+5 \mathrm{vol} \% \\
\beta-\mathrm{Si}_{3} \mathrm{~N}_{4} \text { seeds }+ \\
5 \mathrm{~mol}^{2} \mathrm{Y}_{2} \mathrm{O}_{3}+ \\
2.5 \mathrm{~mol} \% \mathrm{SiO}_{2}\end{array}$} & $\begin{array}{c}\text { Diameter }=0.47 \mu \mathrm{m} \\
\text { Aspect ratio }=4.2 \\
\end{array}$ & \multirow{2}{*}{$\begin{array}{c}\text { TGG \& } \\
\text { gas pressure } \\
\text { sintering }\end{array}$} & \multirow{2}{*}{$\begin{array}{l}\text { Relative density } \\
\geqslant 97 \%\end{array}$} & $f_{0}=0.35-0.51$ & $\begin{array}{c}1396(/ / c \text {-axis }) \\
724(\perp c \text {-axis })\end{array}$ & $\begin{array}{l}12.4(/ / c \text {-axis }) \\
7.2(\perp c \text {-axis })\end{array}$ & - \\
\hline & & $\begin{array}{c}\text { Diameter }=1.29 \mu \mathrm{m} \\
\text { Aspect ratio }=4\end{array}$ & & & $f_{0}=-0.04-0.37$ & $\begin{array}{l}1215(/ / c \text {-axis }) \\
723(\perp c \text {-axis })\end{array}$ & $\begin{array}{l}11.6(/ / c \text {-axis }) \\
7.3(\perp c \text {-axis })\end{array}$ & - \\
\hline \multirow{2}{*}{$\begin{array}{c}\text { Bae et al. } \\
\text { [213] }\end{array}$} & \multirow{2}{*}{$\begin{array}{c}\mathrm{Si}_{3} \mathrm{~N}_{4}+3 \mathrm{wt} \% \\
\beta-\mathrm{Si}_{3} \mathrm{~N}_{4} \text { seeds }+ \\
6 \mathrm{wt} \% \mathrm{Y}_{2} \mathrm{O}_{3}+ \\
1 \mathrm{wt} \% \mathrm{Al}_{2} \mathrm{O}_{3}\end{array}$} & $\begin{array}{l}\text { Diameter }=1.1 \mu \mathrm{m} \\
\text { Aspect ratio }=11.1\end{array}$ & \multirow{2}{*}{$\begin{array}{c}\text { TGG \& } \\
\text { gas pressure } \\
\text { sintering }\end{array}$} & \multirow{2}{*}{$\begin{array}{c}\text { Relative density } \approx \\
98 \%\end{array}$} & $f_{002}=0.38$ & - & $\begin{array}{l}7.1 \text { (//c-axis }) \\
5.0(\perp c \text {-axis })\end{array}$ & - \\
\hline & & $\begin{array}{c}\text { Diameter }=2.8 \mu \mathrm{m} \\
\text { Aspect ratio }=6.7\end{array}$ & & & $f_{002}=0.3$ & - & $\begin{array}{l}6.9(/ / c \text {-axis }) \\
5.5(\perp c \text {-axis })\end{array}$ & - \\
\hline \multirow{2}{*}{$\begin{array}{l}\text { Pablos et al. } \\
{[6]}\end{array}$} & \multirow{2}{*}{$\begin{array}{c}\alpha-\mathrm{Si}_{3} \mathrm{~N}_{4}+10 \mathrm{wt} \% \\
\mathrm{Y}_{2} \mathrm{O}_{3}\end{array}$} & \multirow{2}{*}{ - } & $\begin{array}{c}\mathrm{HP}(\text { holding time }= \\
1.5 \mathrm{~h})\end{array}$ & $\begin{array}{c}\text { Bulk density }= \\
3.26 \mathrm{~g} / \mathrm{cm}^{3}\end{array}$ & - & - & - & $42(\perp c$-axis $)$ \\
\hline & & & $\begin{array}{l}\mathrm{HP}(\text { holding time }= \\
\qquad 2 \mathrm{~h})\end{array}$ & $\begin{array}{c}\text { Bulk density }= \\
3.26 \mathrm{~g} / \mathrm{cm}^{3}\end{array}$ & - & - & - & $\begin{array}{l}82 \text { (//c-axis }) \\
62(\perp c \text {-axis })\end{array}$ \\
\hline \multirow{2}{*}{$\begin{array}{l}\text { Hirao et al. } \\
\text { [220] }\end{array}$} & \multirow{2}{*}{$\begin{array}{c}\alpha-\mathrm{Si}_{3} \mathrm{~N}_{4}+5 \text { vol } \% \\
\beta-\mathrm{Si}_{3} \mathrm{~N}_{4} \text { seeds }+ \\
5 \mathrm{wt} \% \mathrm{Y}_{2} \mathrm{O}_{3}\end{array}$} & \multirow{2}{*}{$\begin{array}{l}\text { Diameter }=1 \mu \mathrm{m} \\
\text { Aspect ratio }=10\end{array}$} & $\begin{array}{c}\text { TGG \& HP \& } \\
\text { annealing for } 2 \mathrm{~h}\end{array}$ & $\begin{array}{c}\text { Relative density }> \\
99 \%\end{array}$ & - & - & - & $\begin{array}{l}87(/ / c \text {-axis }) \\
50(\perp c \text {-axis })\end{array}$ \\
\hline & & & $\begin{array}{c}\text { TGG \& HP \& } \\
\text { annealing for } 66 \mathrm{~h}\end{array}$ & $\begin{array}{c}\text { Relative density }> \\
99 \%\end{array}$ & - & - & - & $\begin{array}{c}121(/ / c \text {-axis }) \\
59(\perp c \text {-axis })\end{array}$ \\
\hline \multirow{2}{*}{$\begin{array}{l}\text { Watari et al. } \\
\text { [221] }\end{array}$} & \multirow{2}{*}{$\begin{array}{c}\alpha-\mathrm{Si}_{3} \mathrm{~N}_{4}+5 \text { vol. } \% \\
\beta-\mathrm{Si}_{3} \mathrm{~N}_{4} \text { seeds }+ \\
5 \mathrm{wt} \% \mathrm{Y}_{2} \mathrm{O}_{3}\end{array}$} & \multirow{2}{*}{$\begin{array}{l}\text { Diameter }=1.3 \mu \mathrm{m} \\
\text { Aspect ratio }=4.15\end{array}$} & TGG \& HP & $\begin{array}{c}\text { Bulk density }= \\
3.190 \mathrm{~g} / \mathrm{cm}^{3}\end{array}$ & - & - & - & $\begin{array}{l}70 \text { (//c-axis }) \\
30(\perp c \text {-axis })\end{array}$ \\
\hline & & & TGG \& HP \& HIP & $\begin{array}{c}\text { Bulk density }= \\
3.205 \mathrm{~g} / \mathrm{cm}^{3}\end{array}$ & - & - & - & $\begin{array}{c}155(/ / c \text {-axis }) \\
52(\perp c \text {-axis })\end{array}$ \\
\hline \multirow{2}{*}{$\begin{array}{l}\text { Zhu et al. } \\
\text { [219] }\end{array}$} & \multirow{2}{*}{$\begin{array}{c}\alpha-\mathrm{Si}_{3} \mathrm{~N}_{4}+5 \mathrm{~mol} \% \\
\beta-\mathrm{Si}_{3} \mathrm{~N}_{4} \text { seeds }+ \\
2 \mathrm{~mol}_{0} \mathrm{Y}_{2} \mathrm{O}_{3}+ \\
5 \mathrm{~mol}^{2} \mathrm{MgSiN}_{2}\end{array}$} & $\begin{array}{c}\text { Diameter }= \\
0.63 \mu \mathrm{m} \\
\text { Aspect ratio }=1\end{array}$ & \multirow{2}{*}{$\begin{array}{l}\text { Magnetic alignment } \\
\text { \& gas pressure } \\
\text { sintering } \\
6\end{array}$} & $\begin{array}{l}\text { Relative density = } \\
\quad 99.1 \%\end{array}$ & $f_{001}=0.98$ & - & - & $\begin{array}{c}176(/ / c \text {-axis }) \\
62(\perp c \text {-axis })\end{array}$ \\
\hline & & $\begin{array}{c}\text { Diameter }= \\
0.43 \mu \mathrm{m} \\
\text { Aspect ratio }=8.86\end{array}$ & & $\begin{array}{c}\text { Relative density }= \\
97.2 \%\end{array}$ & $f_{001}=0.97$ & - & - & $\begin{array}{c}168(/ / c \text {-axis }) \\
60(\perp c \text {-axis })\end{array}$ \\
\hline
\end{tabular}



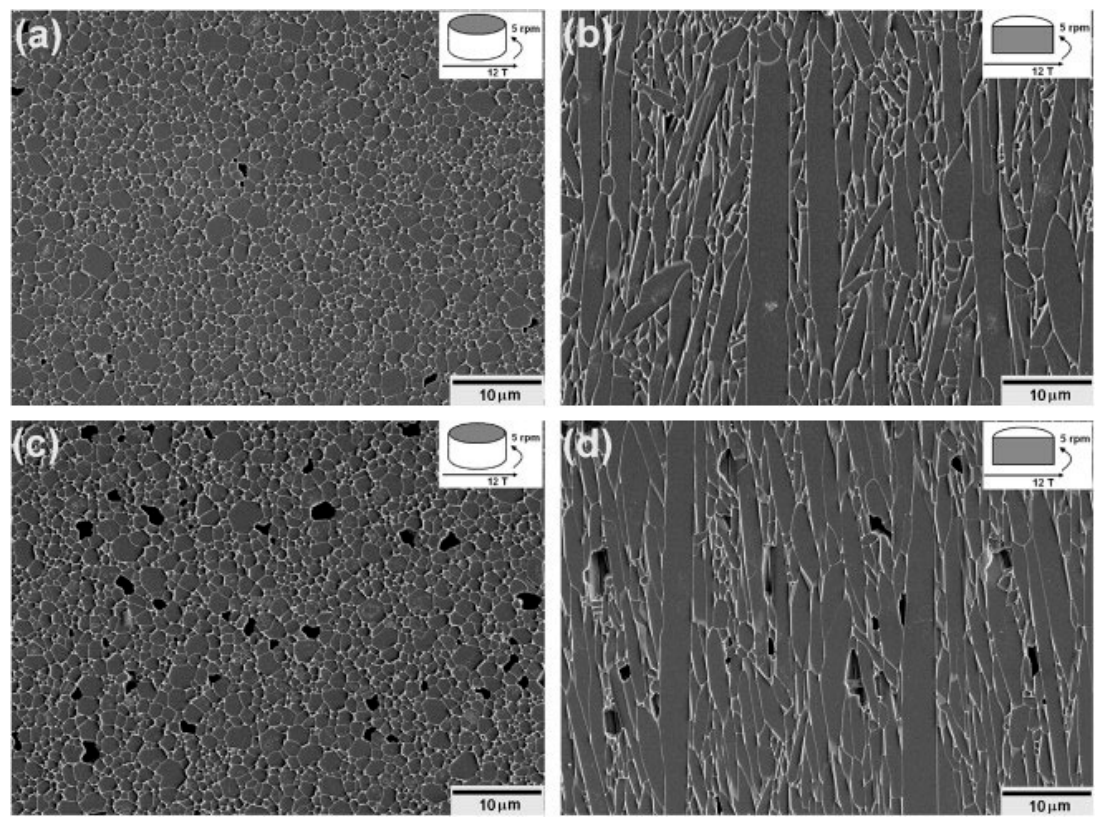

Fig. 28 Polished and plasma-etched surface morphologies of textured $\mathrm{Si}_{3} \mathrm{~N}_{4}$ specimens: $(\mathrm{a}, \mathrm{b})$ surfaces perpendicular and parallel to the $c$-axis orientation of the specimen prepared using near-equiaxed $\beta-\mathrm{Si}_{3} \mathrm{~N}_{4}$ seeds, respectively; (c, d) surfaces perpendicular and parallel to the $c$-axis orientation of the specimen prepared using rodlike $\beta-\mathrm{Si}_{3} \mathrm{~N}_{4}$ seeds, respectively. Reproduced with permission from Ref. [219], (C) Elsevier Ltd. 2014.

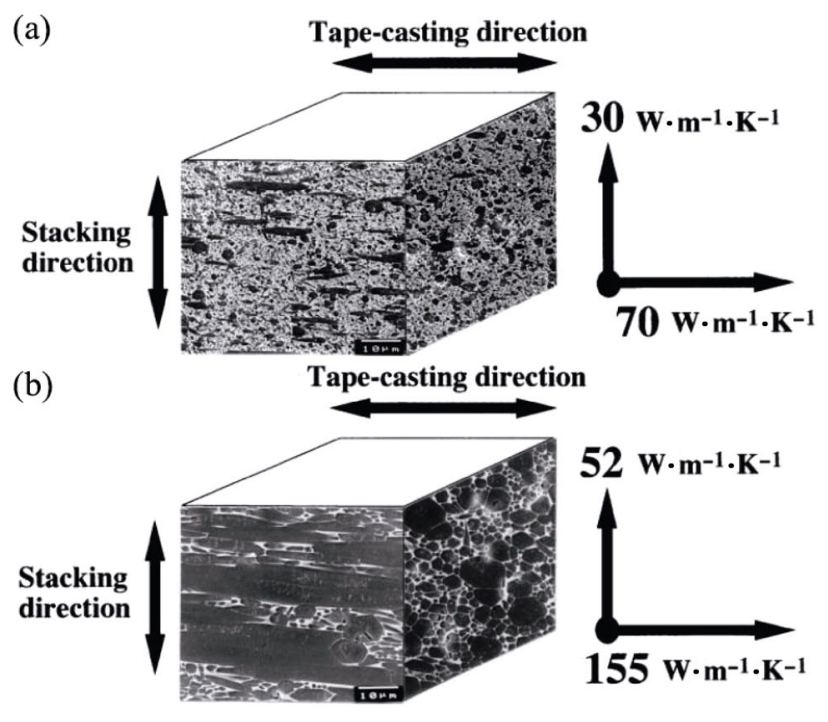

Fig. 29 Plasma-etched surface morphologies and thermal conductivities of textured $\mathrm{Si}_{3} \mathrm{~N}_{4}$ fabricated by: (a) TGG and HP; (b) TGG, HP, and HIP. Reproduced with permission from Ref. [221], C Materials Research Society 1999.

direction, higher than $70 \mathrm{~W} /(\mathrm{m} \cdot \mathrm{K})$ of that prepared without HIP.

SiAlON is a kind of solid solutions of $\mathrm{Si}_{3} \mathrm{~N}_{4}$ where some $\mathrm{Si}-\mathrm{N}$ bonds are replaced by $\mathrm{Al}-\mathrm{O}$ or $\mathrm{Al}-\mathrm{N}$ bonds. $\beta$-SiAlON and $\alpha$-SiAlON are the solid solutions of $\beta-\mathrm{Si}_{3} \mathrm{~N}_{4}$ and $\alpha-\mathrm{Si}_{3} \mathrm{~N}_{4}$, respectively [222]. The general formula of $\alpha-\mathrm{SiAlON}$ is $\mathrm{Me}_{x} \mathrm{Si}_{12-(m+n)} \mathrm{Al}_{m+n} \mathrm{O}_{n} \mathrm{~N}_{16-n}$, where $m$ represents the number of $\mathrm{Si}-\mathrm{N}$ substituted by $\mathrm{Al}-\mathrm{N}$, $n$ represents the number of $\mathrm{Si}-\mathrm{N}$ substituted by $\mathrm{Al}-\mathrm{O}$, $x=m / v, v$ is the chemical valence of $\mathrm{Me}^{+v}$ cation, and $\mathrm{Me}$ is the metal cation compensating for the imbalance of electrovalence to stabilize the structure, usually is $\mathrm{Li}$, $\mathrm{Mg}, \mathrm{Ca}, \mathrm{Y}$, or some lanthanide [223]. $\beta$-SiAlON's general formula is $\mathrm{Si}_{6-z} \mathrm{Al}_{z} \mathrm{O}_{z} \mathrm{~N}_{8-z}$, where $z$ is the number of $\mathrm{N}$ replaced by $\mathrm{O}$ and ranges from 0 to 4.2 under the normal pressure $[224,225]$. $\alpha$-SiAlON can be prepared by reaction sintering of $\alpha-\mathrm{Si}_{3} \mathrm{~N}_{4}, \mathrm{Al}_{2} \mathrm{O}_{3}, \mathrm{AlN}$, and metal oxide powders [226]. $\beta$-SiAlON can be prepared by reaction sintering of $\alpha-\mathrm{Si}_{3} \mathrm{~N}_{4}$ or $\beta-\mathrm{Si}_{3} \mathrm{~N}_{4}, \mathrm{Al}_{2} \mathrm{O}_{3}$, and AlN powders $[224,225]$. It was found by Muscat et al. [179] that there are epitaxial growth of $\beta$-SiAlON on $\beta-\mathrm{Si}_{3} \mathrm{~N}_{4}$ whiskers during reaction sintering, and the nucleation and growth of $\beta$-SiAlON also occur between $\beta-\mathrm{Si}_{3} \mathrm{~N}_{4}$ whiskers simultaneously, forming $\beta-\mathrm{Si}_{3} \mathrm{~N}_{4}$ whisker-reinforced $\beta$-SiAlON composites composed of $\beta$-SiAlON matrix and whiskers containing a $\beta-\mathrm{Si}_{3} \mathrm{~N}_{4}$ core and a $\beta$-SiAlON sheath layer.

When the raw material suspension for preparation of SiAlON is placed in a magnetic field, $\mathrm{Si}_{3} \mathrm{~N}_{4}$ grains can be oriented with the $c$-axis perpendicular to the magnetic field. Then after the reaction sintering of the green body, textured SiAlON ceramics can be prepared. $\mathrm{Zhu}$ et al. [227] prepared $\mathrm{Ca}-\alpha-\mathrm{SiAlON}$ ceramics using $\alpha-\mathrm{Si}_{3} \mathrm{~N}_{4}, \mathrm{CaCO}_{3}$ (the source of $\mathrm{CaO}$ ), $\mathrm{Al}_{2} \mathrm{O}_{3}$, and 
AlN as raw materials by slip casting without and with a $12 \mathrm{~T}$ magnetic field and subsequent sintering (marked as $0 \mathrm{~T}$ specimen and $12 \mathrm{~T}$ specimen, respectively). Figure 30 shows the surface morphologies of $\mathrm{Ca}-\alpha-\mathrm{SiAlON}$ ceramics. The transformation from $\mathrm{Si}_{3} \mathrm{~N}_{4}$ to $\mathrm{SiAlON}$ can be completed within $5 \mathrm{~min}$ at $1800{ }^{\circ} \mathrm{C}$. The orientation factors $I_{210} / I_{102}$ on the $0 \mathrm{~T}$ specimen surfaces perpendicular and parallel to the slip casting direction are 1.02 and 0.92 , respectively, with small difference. However, the orientation factors $I_{210} / I_{102}$ on the $12 \mathrm{~T}$ specimen surfaces perpendicular and parallel to the magnetic field were 1.51 and 0.72 , respectively, indicating the formation of stronger texture. It was revealed by Zhu et al. [225] that $\beta-\mathrm{Si}_{3} \mathrm{~N}_{4}$ is more beneficial to texture formation of $\beta-\mathrm{SiAlON}$ than $\alpha-\mathrm{Si}_{3} \mathrm{~N}_{4} \cdot \alpha-\mathrm{Si}_{3} \mathrm{~N}_{4}, \beta-\mathrm{Si}_{3} \mathrm{~N}_{4}, \mathrm{Al}_{2} \mathrm{O}_{3}$, and AlN powders were used to prepare textured $\beta$-SiAlON ceramics by magnetic alignment and sintering. The specimen prepared using $\beta-\mathrm{Si}_{3} \mathrm{~N}_{4}$ powders containing $3.4 \mathrm{wt} \% \alpha-\mathrm{Si}_{3} \mathrm{~N}_{4}$ is higher than 0.97 and even reaches 1 after sintering for $6 \mathrm{~h}$. While that of the specimen prepared using $\alpha-\mathrm{Si}_{3} \mathrm{~N}_{4}$ powders containing $4.6 \mathrm{wt} \% \beta-\mathrm{Si}_{3} \mathrm{~N}_{4}$ is only 0.47 after sintering for $6 \mathrm{~h}$.

Under uniaxial pressure, SiAlON can grow along the $c$-axis, forming elongated grains perpendicular to the pressure direction. Normally, for hot working, elongated SiAlON grains are oriented with the $c$-axis perpendicular to the external pressure, that is, the $c$-axis can be arbitrarily oriented in the plane perpendicular to the external pressure, forming the $a, b$-axis oriented texture. But the $c$-axis oriented texture has been obtained by Carman et al. [124] by conducting $\mathrm{HF}$ perpendicular to the direction of previous HP. The fracture toughness of $\alpha$-SiAlON ceramics with the $c$-axis oriented texture possess more significantly anisotropic fracture toughness (5.7 and 2.9 $\mathrm{MPa} \cdot \mathrm{m}^{1 / 2}$ perpendicular and parallel to the $c$-axis orientation, respectively) than that with $a, b$-axis oriented texture $\left(4.9\right.$ and $3.0 \mathrm{MPa} \cdot \mathrm{m}^{1 / 2}$ perpendicular and parallel to the $c$-axis orientation, respectively). The $\mathrm{HF}$ after HP can lead to more significant texture and better mechanical properties of SiAlON ceramics due to the grain pull-out toughening mechanism [228].

For textured SiAlON ceramics, the fracture toughness perpendicular to the $c$-axis orientation is usually higher than that parallel to the $c$-axis orientation due to deflection and grain pull-out mechanisms. However, if graphene nanoplatelets (GNPs) are introduced during the preparation of SiAlON ceramics, bridging can become the dominant toughening mechanism, and the
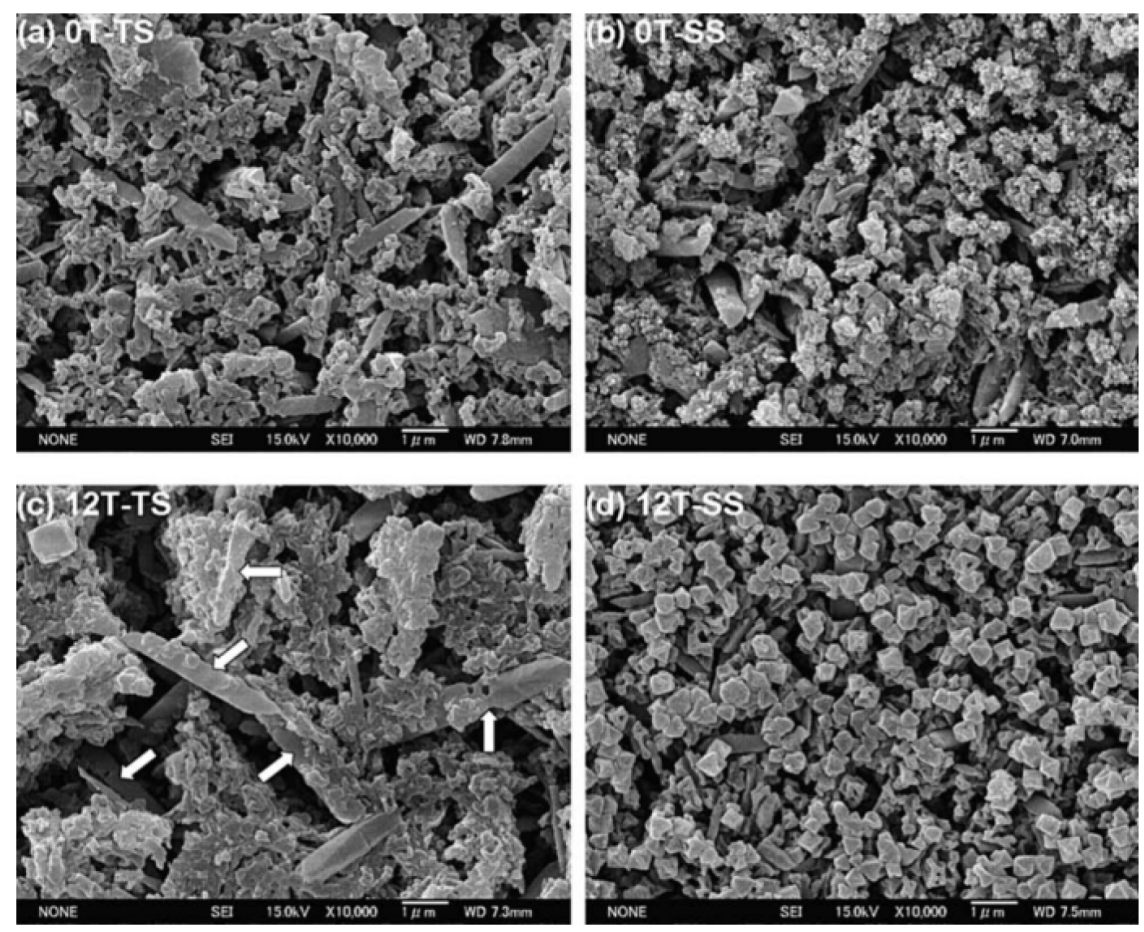

Fig. 30 Polished and molten $\mathrm{NaOH}$-etched surface morphologies of $\mathrm{Ca}-\alpha$-SiAlON ceramics: $(\mathrm{a}, \mathrm{b})$ top surface $(\perp$ casting) and side surface (// casting) of $0 \mathrm{~T}$ specimen, respectively; (c, d) top surface $(\perp B)$ and side surface $(/ / B)$ of $12 \mathrm{~T}$ specimen, respectively. White arrows indicate these oriented rodlike grains. Reproduced with permission from Ref. [227], (C) The Ceramic Society of Japan 2007. 
opposite situation may happen. By adding $4 \mathrm{wt} \%$ GNPs, the fracture toughness of SiAlON ceramics perpendicular to the $c$-axis orientation decreases from 5.28 to 4.83 $\mathrm{MPa} \cdot \mathrm{m}^{1 / 2}$, while that parallel to the $c$-axis orientation increases from 5.00 to $5.80 \mathrm{MPa} \cdot \mathrm{m}^{1 / 2}$ [229].

\section{3 h-BN}

Hexagonal boron nitride (h-BN) has a lamellar structure similar to graphite. In each layer, $\mathrm{B}$ atoms and $\mathrm{N}$ atoms are connected by strong sp2 covalent bonds, while different layers are connected by weak van der Waals forces. So h-BN is also called as "white graphite" $[230,231]$. h-BN has many special properties such as high thermal conductivity, low dielectric coefficient, outstanding thermal shock resistance, etc. [232,233].

Due to the special lamellar structure of h-BN, its properties along different directions are significantly different. Taking its elastic properties as an example, for materials belonging to the hexagonal crystal lattice, there are five independent elastic constants, $c_{11}, c_{12}, c_{13}$, $c_{33}$, and $c_{44}$ [234]. The five elastic constants of h-BN have been calculated by Xiao et al. [235] using the first-principles pseudopotential method, and the five elastic compliance coefficients $s_{11}, s_{12}, s_{13}, s_{33}$, and $s_{44}$ can be calculated according to the relationship between $c_{i j}$ and $s_{i j}$, as shown in Table 7.

The Young's moduli along [100] and [001] are $1 / s_{i j}$ and $1 / s_{33}$, respectively [234]. It can be calculated that the Young's moduli along the $a$-axis and the $c$-axis of h-BN are 837.99 and $33.40 \mathrm{GPa}$, respectively. The elastic property of h-BN shows obvious anisotropy, so deformation is much harder to occur within the layer than perpendicular to the layer. It is in accordance with the fact that $\mathrm{B}$ atoms and $\mathrm{N}$ atoms are connected by strong sp2 covalent bonds in each layer while different layers are connected by weak van der Waals forces. Besides the elastic property, the thermal conductivity of h-BN also shows obvious anisotropy. The theoretical thermal conductivities parallel and perpendicular to the $c$-axis of bulk h-BN single crystal were calculated to be 4.1 and $537 \mathrm{~W} /(\mathrm{m} \cdot \mathrm{K})$, respectively [13]. So the

Table 7 Elastic constants and compliance coefficients of $\mathrm{h}-\mathrm{BN}$ at room temperature, $P=\mathbf{0}$ [235]

\begin{tabular}{cccccc}
\hline \multirow{2}{*}{$c_{i j}(\mathrm{GPa})$} & $c_{11}$ & $c_{12}$ & $c_{13}$ & $c_{33}$ & $c_{44}$ \\
\cline { 2 - 6 } & 880.59 & 193.39 & 2.7 & 33.41 & 5.22 \\
\hline \multirow{2}{*}{$s_{i j}\left(\mathrm{TPa}^{-1}\right)$} & $s_{11}$ & $s_{12}$ & $s_{13}$ & $s_{33}$ & $s_{44}$ \\
\cline { 2 - 6 } & 1.193 & -0.262 & -0.075 & 29.943 & 191.571 \\
\hline
\end{tabular}

texturing of h-BN matrix ceramics can significantly improve their performances along specific direction and expand their application fields, for example, as heat sinks for semiconductor parts [170].

h-BN is usually textured by HP due to its lamellar structure. It is worth noting that HP will not definitely lead to texture microstructures where the $c$-axis of $\mathrm{h}-\mathrm{BN}$ is parallel to the external pressure. Sometimes, when the h-BN raw powders have a low degree of order and a broad size distribution, no or little sintering additive is used, the external pressure is moderate, and the temperature is high enough, a completely different texture can be produced, where the $c$-axis can be oriented perpendicular to the pressure direction. This is because that the uniaxial pressure has two effects on h-BN grains during sintering. One is called "grow effect", promoting the contact of h-BN grains and the plate-like grain growth along the pressure direction. The other is called "rotate effect", making plate-like $\mathrm{h}$-BN grains rotated to be perpendicular to the pressure direction. The texture microstructures of sintered h-BN specimens are determined by the leading effect $[170,236]$. When the temperature is high enough and the pressure is not very high, the "grow effect" will be dominant, because high temperature can accelerate atomic diffusion, which is beneficial to the grain growth. In the meantime, the moderate pressure cannot rotate grains dramatically, so the $c$-axis tends to be perpendicular to the pressure direction. When the temperature is not very high and the pressure is high enough, the "rotate effect" will be dominant, leading to a microstructure where the $c$-axis tends to be parallel to the pressure direction. The two different texture microstructures can lead to different anisotropy. However, h-BN ceramics HPed with no or little sintering additive can hardly possess dramatic texture $[1,170]$.

The mechanical and thermal properties of textured h-BN matrix ceramics are displayed in Table 8. Fracture mechanisms under different loading situations of textured h-BN matrix ceramics with lamellar structure are shown in Figs. 31(a), 31(c), and 31(e). Figures 31(b), 31(d), and 31(f) show the corresponding fracture morphologies of textured h-BN-mullite composites [4]. The mechanical properties are the worst when the crack propagates between h-BN layers, corresponding to D1 loading situation shown in Fig. 31(a). When the external force is perpendicular to h-BN layers, the crack needs to go through a longer path to make it fracture, corresponding to D2 in Fig. 31(c). Another 
Table 8 Properties of textured h-BN matrix ceramics

\begin{tabular}{|c|c|c|c|c|c|c|c|c|c|}
\hline Researchers & $\begin{array}{c}\text { Raw } \\
\text { materials }\end{array}$ & Sintering additives & $\begin{array}{l}\text { Preparation } \\
\text { method }\end{array}$ & $\begin{array}{l}\text { Relative density/ } \\
\text { bulk density }\end{array}$ & $\begin{array}{l}\text { Orientation } \\
\text { factor }\end{array}$ & $\begin{array}{c}\text { Elastic } \\
\text { modulus } \\
(\mathrm{GPa})\end{array}$ & $\begin{array}{l}\text { Flexural } \\
\text { strength } \\
(\mathrm{MPa})\end{array}$ & $\begin{array}{c}\text { Fracture } \\
\text { toughness } \\
\left(\mathrm{MPa} \cdot \mathrm{m}^{1 / 2}\right)\end{array}$ & $\begin{array}{c}\text { Thermal } \\
\text { conductivity } \\
(\mathrm{W} /(\mathrm{m} \cdot \mathrm{K}))\end{array}$ \\
\hline \multirow{2}{*}{$\begin{array}{c}\text { Xue et al. } \\
\text { [170] }\end{array}$} & \multirow{2}{*}{$\begin{array}{c}\text { Irregular } \\
\text { shaped h-BN }\end{array}$} & \multirow{2}{*}{ 一 } & \multirow{2}{*}{ HP } & \multirow{2}{*}{$\begin{array}{c}\text { Relative density }= \\
93.5 \%\end{array}$} & \multirow{2}{*}{$I O P=27.2$} & \multirow{2}{*}{ 一 } & 55.2 (D1) & \multirow{2}{*}{ - } & 67 (//c-axis) \\
\hline & & & & & & & 43.1 (D2) & & $35(\perp c$-axis $)$ \\
\hline \multirow{9}{*}{$\begin{array}{c}\text { Duan et al. } \\
{[4,236]}\end{array}$} & \multirow{9}{*}{$\begin{array}{l}\text { Plate-like } \\
\text { h-BN }\end{array}$} & \multirow{9}{*}{$20 \mathrm{wt} \%$ mullite } & \multirow{3}{*}{$\begin{array}{c}\mathrm{HP} \\
(10 \mathrm{MPa})\end{array}$} & \multirow{3}{*}{$\begin{array}{l}\text { Bulk density }= \\
2.00 \mathrm{~g} / \mathrm{cm}^{3}\end{array}$} & \multirow{3}{*}{$I O P=-178$} & 3.68 (D1) & 23.68 (D1) & 0.41 (D1) & \multirow{3}{*}{-} \\
\hline & & & & & & 64.64 (D2) & 74.49 (D2) & 1.20 (D2) & \\
\hline & & & & & & 70.44 (D3) & $43.90(\mathrm{D} 3)$ & $1.22(\mathrm{D} 3)$ & \\
\hline & & & \multirow{3}{*}{$\begin{array}{c}\mathrm{HP} \\
(20 \mathrm{MPa})\end{array}$} & \multirow{3}{*}{$\begin{array}{l}\text { Bulk density }= \\
2.09 \mathrm{~g} / \mathrm{cm}^{3}\end{array}$} & \multirow{3}{*}{$I O P=-350$} & $5.34(\mathrm{D} 1)$ & $27.61(\mathrm{D} 1)$ & 0.42 (D1) & \multirow{3}{*}{ - } \\
\hline & & & & & & 69.78 (D2) & 93.26 (D2) & 1.49 (D2) & \\
\hline & & & & & & $84.02(\mathrm{D} 3)$ & $81.58(\mathrm{D} 3)$ & $2.00(\mathrm{D} 3)$ & \\
\hline & & & \multirow{3}{*}{$\begin{array}{c}\mathrm{HP} \\
(30 \mathrm{MPa})\end{array}$} & \multirow{3}{*}{$\begin{array}{c}\text { Bulk density }= \\
2.17 \mathrm{~g} / \mathrm{cm}^{3}\end{array}$} & & $5.82(\mathrm{D} 1)$ & 28.93 (D1) & 0.45 (D1) & \multirow{3}{*}{$\begin{array}{l}11.3(/ / c \text {-axis }) \\
94.7(\perp c \text {-axis })\end{array}$} \\
\hline & & & & & $I O P=-2160$ & 90.32 (D2) & $100.22(\mathrm{D} 2)$ & $2.08(\mathrm{D} 2)$ & \\
\hline & & & & & & 107.77 (D3) & 104.95 (D3) & 2.36 (D3) & \\
\hline \multirow{6}{*}{$\begin{array}{c}\text { Zhang et al. } \\
\text { [233] }\end{array}$} & \multirow{6}{*}{$\begin{array}{l}\text { Plate-like } \\
\text { h-BN }\end{array}$} & \multirow{3}{*}{$20 \mathrm{wt} \% 3 \mathrm{Y}_{2} \mathrm{O}_{3}-5 \mathrm{Al}_{2} \mathrm{O}_{3}$} & \multirow{6}{*}{ HP } & \multirow{3}{*}{$\begin{array}{c}\text { Relative density }= \\
88.7 \%\end{array}$} & \multirow{3}{*}{$I O P=-530$} & 8.56 (D1) & 16.46 (D1) & 0.36 (D1) & \multirow{3}{*}{$\begin{array}{c}17.62(/ / c \text {-axis }) \\
154.62(\perp c \text {-axis })\end{array}$} \\
\hline & & & & & & $66.86(\mathrm{D} 2)$ & 73.07 (D2) & 1.87 (D2) & \\
\hline & & & & & & $82.76(\mathrm{D} 3)$ & $77.92(\mathrm{D} 3)$ & $2.10(\mathrm{D} 3)$ & \\
\hline & & \multirow{3}{*}{$\begin{array}{c}20 \mathrm{wt} \% \\
3 \mathrm{Y}_{2} \mathrm{O}_{3}-5 \mathrm{Al}_{2} \mathrm{O}_{3}-4 \mathrm{MgO}\end{array}$} & & & & 6.91 (D1) & 17.53 (D1) & 0.45 (D1) & \\
\hline & & & & Relative density $=$ & $I O P=-976$ & 83.15 (D2) & 81.78 (D2) & 2.00 (D2) & $22.14(/ /(-\mathrm{d} x \mathrm{~s})$ \\
\hline & & & & & & 88.04 (D3) & 84.03 (D3) & $2.36(\mathrm{D} 3)$ & $15 / .01(\perp c-\mathrm{d} \times 1 \mathrm{~s})$ \\
\hline & Irregularly & & & Relative density $=$ & & & & & 29.8 (// c-axis) \\
\hline $\mathrm{Ni}$ ot al $[701$ & shaped h-BN & $1.98 \mathrm{wt} \% \mathrm{SiO}_{2}+$ & & $92.0 \%$ & $M R D=7.6$ & - & & & $35.5(\perp c$-axis $)$ \\
\hline Niel al. [19] & Plate-like & $266 \mathrm{wt}^{0} \% \mathrm{Y}_{2} \mathrm{O}_{3}$ & SPS & Relative density $=$ & & & & & 15.3 (// c-axis) \\
\hline & h-BN & & & $88.9 \%$ & $M R D=15.4$ & - & - & - & $23.7(\perp c$-axis $)$ \\
\hline & & & & 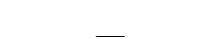 & - & - & $\bar{T}$ & - & 14 (//c-axis) \\
\hline & & 15 vol\% $\mathrm{l}$.g & & - & - & - & & - & $113(\perp c$-axis $)$ \\
\hline Kusunose & Plate-like & & HP & - & 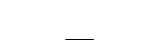 & $\overline{-}$ & $\overline{-}$ & $\bar{T}$ & 14 (// c-axis) \\
\hline $\begin{array}{c}\text { and Sekino } \\
{[127]}\end{array}$ & h-BN & $15 \mathrm{vol} \% \mathrm{Yb}_{2} \mathrm{O}_{3}-\mathrm{MgO}$ & HP & - & - & - & - & - & $212(\perp c$-axis $)$ \\
\hline & & & & $\overline{-}$ & - & & & - & 12 (//c-axis) \\
\hline & & & & - & - & - & & & $173(\perp c$-axis $)$ \\
\hline
\end{tabular}

loading situation is D3 in Fig. 31(e), that is, although the loading force is parallel to the layers, the initial crack is tortuous and the crack path is similar to that of D2. To generate initial crack for D2, only chemical bonds in one h-BN layer need to be broken. When it comes to D3, not only chemical bonds but also van der Waals forces are broken. So the flexural strength of D3 is a little higher than that of D2.

As discussed in Section 3.2.1, the composite additives of a rare-earth oxide and an alkaline-earth oxide are better to the texture formation and directional thermal conduction performance of HPed h-BN matrix ceramics than the simple additive of an alkaline-earth oxide. Our previous study shows that $\mathrm{Y}_{3} \mathrm{Al}_{5} \mathrm{O}_{12}$ liquid phase formed from $\mathrm{Y}_{2} \mathrm{O}_{3}$ and $\mathrm{Al}_{2} \mathrm{O}_{3}$ sintering additives has good wettability to h-BN grains [233]. The fracture morphologies and polished surfaces of HPed h-BN matrix ceramics using $15 \mathrm{vol} \% \mathrm{MgO}$ and $15 \mathrm{vol} \%$ $\mathrm{Yb}_{2} \mathrm{O}_{3}-\mathrm{MgO}$ as additives are shown in Fig. 32 [127]. $\mathrm{Yb}_{2} \mathrm{O}_{3}-\mathrm{MgO}$ additives are distributed in h-BN matrix more homogeneously. The specimen sintered with $15 \mathrm{vol} \%$ $\mathrm{Yb}_{2} \mathrm{O}_{3}-\mathrm{MgO}$ possesses larger grain size and more significant texture and better directional thermal conduction performance. $\mathrm{Yb}_{2} \mathrm{O}_{3}-\mathrm{MgO}$ exhibits better wettability to h-BN grains than the single component $\mathrm{MgO}$ additive, thus promoting preferred orientation growth via solution reprecipitation and improving the thermal conductivity.

\section{4. $4 \mathrm{MB}_{2}$ matrix ultra-high temperature ceramics}

Ultra-high temperature ceramics (UHTCs) are a class of ceramics that have melting point above $3000{ }^{\circ} \mathrm{C}$ and can be used at temperatures above $1650{ }^{\circ} \mathrm{C}$ continually. Almost all UHTCs are borides, carbides, and nitrides of early transition metals such as $\mathrm{Zr}$, Hf, Ti, and $\mathrm{Ta}$ [184,237]. UHTCs have high strength and hardness, good thermal shock resistance, and good chemical stability [238-240]. Their good properties at extreme high temperature allow them to be used in aerospace sharp-shaped hot-structures, leading edge parts on re-entry vehicles, etc. $[183,241,242]$.

Among the family of UHTCs, transition metal diboride $\left(\mathrm{MB}_{2}\right)$ belongs to the hexagonal crystal lattice and is easy to be textured under the external magnetic field or uniaxial pressure. $\mathrm{MB}_{2}$ matrix ceramics can be prepared by both non-reactive sintering and reactive 

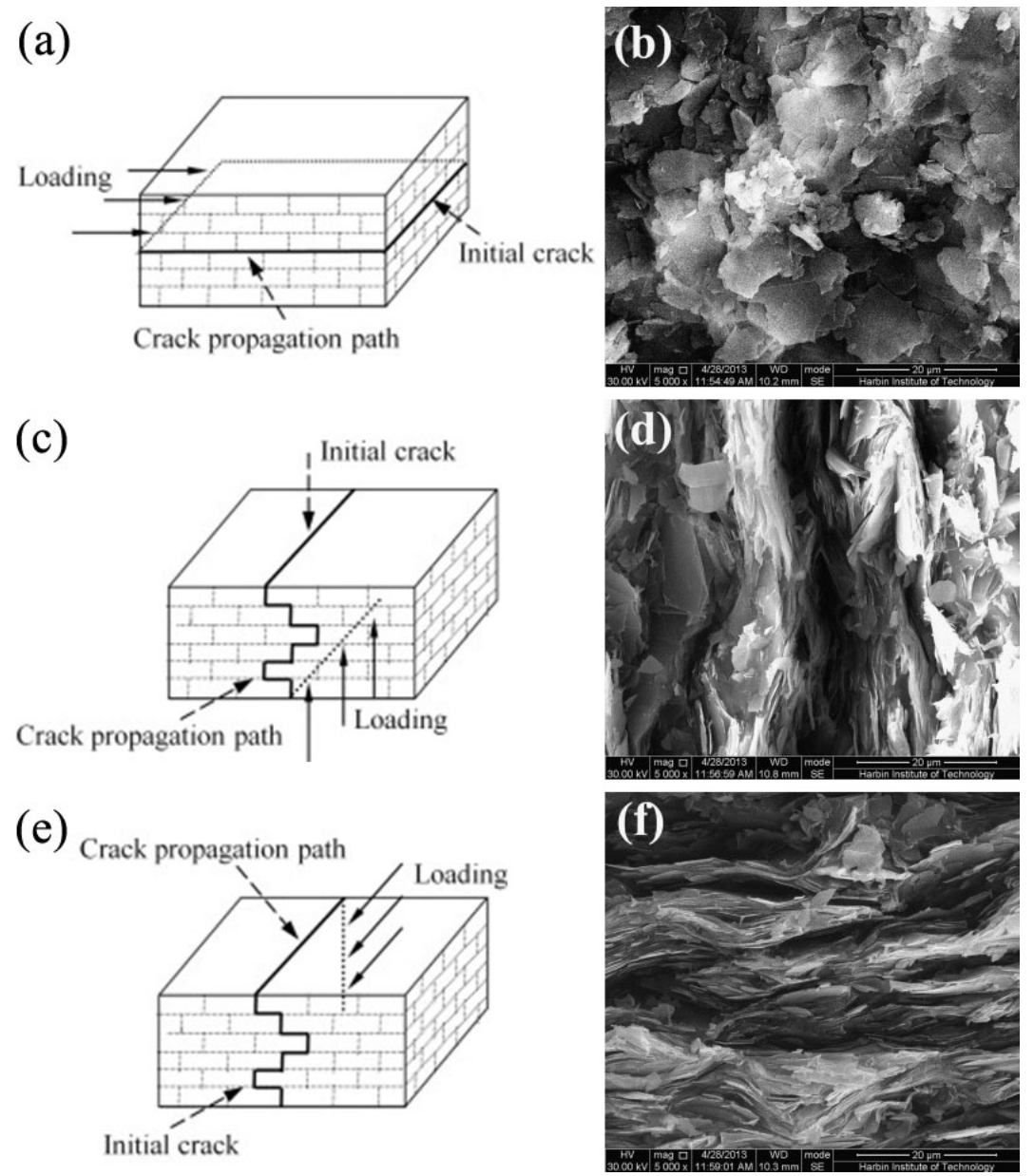

Fig. 31 Fracture mechanisms and fracture morphologies of textured h-BN-mullite composites with lamellar structure under different loading situations: (a, b) D1; (c, d) D2; (e, f) D3. Reproduced with permission from Ref. [4], C Elsevier B.V. 2014.
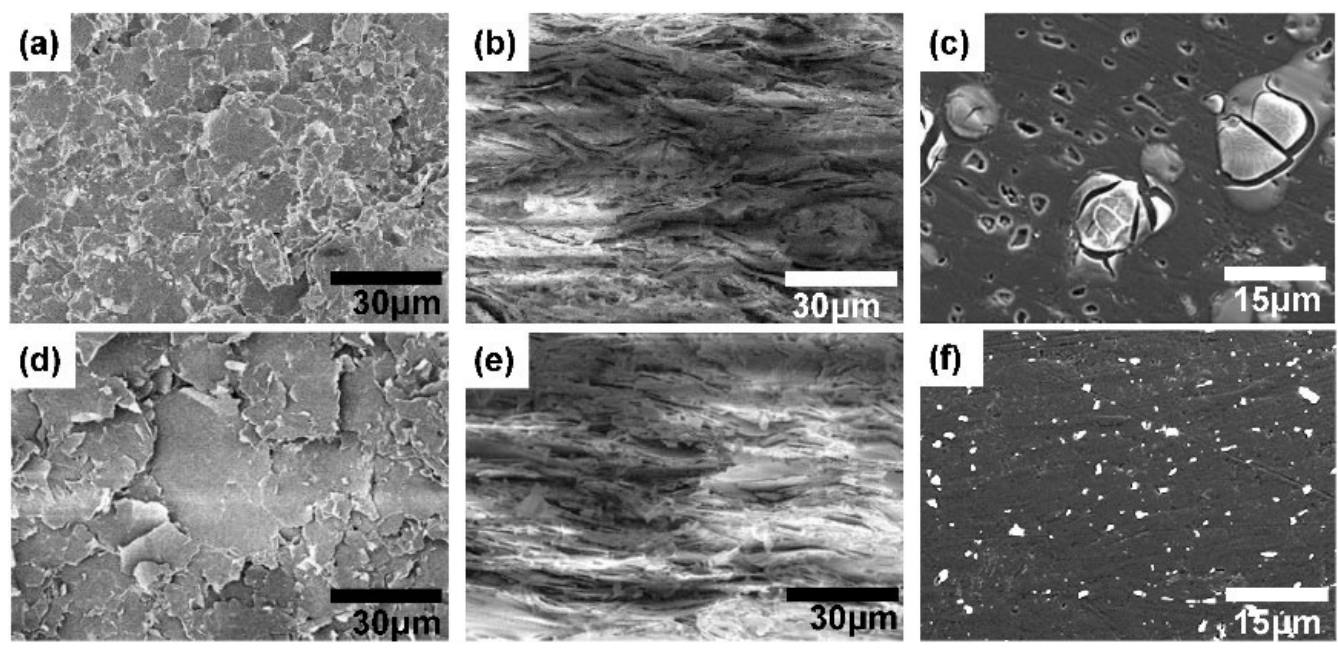

Fig. 32 Fracture morphologies perpendicular $(a, d)$ and parallel $(b, e)$ to the pressure direction and $(c, f)$ polished surfaces perpendicular to the pressure direction of HPed h-BN matrix ceramics with different additives: $(\mathrm{a}-\mathrm{c}) 15$ vol\% $\mathrm{MgO} ;(\mathrm{d}-\mathrm{f}) 15$ vol $\% \mathrm{Yb}_{2} \mathrm{O}_{3}-\mathrm{MgO}$. Reproduced with permission from Ref. [127], (C) Acta Materialia Inc. 2016.

sintering which combines synthesis and densification into one step using elemental powders [239,243,244]. The high temperature oxidation resistance of pure $\mathrm{MB}_{2}$ ceramics is limited due to the evaporation of $\mathrm{B}_{2} \mathrm{O}_{3}$ above $1200{ }^{\circ} \mathrm{C}$, which makes oxygen diffuse more easily into $\mathrm{MB}_{2}$ substrate. But their oxidation resistance 
can be improved when combined with $\mathrm{SiC}$, which can provide an outer $\mathrm{SiO}_{2}$-rich glassy layer acting as a barrier to diffusion of oxygen to the $\mathrm{MB}_{2}$ substrate $[183,243$, 245]. Among $\mathrm{MB}_{2}$ matrix ceramics, $\mathrm{ZrB}_{2}$ and $\mathrm{HfB}_{2}$ based ceramics are the most two promising candidates for extreme environmental applications. While the application of $\mathrm{TiB}_{2}$ is limited to armor and cutting tools [246-248].

The preferred orientation growth of $\mathrm{MB}_{2}$ grains are strongly depended on liquid phase environment during sintering $[245,249,250]$. As UHTCs, $\mathrm{MB}_{2}$ matrix ceramics are demanded to have high melting temperature, and there is usually no low melting point substance in the sintered specimens. So reactive sintering became an effective method to prepare $\mathrm{MB}_{2}$ matrix ceramics with strong morphological texture. During reactive sintering, these single elements can form low melting point liquid phases, which are favorable to preferred orientation growth and grain rotation under external pressure.
$\mathrm{Wu}$ et al. [251] prepared highly textured $\mathrm{ZrB}_{2}$ $5 \mathrm{vol} \% \mathrm{~B}_{4} \mathrm{C}$ composites by slip casting in a magnetic field followed by SPS. The XRD patterns and surface morphologies perpendicular (TS) and parallel (SS) to the magnetic field direction are presented in Fig. 33. The main diffraction peaks on TS and SS are (001) and (100), respectively. The $c$-axis of $\mathrm{ZrB}_{2}$ is oriented parallel to the magnetic field direction. The Lotgering factor $f_{00 l}$ is as high as 0.92 . But there is no obvious difference between surface morphologies of SS and TS. The grain sizes for the TS and SS are 2.5 and $2.4 \mu \mathrm{m}$, respectively, indicating there is no preferred orientation growth of $\mathrm{ZrB}_{2}$ grains during sintering. Liu et al. [250] prepared textured and platelet-reinforced $\mathrm{ZrB}_{2}-20$ vol\% $\mathrm{MoSi}_{2}$ composites by reactive hot pressing (RHP) and subsequent hot forging (HF) with simple compression using powders of elemental Zr, B, Mo, and Si. Figure 34 shows the XRD, TEM, and SEM analysis of the
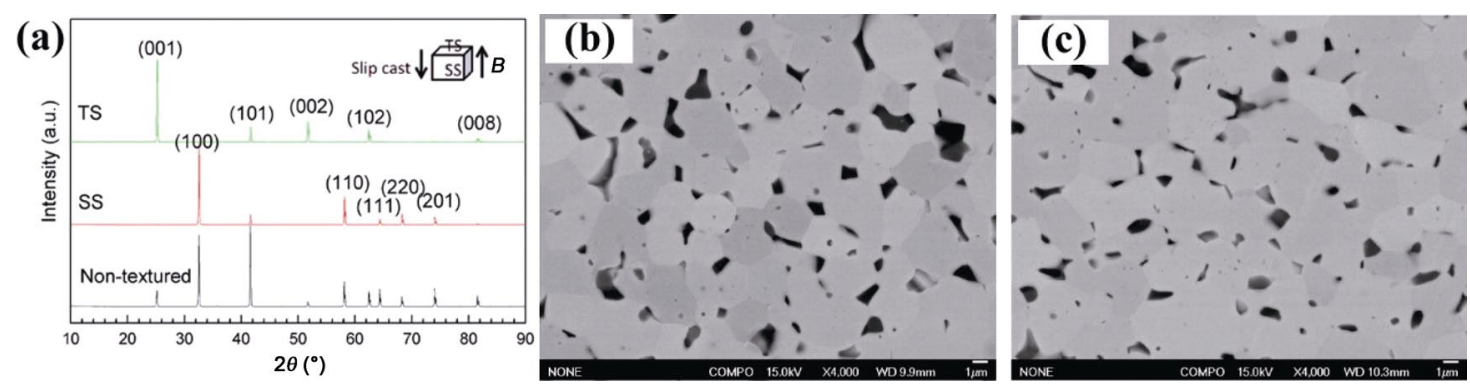

Fig. 33 XRD patterns and surface morphologies of textured $\mathrm{ZrB}_{2}-5$ vol\% $\mathrm{B}_{4} \mathrm{C}$ composites prepared by magnetic alignment and SPS: (a) XRD patterns of TS and SS; (b, c) surface morphologies of TS and SS, respectively. Reproduced with permission from Ref. [251], (c) National Institute for Materials Science 2014.

(a)

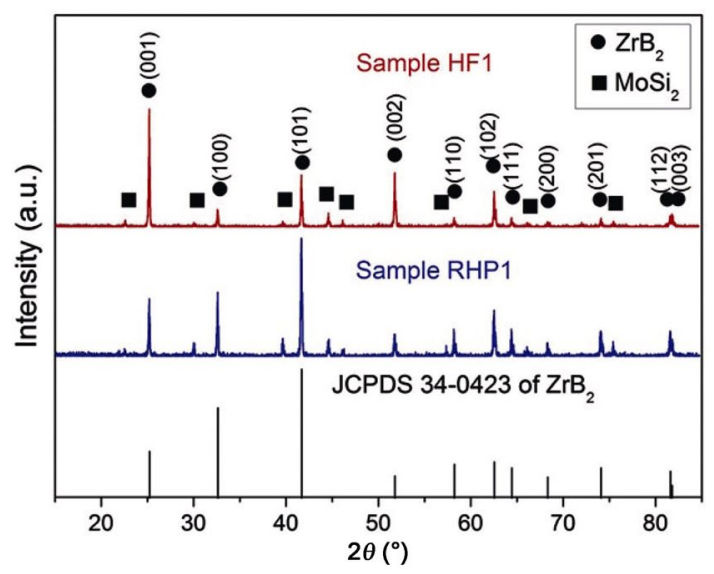

(b)

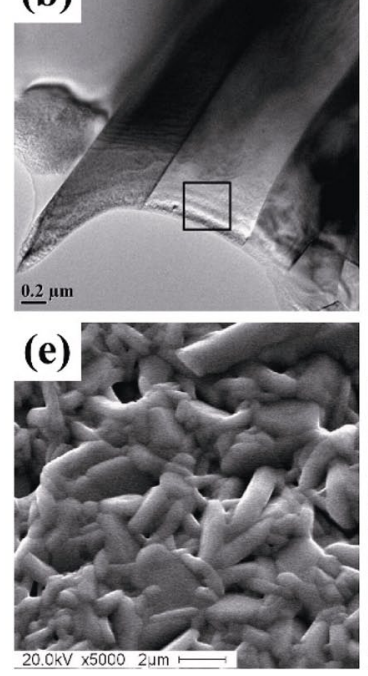

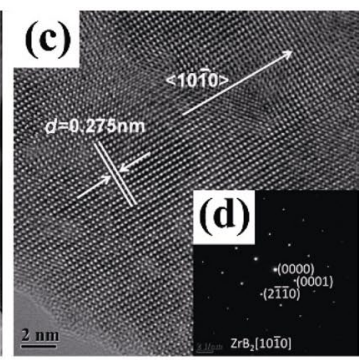

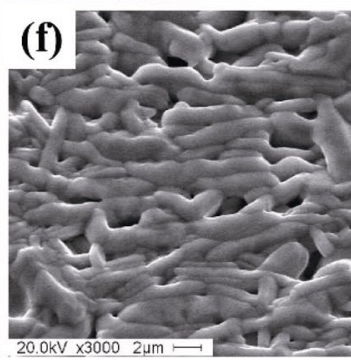

Fig. $34 \mathrm{XRD}$, TEM, and SEM analysis of textured $\mathrm{ZrB}_{2}-20$ vol\% $\mathrm{MoSi}_{2}$ composites prepared by RHP and HF: (a) XRD patterns of specimen surfaces perpendicular to the pressure direction; (b, c, d) TEM image, HRTEM image, and selected-area electron diffraction pattern of $\mathrm{ZrB}_{2}$ platelet grains, respectively; (e, f) SEM images of polished surface parallel to the pressure direction for sample RHP1 and HF1, respectively. Reproduced with permission from Ref. [250], (C) Acta Materialia Inc. 2011. 
as-RHPed specimen before HF (RHP1) and the specimen after HF (HF1). The $c$-axis of $\mathrm{ZrB}_{2}$ is oriented parallel to the pressure direction, and the Lotgering factors $f_{00 l}$ of the RHP1 and HF1 specimens are 0.33 and 0.59 , respectively, indicating HF after RHP further enhanced the crystallographic texture. The TEM analysis demonstrated the preferred orientation growth of platelet $\mathrm{ZrB}_{2}$ grains along the $a, b$-axis, whose morphologies are shown in the SEM images. After HF, the platelet $\mathrm{ZrB}_{2}$ grains further grew from $0.57 \mu \mathrm{m}$ in thickness and $2.28 \mu \mathrm{m}$ in diameter to $0.95 \mu \mathrm{m}$ in thickness and $5.71 \mu \mathrm{m}$ in diameter. The anisotropic grain growth is probably related to the $\mathrm{Zr}-\mathrm{Mo} / \mathrm{Si}-\mathrm{Mo}$ liquid phase. The more elongated grains after HF are favorable to grain rotation under applied pressure, resulting in more significant morphological and crystallographic texture compared with the as-RHPed specimen before HF.

Table 9 lists anisotropic properties of textured $\mathrm{MB}_{2}$ matrix ceramics. The mechanical properties of textured $\mathrm{MB}_{2}$ matrix ceramics are strongly related to grain orientation, grain shape, and slip plane. It was demonstrated the slip occurred along $<1000>$ direction on prismatic $\{10 \overline{1} 0\}$ planes at room temperature but on the basal $\{0001\}$ plane at high temperature in the $\mathrm{ZrB}_{2}$ crystal [252]. For textured $\mathrm{ZrB}_{2}-5$ vol\% $\mathrm{B}_{4} \mathrm{C}$ composites with equiaxed grains prepared by $\mathrm{Wu}$ et al. [251], there is more plastic deformation to increase the required strength for fracture when the loading direction is perpendicular to the $c$-axis orientation than parallel to the $c$-axis orientation at low temperature. However, the opposite situation happens at high temperatures. The higher strength at $1600{ }^{\circ} \mathrm{C}$ than at room temperature is also related to the more plastic deformation at high temperature and besides, the suppression of crack extension along the grain boundaries due to the strong bonding of clean $\mathrm{ZrB}_{2} / \mathrm{ZrB}_{2}$ interfaces. However, for textured $\mathrm{ZrB}_{2}$ matrix ceramics composed of elongated grains or platelet grains, the influence of grain shape on the anisotropy of mechanical properties is more remarkable than that of slip plane [249,250].

$\mathrm{HfB}_{2}$ matrix ceramics have better oxidation resistance than $\mathrm{ZrB}_{2}$ matrix ceramics. Ni et al. [253,254] studied the oxidation resistance of textured $\mathrm{ZrB}_{2}-20$ vol\% $\mathrm{SiC}$ composites (ZS20) and textured $\mathrm{HfB}_{2}-20$ vol\% $\mathrm{SiC}$ composites (HS20) prepared by magnetic alignment and SPS with the same process parameters. After holding at $1600{ }^{\circ} \mathrm{C}$ for $10 \mathrm{~min}$ in stagnant air, there are $\mathrm{SiO}_{2}$-rich glassy layers of 40 and $15 \mu \mathrm{m}$ on the surfaces perpendicular and parallel to the magnetic field direction for ZS20, respectively, but there is no obvious oxidation on both surfaces perpendicular and parallel to the magnetic field direction for HS20. Figure 35 shows the cross-section images of HS20 after oxidation at $1600{ }^{\circ} \mathrm{C}$ for $10 \mathrm{~h}$ in stagnant air. There are $\mathrm{SiO}_{2}$-rich glassy layers of 60 and $20 \mu \mathrm{m}$ on the surfaces perpendicular and parallel to the magnetic field direction, respectively. There is no oxygen in $\mathrm{HfB}_{2}-\mathrm{SiC}$ matrix on the surface perpendicular to the magnetic field direction, but there is a $\mathrm{HfO}_{2}-\mathrm{SiO}_{2}$ layer of $60 \mu \mathrm{m}$ on the surface parallel to the magnetic field

Table 9 Properties of textured MB2 matrix ceramics

\begin{tabular}{|c|c|c|c|c|c|c|c|}
\hline Researchers & Compositions & Preparation methods & $\begin{array}{l}\text { Relative density/bulk } \\
\text { density }\end{array}$ & $\begin{array}{l}\text { Lotgering } \\
\text { factor } f_{00 l}\end{array}$ & $\begin{array}{l}\text { Vickers hardness } \\
(\mathrm{GPa})\end{array}$ & $\begin{array}{c}\text { Flexural } \\
\text { strength }(\mathrm{MPa})\end{array}$ & $\begin{array}{c}\text { Fracture } \\
\text { toughness } \\
\left(\mathrm{MPa} \cdot \mathrm{m}^{1 / 2}\right)\end{array}$ \\
\hline Ni et al. & & Magnetic alignment & Relative density $=$ & 094 & 16.9 (// c-axis) & - & 3.94 (//c-axis) \\
\hline$[254]$ & $\mathrm{ZrB}_{2}-20$ vol\% $\mathrm{Sic}$ & \& SPS & $96.2 \%$ & 0.94 & $14.7(\perp c$-axis $)$ & & $3.86(\perp c$-axis $)$ \\
\hline \multirow{4}{*}{$\begin{array}{l}\text { Ni et al. } \\
\text { [253] }\end{array}$} & & \multirow{4}{*}{$\begin{array}{c}\text { Magnetic alignment } \\
\text { \& SPS }\end{array}$} & Relative density $=$ & \multirow{2}{*}{0.91} & 21.1 (// c-axis) & \multirow{2}{*}{ - } & 5.9 (//c-axis) \\
\hline & $\mathrm{HfB}_{2}-20 \mathrm{vol} \% \mathrm{SiC}$ & & $98.3 \%$ & & $19.3(\perp c$-axis $)$ & & $5.5(\perp c$-axis $)$ \\
\hline & \multirow{2}{*}{$\mathrm{HfB}_{2}-5$ vol $\% \mathrm{SiC}$} & & Relative density $=$ & & 20.6 (// c-axis) & \multirow{2}{*}{ - } & 5.8 (// c-axis) \\
\hline & & & $97.6 \%$ & 0.91 & $18.9(\perp c$-axis $)$ & & $5.5(\perp c$-axis $)$ \\
\hline \multirow{2}{*}{$\begin{array}{l}\text { Ran et al. } \\
{[245]}\end{array}$} & \multirow{2}{*}{$\mathrm{ZrB}_{2}-20$ vol$\% \mathrm{SiC}$} & \multirow{2}{*}{ Reactive SPS } & Bulk density $=$ & \multirow{2}{*}{0.17} & 21.3 (// c-axis) & \multirow{2}{*}{937} & 3.9 (//c-axis) \\
\hline & & & $5.62 \mathrm{~g} / \mathrm{cm}^{3}$ & & $19.7(\perp c$-axis $)$ & & $4.7(\perp c$-axis $)$ \\
\hline $\begin{array}{c}\text { Wu et al. } \\
\text { [249] }\end{array}$ & $\mathrm{ZrB}_{2}-20$ vol$\% \mathrm{MoSi}_{2}$ & Reactive HP & $\begin{array}{c}\text { Relative density }= \\
99.2 \%\end{array}$ & - & 15 & 456.9 & 4.9 \\
\hline \multirow{4}{*}{$\begin{array}{l}\text { Liu et al. } \\
\text { [250] }\end{array}$} & \multirow{4}{*}{$\mathrm{ZrB}_{2}-20$ vol\% $\mathrm{MoSi}_{2}$} & \multirow{2}{*}{ Reactive HP } & \multirow{2}{*}{ - } & \multirow{2}{*}{0.33} & \multirow{2}{*}{-} & $572(/ / c$-axis $)$ & \multirow{2}{*}{-} \\
\hline & & & & & & $499(\perp c$-axis $)$ & \\
\hline & & \multirow{2}{*}{ Reactive HP \& HF } & \multirow{2}{*}{$\begin{array}{c}\text { Relative density }> \\
98 \%\end{array}$} & \multirow{2}{*}{0.59} & \multirow{2}{*}{-} & 871 (// c-axis) & \multirow{2}{*}{-} \\
\hline & & & & & & $723(\perp c$-axis $)$ & \\
\hline \multirow{4}{*}{$\begin{array}{l}\text { Wu et al. } \\
\text { [251] }\end{array}$} & \multirow{4}{*}{$\mathrm{ZrB}_{2}-5$ vol $\% \mathrm{~B}_{4} \mathrm{C}$} & \multirow{4}{*}{$\begin{array}{c}\text { Magnetic alignment } \\
\text { \& SPS }\end{array}$} & \multirow{4}{*}{$\begin{array}{c}\text { Bulk density }=5.78 \\
\mathrm{~g} / \mathrm{cm}^{3}\end{array}$} & \multirow{4}{*}{0.92} & & 574 (// c-axis, RT) & \multirow{4}{*}{ - } \\
\hline & & & & & 19.1 (// c-axis) & $723(\perp c$-axis, RT $)$ & \\
\hline & & & & & $17.5(\perp c$-axis $)$ & $810\left(/ / c\right.$-axis, $\left.1600{ }^{\circ} \mathrm{C}\right)$ & \\
\hline & & & & & & $650\left(\perp c\right.$-axis $\left(1600{ }^{\circ} \mathrm{C}\right)$ & \\
\hline
\end{tabular}



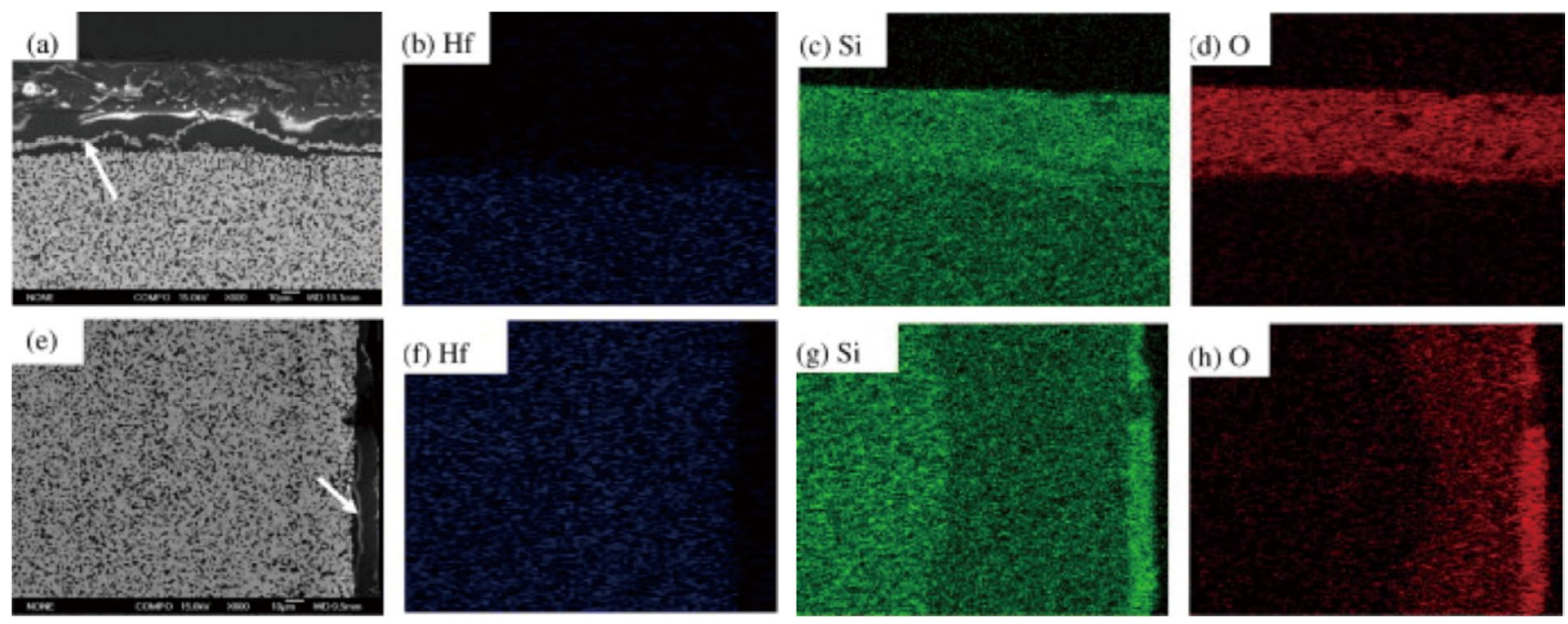

Fig. 35 Cross-section images and EDS elemental maps of different surfaces for HS20 after oxidation at $1600{ }^{\circ} \mathrm{C}$ for $10 \mathrm{~h}$ in stagnant air: $(\mathrm{a}-\mathrm{d})$ the surface perpendicular to the magnetic field direction; $(\mathrm{e}-\mathrm{h})$ the surface parallel to the magnetic field direction. Reproduced with permission from Ref. [253], (c) Acta Materialia Inc. 2009.

direction, indicating the thicker $\mathrm{SiO}_{2}$-rich glassy layer protect the matrix from oxidation better on the surface perpendicular to the magnetic field direction. The results are the same for ZS20. The anisotropic oxidation resistance of textured $\mathrm{MB}_{2}$ matrix ceramics might be related to the anisotropic mass transmission of oxygen.

\section{5 MAX phases}

MAX phases are the family of carbide and nitride ternary ceramics, which belong to the hexagonal crystal lattice and possess lamellar structure. Their general formula is $\mathrm{M}_{n+1} \mathrm{AX}_{n}$, where $n=1-3, \mathrm{M}$ is a transition metal, $\mathrm{A}$ is an $\mathrm{A}$ group element, and $\mathrm{X}$ is $\mathrm{C}$ or $\mathrm{N}$. Their spacial structure can be described as $\mathrm{M}_{n+1} \mathrm{X}_{n}$ layers and A layers alternatively stacking along the $c$-axis. Chemical bonds in MAX phases are a combination of metallic, covalent, and ionic bonds. $\mathrm{M}$ and $\mathrm{X}$ are combined by strong covalent bonds or ionic bonds, while $\mathrm{M}$ and $\mathrm{A}$ are combined by week covalent bonds or metallic bonds. MAX phases can be divided into 211 phases, 312 phases, and 413 phases according to the " $n$ " value. For $\mathrm{M}_{n+1} \mathrm{AX}_{n}$, there are $n+1 \mathrm{M}$ layers between two A layers [255-257]. Besides, some other phases have been discovered in the MAX family, such as 615 phases $\left(\mathrm{Ta}_{6} \mathrm{AlC}_{5}\right)$ and 523 phases $\left(\mathrm{Ti}_{5} \mathrm{Al}_{2} \mathrm{C}_{3}\right)$ [258]. MAX phases have been widely studied due to their excellent properties combining that of metals and ceramics, such as ductile and machinable, strong and light, good electrical and thermal conductivities, good resistance to oxidation and thermal shock, good wear resistance, etc. [180,185-189].

Due to the week combination between $\mathrm{M}_{n+1} \mathrm{X}_{n}$ layers and A layers, A element tends to diffuse more easily than $\mathrm{M}$ and $\mathrm{X}$ and can be oxidized when exposed to oxygen at high temperature [259]. Those existing cracks can be filled by the volume expansion resulting from the oxidation of the A element at high temperature. So MAX phases have been widely used as self-healing materials [260,261].

MAX phases can be synthesized by solid reaction of powders of $\mathrm{M}, \mathrm{A}$, and $\mathrm{X}$ elements. The synthetic MAX phases are ball milled to form fine plate-like powders, and then textured MAX phase ceramics are prepared by hot working or magnetic alignment [262-267]. Some MAX phases can be oriented with the $c$-axis parallel to the magnetic field direction but some may be opposite. That depends on their anisotropic magnetic susceptibility. For example, $\mathrm{Ti}_{3} \mathrm{SiC}_{2}$ grains tend to be oriented with the $c$-axis perpendicular to the magnetic field direction, while $\mathrm{Nb}_{4} \mathrm{AlC}_{3}$ grains tend to be oriented with the $c$-axis parallel to the magnetic field direction $[131,264]$.

Textured MAX phase ceramics prepared using fine plate-like powders after ball milling usually show less damage tolerance than untextured MAX phase ceramics prepared using coarse powders due to the difference between grain sizes. Figure 36 shows the Vickers indentation of the untextured coarse-grained $\mathrm{Cr}_{2} \mathrm{AlC}$ specimen and textured fine-grained $\mathrm{Cr}_{2} \mathrm{AlC}$ specimen [123]. The textured $\mathrm{Cr}_{2} \mathrm{AlC}$ specimen is more brittle than the untextured one and cracks appear at the indentation corners. On the surface parallel to the $c$-axis orientation, it is more easily for the crack to propagate perpendicular to the $c$-axis orientation due to 


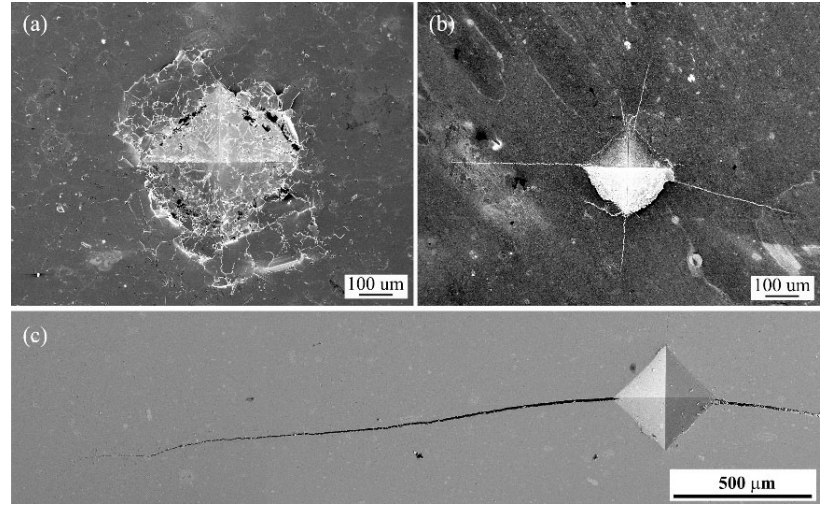

Fig. 36 Morphologies of Vickers indentation of untextured and textured $\mathrm{Cr}_{2} \mathrm{AlC}$ specimens: (a) untextured specimen; $(b, c)$ textured specimen surfaces perpendicular and parallel to the sintering pressure, respectively (the double arrow indicates the pressure direction). Reproduced with permission from Ref. [123], (c) Elsevier Ltd. 2014.

the lamellar texture.

Table 10 lists the anisotropic properties of some typical textured MAX phase ceramics. Due to the lamellar structure, the hardness of MAX phase ceramics along the $c$-axis orientation is normally lower than that perpendicular to the $c$-axis orientation, which has been proved by Mizuno et al. [263]. The textured $\mathrm{Ti}_{3} \mathrm{AlC}_{2}$ specimen prepared by SPS has a Lotgering factor $f_{00 l}$ of 0.69 , and the Vickers hardness under a load of $10 \mathrm{~N}$ parallel and perpendicular to the $c$-axis orientation is 5.9 and $7.0 \mathrm{GPa}$, respectively. But when the load is high enough, an opposite situation may happen. Zhang et al. [266] prepared $\mathrm{Ti}_{3} \mathrm{AlC}_{2}$ ceramics by magnetic alignment and subsequent SPS. When the load reaches $100 \mathrm{~N}$, the Vickers hardness along the $c$-axis orientation is $7.4 \mathrm{GPa}$, higher than $5.8 \mathrm{GPa}$ perpendicular to the $c$-axis orientation. This phenomenon is attributed to the irreversible plastic deformation along the $c$-axis.

If oxygen is introduced during ball milling of MAX phases, oxides of A element can be formed in situ during sintering. These oxide particles homogeneously distributed in the MAX matrix play a significant role of deflecting and blunting the cracks, which are favorable to the improvement of mechanical properties. Figure 37 shows the crack propagation of textured $\mathrm{Ti}_{3} \mathrm{AlC}_{2}$ specimen [266]. The crack deflection and grain pull-out on the surface parallel to the $c$-axis orientation and the crack deflection and grain bridging on the surface perpendicular to the $c$-axis orientation are the main energy dispersive modes, which contribute to high flexural strength and fracture toughness on both surfaces.

The anisotropy of electrical conductivities of different MAX phase ceramics may be different. Textured $\mathrm{Ti}_{3} \mathrm{AlC}_{2}$ ceramics possess higher thermal conductivity perpendicular to the $c$-axis orientation and higher electrical conductivity parallel to the $c$-axis orientation [266]. While textured $\mathrm{Nb}_{4} \mathrm{AlC}_{3}$ ceramics possess both higher thermal conductivity and higher electrical conductivity perpendicular to the $c$-axis orientation [268]. For MAX phases, both phonons and electrons contribute to thermal conduction, but only electrons contribute to electrical conduction. Due to the lamellar structure of MAX phases, phonons are less scattered along the $a, b$-axis orientation, causing higher thermal conductivity. For $\mathrm{Nb}_{4} \mathrm{AlC}_{3}, \mathrm{Nb} d$ electrons mainly contribute to the density of states (DOS) around the

Table 10 Properties of textured MAX phases

\begin{tabular}{|c|c|c|c|c|c|c|c|c|}
\hline Researchers & Composition & $\begin{array}{l}\text { Preparation } \\
\text { methods }\end{array}$ & $\begin{array}{l}\text { Lotgering } \\
\text { factor } f_{00 l}\end{array}$ & $\begin{array}{l}\text { Vickers hardness } \\
\text { (GPa) }\end{array}$ & $\begin{array}{c}\text { Flexural } \\
\text { strength }(\mathrm{MPa})\end{array}$ & $\begin{array}{l}\text { Fracture } \\
\text { toughness } \\
\left(\mathrm{MPa} \cdot \mathrm{m}^{1 / 2}\right)\end{array}$ & $\begin{array}{l}\text { Thermal } \\
\text { conductivity } \\
(\mathrm{W} /(\mathrm{m} \cdot \mathrm{K}))\end{array}$ & $\begin{array}{c}\text { Electrical } \\
\text { conductivity } \\
\left(10^{6} \Omega^{-1} \cdot \mathrm{m}^{-1}\right)\end{array}$ \\
\hline $\begin{array}{c}\text { Zhang et al. } \\
\text { [266] }\end{array}$ & $\mathrm{Ti}_{3} \mathrm{AlC}_{2}$ & $\begin{array}{c}\text { Magnetic } \\
\text { alignment \& } \\
\text { SPS }\end{array}$ & - & $\begin{array}{c}8.1(/ / c \text {-axis, } 1 \mathrm{~N}) \\
9.1(\perp c \text {-axis, } 1 \mathrm{~N}) \\
7.4(/ / c \text {-axis, } 100 \mathrm{~N}) \\
5.8(\perp c \text {-axis, } 100 \mathrm{~N})\end{array}$ & $\begin{array}{l}1261 \text { (//c-axis }) \\
1005(\perp c \text {-axis })\end{array}$ & $\begin{array}{l}13.1(/ / c \text {-axis }) \\
14.6(\perp c \text {-axis })\end{array}$ & $\begin{array}{l}14.6(/ / c \text {-axis }) \\
25.3(\perp c \text {-axis })\end{array}$ & $\begin{array}{l}1.01(/ / c \text {-axis }) \\
0.83(\perp c \text {-axis })\end{array}$ \\
\hline $\begin{array}{l}\text { Mizuno et al. } \\
{[263]}\end{array}$ & $\mathrm{Ti}_{3} \mathrm{AlC}_{2}$ & SPS & 0.69 & $\begin{array}{l}5.9(/ / c \text {-axis, } 10 \mathrm{~N}) \\
7.0(\perp c \text {-axis, } 10 \mathrm{~N})\end{array}$ & - & - & - & - \\
\hline $\begin{array}{l}\text { Sato et al. } \\
\quad[265]\end{array}$ & $\mathrm{Ti}_{3} \mathrm{SiC}_{2}$ & $\begin{array}{c}\text { Magnetic } \\
\text { alignment \& } \\
\text { pressureless } \\
\text { sintering }\end{array}$ & 0.97 & - & 623 & 5.9 & - & 3.23 \\
\hline $\begin{array}{l}\text { Hu et al. } \\
\text { [131] }\end{array}$ & $\mathrm{Ti}_{3} \mathrm{SiC}_{2}$ & SPS & 0.95 & $\begin{array}{l}8.70(/ / c \text {-axis, } 9.8 \mathrm{~N}) \\
7.31(\perp c \text {-axis, } 9.8 \mathrm{~N})\end{array}$ & - & - & - & - \\
\hline $\begin{array}{l}\text { Hu et al. } \\
\text { [268] }\end{array}$ & $\mathrm{Nb}_{4} \mathrm{AlC}_{3}$ & $\begin{array}{c}\text { Magnetic } \\
\text { alignment \& } \\
\text { SPS }\end{array}$ & $\sim 1$ & $\begin{array}{c}10.4(/ / c \text {-axis, } 0.245 \mathrm{~N}) \\
12.4(\perp c \text {-axis, } 0.245 \mathrm{~N}) \\
7.0(/ / c \text {-axis, } 49 \mathrm{~N}) \\
4.9(\perp c \text {-axis, } 49 \mathrm{~N})\end{array}$ & $\begin{array}{l}881(/ / c \text {-axis }) \\
789(\perp c \text {-axis })\end{array}$ & $\begin{array}{l}14.1(/ / c \text {-axis }) \\
9.3(\perp c \text {-axis })\end{array}$ & $\begin{array}{l}14.1(/ / c \text {-axis }) \\
21.1(\perp c \text {-axis })\end{array}$ & $\begin{array}{l}0.49(/ / c \text {-axis }) \\
0.81(\perp c \text {-axis })\end{array}$ \\
\hline
\end{tabular}



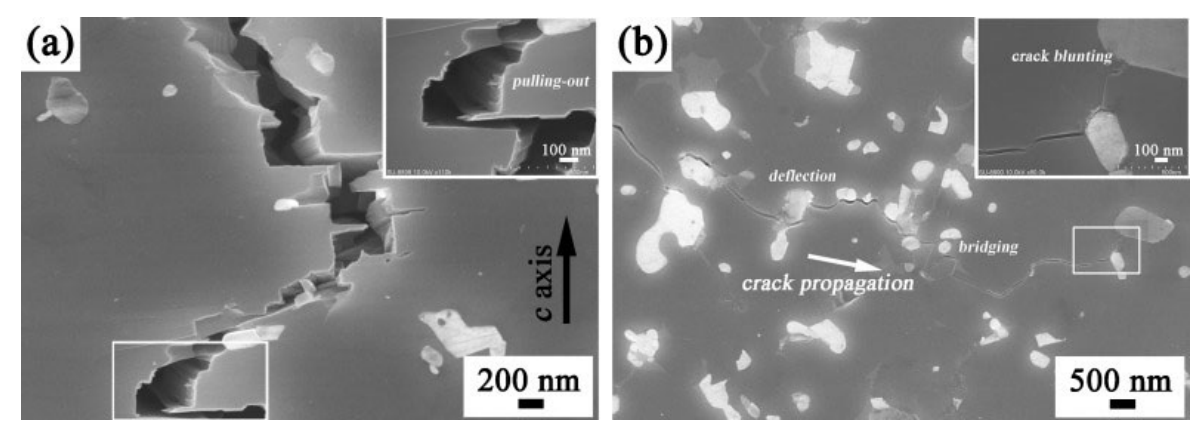

Fig. 37 Crack propagation on different polished surfaces of textured $\mathrm{Ti}_{3} \mathrm{AlC}_{2}$ ceramic: (a) parallel to the $c$-axis orientation; (b) perpendicular to the $c$-axis orientation. The inset micrographs are the magnified region in the figures. Reproduced with permission from Ref. [266], (C) Elsevier Ltd. 2014.

Fermi level. So textured $\mathrm{Nb}_{4} \mathrm{AlC}_{3}$ ceramics possess higher electrical conductivity along the $a, b$-axis orientation [269]. For textured $\mathrm{Ti}_{3} \mathrm{AlC}_{2}$, the metallic bonds between $\mathrm{Ti}$ and $\mathrm{Al}$ mainly contribute to the electrical conductivity. So textured $\mathrm{Ti}_{3} \mathrm{AlC}_{2}$ ceramics possess higher electrical conductivity along the $c$-axis orientation, where Ti and Al planes are stacked [270].

\section{6 Other ceramics}

Besides these typical textured structural ceramics discussed in Sections 3.1-3.4, there are also many other structural ceramics can be textured to improve their performances, such as silicon carbide ( $\mathrm{SiC})$, yttria partially stabilized tetragonal zirconia (Y-TZP), boron carbide $\left(\mathrm{B}_{4} \mathrm{C}\right)$, etc. $\mathrm{SiC}$ is one important high temperature structural material due to its excellent mechanical, thermal, and chemical properties [271,272]. Y-TZP is frequently used as thermal barrier coatings [273]. $\mathrm{B}_{4} \mathrm{C}$ is one kind of important hard materials [274].

$\alpha$-SiC belongs to the hexagonal crystal lattice and usually presents plate-like and rod-like shapes. The $c$-axis of $\alpha$-SiC can be oriented parallel to the magnetic field direction, and the anisometric shape of $\mathrm{SiC}$ also makes it can be easily textured by hot working and
TGG [275-277]. The preferred orientation growth and texture formation in $\mathrm{SiC}$ ceramics are usually resulted from the phase transformation from $\beta$-SiC with the cubic crystal lattice to $\alpha$-SiC with the hexagonal crystal lattice, and the phase transformation usually happens during HF of the sintered specimens at high temperature, which can greatly improve their mechanical properties [160,278]. Lee et al. [279] prepared textured SiC-YAG composites by HP and subsequent HF. The HPed specimen possesses equiaxed microstructure with random grain orientation, while the HFed specimen possesses texture microstructure with platelike grains, as shown in Fig. 38. The $c$-axis of $\mathrm{SiC}$ in the HFed specimen is oriented parallel to the pressure direction. The textured $\mathrm{SiC}-\mathrm{YAG}$ specimen has more significantly anisotropic and higher flexural strength, fracture toughness, and Vickers hardness perpendicular $\left(810 \mathrm{MPa}, 5.9 \mathrm{MPa} \cdot \mathrm{m}^{1 / 2}\right.$, and $24.4 \mathrm{GPa})$ and parallel $\left(1150 \mathrm{MPa}, 4.4 \mathrm{MPa} \cdot \mathrm{m}^{1 / 2}\right.$, and $26.8 \mathrm{GPa}$ ) to the $c$-axis orientation compared with the untextured $\mathrm{SiC}-$ YAG specimen (600 MPa, $3.9 \mathrm{MPa} \cdot \mathrm{m}^{1 / 2}$, 23.7 GPa, and $640 \mathrm{MPa}, 3.8 \mathrm{MPa} \cdot \mathrm{m}^{1 / 2}$, and $23.9 \mathrm{GPa}$ ).

Monoclinic zirconia can be oriented with the (100) direction parallel to the magnetic field and transforms to tetragonal zirconia after sintering. It was found that
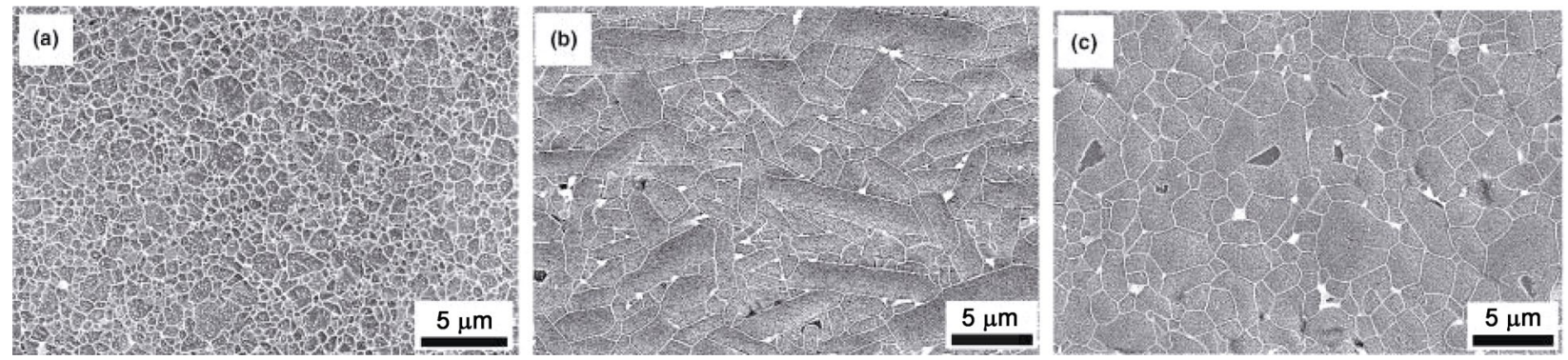

Fig. 38 Surface morphologies of the untextured HPed SiC-YAG specimen and the textured HFed SiC-YAG specimen: (a) HPed specimen surface parallel to the pressure direction; (b, c) HFed specimen surfaces parallel and perpendicular to the pressure direction, respectively. Reproduced with permission from Ref. [279], (c) Acta Materialia Inc. 2004. 
the sintered tetragonal zirconia can inherite the alignment of the monoclinic zirconia particle, forming textured 3Y-TZP ceramics [280]. Vriami et al. [100] prepared textured 3Y-TZP ceramics using cubic $8 \mathrm{~mol} \%$ yttria stabilized zirconia and unstabilized monoclinic zirconia as raw materials by magnetic alignment and pressureless sintering. The (001) direction of sintered tetragonal zirconia is parallel to the (100) direction of monoclinic zirconia. So the $c$-axis oriented 3Y-TZP ceramics are formed. But the textured specimen is almost entirely composed of equiaxed grains. Figure 39 shows the microstructure and Vickers indentations of untextured and textured zirconia ceramics. For the untextured specimen and the textured specimen surface perpendicular to the magnetic field direction, crack propagations are isotropic along diagonal lines of the indentations, and the indentation toughness is 5.4 and $6.6 \mathrm{MPa} \cdot \mathrm{m}^{1 / 2}$, respectively. But for the textured specimen surface parallel to the magnetic field direction, there is hardly any crack propagation parallel to the $c$-axis orientation, and the crack propagation along the other direction (an indentation toughness of $11.8 \mathrm{MPa} \cdot \mathrm{m}^{1 / 2}$ ) is also much less obvious than that on the textured specimen surface perpendicular to the magnetic field. The anisotropy can be attributed to that martensitic transformation toughening mechanism is more predominant along the $c$-axis than perpendicular to the $c$-axis [281].

The texturing of $\mathrm{B}_{4} \mathrm{C}$ ceramics can significantly

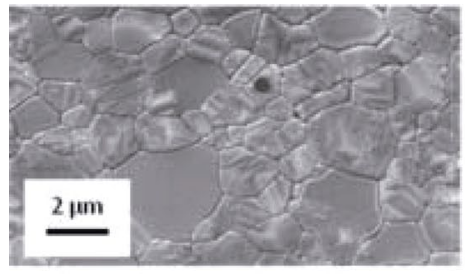

(a)

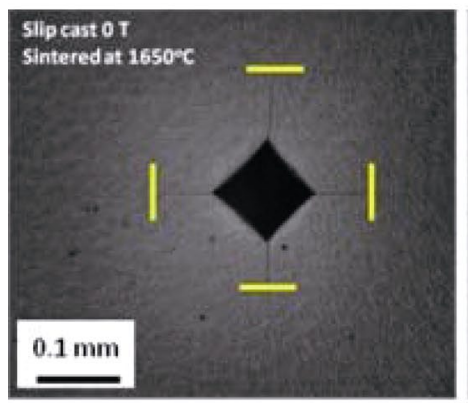

(d)

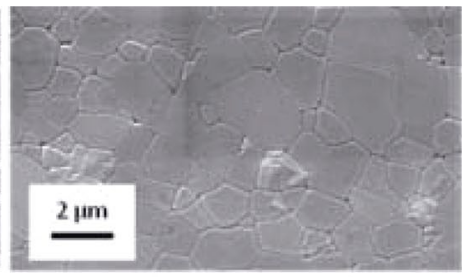

(b)

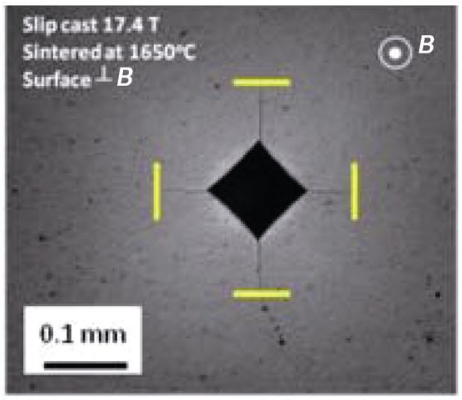

(e)

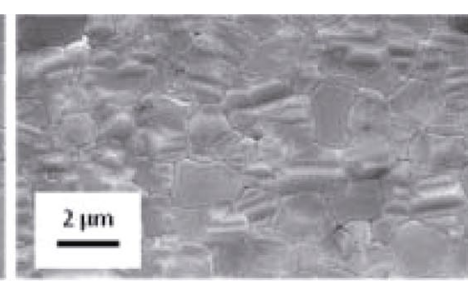

(c)

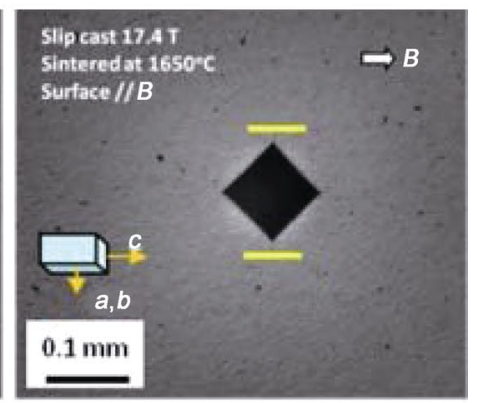

(f)

Fig. 39 Microstructure and $10 \mathrm{~kg}$ Vickers indentations of untextured and textured zirconia specimens: (a, d) untextured specimen; (b, c, e, f) textured specimen surfaces perpendicular (b, e) and parallel (c, f) to the magnetic field, respectively. Reproduced with permission from Ref. [100], (C) Elsevier Ltd. 2015.
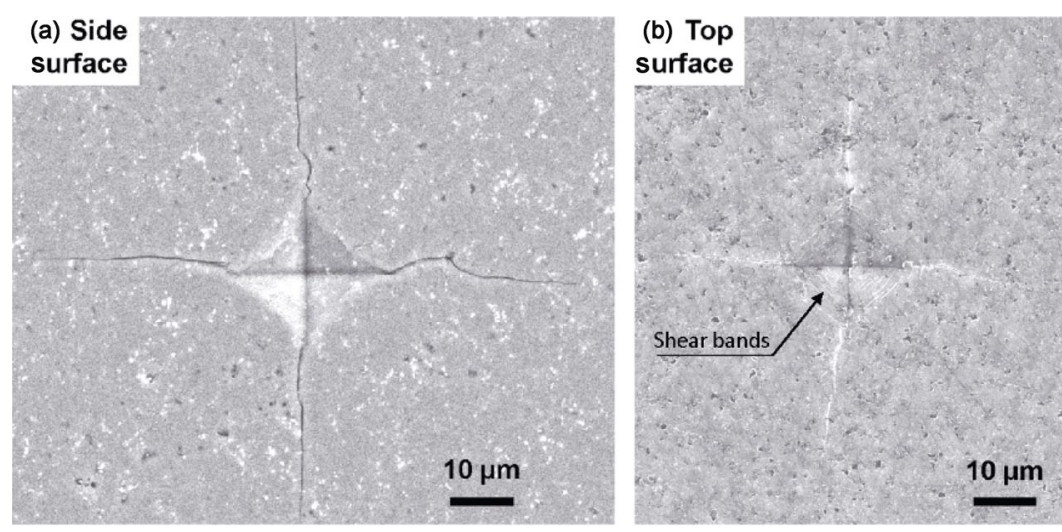

Fig. 40 Vickers indentations on textured $\mathrm{B}_{4} \mathrm{C}$ specimen surfaces: (a) parallel to the $c$-axis orientation; (b) perpendicular to the $c$-axis orientation. Reproduced with permission from Ref. [283], (C) Acta Materialia Inc. 2010. 
improve their hardness, even close to that of $\mathrm{B}_{4.38} \mathrm{C}$ monocrystal [274,282]. Grasso et al. [283] prepared textured $\mathrm{B}_{4} \mathrm{C}$ ceramics by magnetic alignment and SPS. The Vickers indentations on the sintered specimen surfaces perpendicular and parallel to the $c$-axis orientation are shown in Fig. 40. The hardness measured on the surfaces perpendicular and parallel to the $c$-axis orientation is 36.7 and $33.8 \mathrm{GPa}$, respectively. The fracture toughness measured on the surfaces perpendicular and parallel to the $c$-axis orientation is 3.65 and $2.84 \mathrm{MPa} \cdot \mathrm{m}^{1 / 2}$, respectively. The higher fracture toughness on the surface perpendicular to the $c$-axis orientation is attributed to the shear bands observed in fragments with thin edges, as shown in Fig. 40(b).

Structural ceramics can also be compounded to prepare textured composites possessing better properties. Poorteman et al. [284] prepared SiC platelets reinforced $\mathrm{Si}_{3} \mathrm{~N}_{4}$ composites by HP. The $\mathrm{SiC}$ reinforced $\mathrm{Si}_{3} \mathrm{~N}_{4}$ composites possess higher fracture toughness (7.7 $\left.\mathrm{MPa} \cdot \mathrm{m}^{1 / 2}\right)$ than that sintered without $\mathrm{SiC}$ platelets $(6.3$ $\mathrm{MPa} \cdot \mathrm{m}^{1 / 2}$ ) along the pressure direction. Wilk et al. [285] introduced h-BN to AlON ceramics by self-propagating high-temperature synthesis (SHS) and subsequent HP to improve the thermal conductivity of the composites. The texture degree of the composites reaches the highest with $30 \mathrm{wt} \% \mathrm{~h}-\mathrm{BN}$. The further increase of h-BN does not lead to higher texture degree due to the interlocking between plate-like h-BN grains. Thermal conductivities both parallel and perpendicular to the pressure direction direction reach the highest (13.9 and $42.0 \mathrm{~W} /(\mathrm{m} \cdot \mathrm{K})$, respectively) with $30 \mathrm{wt} \% \mathrm{~h}-\mathrm{BN}$.

\section{Summary and outlook}

The preparation methods and anisotropic properties of textured structural ceramics are reviewed. For ceramic materials, grains can be preferentially aligned along specific crystallographic directions under external physical field environments such as stress fields, electromagnetic fields, and temperature fields, forming texture microstructures. Several preparation methods of textured structural ceramics have been developed such as hot working, magnetic alignment, and TGG. Textured structural ceramics show obvious anisotropic properties and various damage mechanisms along different directions. Due to the grain orientation in textured structural ceramics, there are many strengthening and toughening mechanisms such as crack deflection, crack bridging, and grain pull-out, resulting in higher strength and toughness along specific directions. The thermal conductivity along grain alignment direction is also higher than that perpendicular to the grain alignment direction due to the anisotropic phonon scattering. The good properties along specific directions of textured structural ceramics can greatly broaden their application fields.

Although much progress has been achieved, many issues are still not solved or need to be deeply investigated. For example, the dynamic mechanisms of preferred orientation growth of grains and its influence factors during preparation process of textured structural ceramics are still not clear, and the effects of phase transformation at high temperature on preferred orientation growth of grains, such as the transformation from $\alpha-\mathrm{Si}_{3} \mathrm{~N}_{4}$ to $\beta-\mathrm{Si}_{3} \mathrm{~N}_{4}$ and from $\beta-\mathrm{SiC}$ to $\alpha-\mathrm{SiC}$, need to be studied. Besides, the combination of various texturing techniques, such as magnetic alignment and SPS, HP, and $\mathrm{HF}$, have shown good potential in the preparation of ceramics with high texture degree. These and similar techniques need to be given more attention. Some textured composite ceramics and bioinspired ceramics with the hierarchical structure, which have shown excellent properties, need to be further developed.

There are many issues existing in this field, but there are also great potentials for optimizing the performances of textured structural ceramics. By further considering and investigating these issues, the microstructures and anisotropic properties of textured structural ceramics can be better controlled, and their application fields can be further expanded.

\section{Acknowledgements}

This work was supported by the National Key R\&D Program of China (No. 2017YFB0703200), and the National Natural Science Foundation of China (Nos. 51672060, 51621091, and 51372050).

\section{References}

[1] Duan XM, Jia DC, Wu ZL, et al. Effect of sintering pressure on the texture of hot-press sintered hexagonal boron nitride composite ceramics. Scripta Mater 2013, 68: 104-107.

[2] Li SQ, Wu CY, Sassa K, et al. The control of crystal orientation in ceramics by imposition of a high magnetic field. Mat Sci Eng A 2006, 422: 227-231. 
[3] Takatori K, Kadoura H, Matsuo H, et al. Microstructural evolution of high purity alumina ceramics prepared by a templated grain growth method. J Ceram Soc Jpn 2016, 124: 432-441.

[4] Duan XM, Wang MR, Jia DC, et al. Anisotropic mechanical properties and fracture mechanisms of textured h-BN composite ceramics. Mat Sci Eng A 2014, 607: 38-43.

[5] Duan XM, Ding YJ, Jia DC, et al. Ion sputtering erosion mechanisms of h-BN composite ceramics with textured microstructures. J Alloys Compd 2014, 613: 1-7.

[6] De Pablos A, Osendi MI, Miranzo P. Effect of microstructure on the thermal conductivity of hot-pressed silicon nitride materials. $J$ Am Ceram Soc 2002, 85: 200-206.

[7] Huang XS, Suzuki K, Chino Y, et al. Influence of initial texture on rolling and annealing textures of $\mathrm{Mg}-3 \mathrm{Al}-1 \mathrm{Zn}$ alloy sheets processed by high temperature rolling. J Alloys Compd 2012, 537: 80-86.

[8] Huang XS, Suzuki K, Saito N. Textures and stretch formability of Mg-6Al-1Zn magnesium alloy sheets rolled at high temperatures up to 793 K. Scripta Mater 2009, 60: 651-654.

[9] Biswas S, Suwas S, Sikand R, et al. Analysis of texture evolution in pure magnesium and the magnesium alloy AM30 during rod and tube extrusion. Mat Sci Eng A 2011, 528: 3722-3729.

[10] Brahme A, Winning M, Raabe D. Prediction of cold rolling texture of steels using an artificial neural network. Comput Mater Sci 2009, 46: 800-804.

[11] Bohlen J, Nürnberg MR, Senn JW, et al. The texture and anisotropy of magnesium-zinc-rare earth alloy sheets. Acta Mater 2007, 55: 2101-2112.

[12] Del Valle JA, Pérez-Prado MT, Ruano OA. Texture evolution during large-strain hot rolling of the Mg AZ61 alloy. Mat Sci Eng A 2003, 355: 68-78.

[13] Park JT, Szpunar JA. Evolution of recrystallization texture in nonoriented electrical steels. Acta Mater 2003, 51: 3037-3051.

[14] Daaland O, Nes E. Recrystallization texture development in commercial Al-Mn-Mg alloys. Acta Mater 1996, 44: 1413-1435.

[15] Lee DN. The evolution of recrystallization textures from deformation textures. Scripta Metall Et Mater 1995, 32: 1689-1694.

[16] Hölscher M, Raabe D, Lücke K. Rolling and recrystallization textures of bcc steels. Steel Res 1991, 62: 567-575.

[17] MacKenzie L, Pekguleryuz M. The recrystallization and texture of magnesium-zinc-cerium alloys. Scripta Mater 2008, 59: 665-668.

[18] Lim HK, Lee JY, Kim DH, et al. Enhancement of mechanical properties and formability of $\mathrm{Mg}-\mathrm{MM}-\mathrm{Sn}-\mathrm{Al}-\mathrm{Zn}$ alloy sheets fabricated by cross-rolling method. Mat Sci Eng A 2009, 506: 63-70.

[19] Foley DC, Al-Maharbi M, Hartwig KT, et al. Grain refinement vs. crystallographic texture: Mechanical anisotropy in a magnesium alloy. Scripta Mater 2011, 64: 193-196.

[20] Jata KV, Panchanadeeswaran S, Vasudevan AK. Evolution of texture, micro structure and mechanical property anisotropy in an Al-Li-Cu alloy. Mat Sci Eng A 1998, 257: 37-46.

[21] Al-Maharbi M, Karaman I, Beyerlein IJ, et al. Microstructure, crystallographic texture, and plastic anisotropy evolution in an
$\mathrm{Mg}$ alloy during equal channel angular extrusion processing. Mat Sci Eng A 2011, 528: 7616-7627.

[22] Seabaugh MM, Hong SH, Messing GL. Processing of textured ceramics by templated grain growth. In Ceramic Microstructures. Tomsia AP, Glaeser AM, Eds. Springer Boston, 1998: 303-310.

[23] Zhu XW, Sakka Y. Textured silicon nitride: Processing and anisotropic properties. Sci Technol Adv Mater 2008, 9: 033001.

[24] Maeda H, Ohya K, Sato M, et al. Microstructure and critical current density of Bi2212 tapes grown by magnetic melt-processing. Physica C 2002, 382: 33-37.

[25] Chen WP, Maeda H, Kakimoto K, et al. Processing of Ag-doped Bi2212 bulks in high magnetic fields: A strong correlation between degree of texture and field strength. Physica C 1999, 320: 96-100.

[26] Maeda H, Sastry PVPSS, Trociewitz UP, et al. Effect of magnetic field strength in melt-processing on texture development and critical current density of Bi-oxide superconductors. Physica $C$ 2003, 386: 115-121.

[27] Fuierer P, Maier R, Röder-Roith U, et al. Processing issues related to the bi-dimensional ionic conductivity of BIMEVOX ceramics. J Mater Sci 2011, 46: 5447-5453.

[28] Wang M, Pan X, Xiao SF, et al. Regulating mesogenic properties of ionic liquid crystals by preparing binary or multi-component systems. J Mater Chem 2012, 22: 2299-2305.

[29] Solovyova ED, Calzada ML, Belous AG. The effect of sol-gel preparation conditions on structural characteristics and magnetic properties of M-type barium hexaferrite thin films. J Sol-Gel Sci Technol 2015, 75: 215-223.

[30] Chen DM, Liu YL, Li YX, et al. Evolution of crystallographic texture and magnetic properties of polycrystalline barium ferrite thick films with $\mathrm{Bi}_{2} \mathrm{O}_{3}$ additive. J Appl Phys 2012, 111: 07A511.

[31] Kaneva II, Kostishin VG, Andreev VG, et al. Obtaining barium hexaferrite Brand 7BI215 with improved isotropic properties. Russ Microelectron 2015, 44: 517-522.

[32] Kimura T. Microstructure development and texture formation in lead-free piezoelectric ceramics prepared by templated grain growth process. J Ceram Soc Jpn 2016, 124: 268-282.

[33] Yilmaz H, Trolier-McKinstry S, Messing GL. (Reactive) templated grain growth of textured sodium bismuth titanate $\left(\mathrm{Na}_{1 / 2} \mathrm{Bi}_{1 / 2} \mathrm{TiO}_{3}\right.$ $\mathrm{BaTiO}_{3}$ ) ceramics-II Dielectric and piezoelectric properties. $J$ Electroceram 2003, 11: 217-226.

[34] Ahn CW, Jeong ED, Kim YH, et al. Piezoelectric properties of textured $\mathrm{Bi}_{3.25} \mathrm{La}_{0.75} \mathrm{Ti}_{2.97} \mathrm{~V}_{0.03} \mathrm{O}_{12}$ ceramics fabricated by reactive templated grain growth method. $J$ Electroceram 2009, 23: 392-396.

[35] Li LY, Bai WF, Zhang Y, et al. The preparation and piezoelectric property of textured KNN-based ceramics with plate-like $\mathrm{NaNbO}_{3}$ powders as template. J Alloys Compd 2015, 622: $137-$ 142.

[36] Zhu XW, Suzuki TS, Uchikoshi T, et al. Texture development in $\mathrm{Si}_{3} \mathrm{~N}_{4}$ ceramics by magnetic field alignment during slip casting. $J$ Ceram Soc Jpn 2006, 114: 979-987.

[37] Kim W, Kim YW, Cho DH. Texture and fracture toughness anisotropy in silicon carbide. J Am Ceram Soc 2005, 81: 16691672 . 
[38] Lee F, Bowman KJ. Texture and anisotropy in silicon nitride. $J$ Am Ceram Soc 1992, 75: 1748-1755.

[39] Du AB, Wan CL, Qu ZX, et al. Effects of texture on the thermal conductivity of the $\mathrm{LaPO}_{4}$ monazite. J Am Ceram Soc 2010, 93: 2822-2827.

[40] Honda S, Hashimoto S, Iwata S, et al. Anisotropic properties of highly textured porous alumina formed from platelets. Ceram Int 2016, 42: 1453-1458.

[41] Wegst UGK, Bai H, Saiz E, et al. Bioinspired structural materials. Nat Mater 2015, 14: 23-36.

[42] Romano P, Fabritius H, Raabe D. The exoskeleton of the lobster Homarus americanus as an example of a smart anisotropic biological material. Acta Biomater 2007, 3: 301-309.

[43] Raabe D, Al-Sawalmih A, Yi SB, et al. Preferred crystallographic texture of $\alpha$-chitin as a microscopic and macroscopic design principle of the exoskeleton of the lobster Homarus americanus. Acta Biomater 2007, 3: 882-895.

[44] Raabe D, Romano P, Sachs C, et al. Microstructure and crystallographic texture of the chitin-protein network in the biological composite material of the exoskeleton of the lobster Homarus americanus. Mat Sci Eng A 2006, 421: 143-153.

[45] Naleway SE, Taylor JRA, Porter MM, et al. Structure and mechanical properties of selected protective systems in marine organisms. Mat Sci Eng C 2016, 59: 1143-1167.

[46] Meyers MA, Chen PY, Lopez MI, et al. Biological materials: A materials science approach. J Mech Behav Biomed Mater 2011, 4: 626-657.

[47] Wang JF, Cheng QF, Tang ZY. Layered nanocomposites inspired by the structure and mechanical properties of nacre. Chem Soc Rev 2012, 41: 1111-1129.

[48] Barthelat F, Li CM, Comi C, et al. Mechanical properties of nacre constituents and their impact on mechanical performance. $J$ Mater Res 2006, 21: 1977-1986.

[49] Sun JY, Bhushan B. Hierarchical structure and mechanical properties of nacre: A review. RSC Adv 2012, 2: 7617-7632.

[50] Evans AG, Suo Z, Wang RZ, et al. Model for the robust mechanical behavior of nacre. J Mater Res 2001, 16: 2475-2484.

[51] Wang RZ, Suo Z, Evans AG, et al. Deformation mechanisms in nacre. J Mater Res 2001, 16: 2485-2493.

[52] Landi E, Sciti D, Melandri C, et al. Ice templating of $\mathrm{ZrB}_{2}$ porous architectures. J Eur Ceram Soc 2013, 33: 1599-1607.

[53] Deville S. Ice-templating, freeze casting: Beyond materials processing. J Mater Res 2013, 28: 2202-2219.

[54] Cheng QF, Jiang L. Mimicking nacre by ice templating. Angew Chem Int Ed 2017, 56: 934-935.

[55] Bouville F, Maire E, Meille S, et al. Strong, tough and stiff bioinspired ceramics from brittle constituents. Nat Mater 2014, 13: 508-514.

[56] Wilkerson RP, Gludovatz B, Watts J, et al. A novel approach to developing biomimetic ("nacre-like") metal-compliant-phase (nickel-alumina) ceramics through coextrusion. Adv Mater 2016, 28: 10061-10067.

[57] Wegst UGK, Bai H, Saiz E, et al. Bioinspired structural materials. Nat Mater 2015, 14: 23-36.

[58] Studart AR. Turning brittleness into toughness. Nat Mater 2014,
13: $433-435$.

[59] Townsend A, Senin N, Blunt L, et al. Surface texture metrology for metal additive manufacturing: A review. Precis Eng 2016, 46: 34-47.

[60] Sheng YY, Hua YL, Wang XJ, et al. Application of high-density electropulsing to improve the performance of metallic materials: Mechanisms, microstructure and properties. Materials 2018, 11: 185.

[61] Kok Y, Tan XP, Wang P, et al. Anisotropy and heterogeneity of microstructure and mechanical properties in metal additive manufacturing: A critical review. Mater Des 2018, 139: 565-586.

[62] Turner RC, Fuierer PA, Newnham RE, et al. Materials for high temperature acoustic and vibration sensors: A review. Appl Acoust 1994, 41: 299-324.

[63] Messing GL, Trolier-McKinstry S, Sabolsky EM, et al. Templated grain growth of textured piezoelectric ceramics. Crit Rev Solid State Mater Sci 2004, 29: 45-96.

[64] Terada N, Suzuki S, Suzuki S, et al. Neutron diffraction texture analysis for $\alpha-\mathrm{Al}_{2} \mathrm{O}_{3}$ oriented by high magnetic field and sintering. J Phys D: Appl Phys 2009, 42: 105404.

[65] Shamma M, Caspi EN, Anasori B, et al. In situ neutron diffraction evidence for fully reversible dislocation motion in highly textured polycrystalline $\mathrm{Ti}_{2} \mathrm{AlC}$ samples. Acta Mater 2015 , 98: $51-63$.

[66] Rogan RC, Üstündag E, Clausen B, et al. Texture and strain analysis of the ferroelastic behavior of $\mathrm{Pb}(\mathrm{Zr}, \mathrm{Ti}) \mathrm{O}_{3}$ by in situ neutron diffraction. J Appl Phys 2003, 93: 4104-4111.

[67] Terada N, Suzuki HS, Suzuki TS, et al. In situ neutron diffraction study of aligning of crystal orientation in diamagnetic ceramics under magnetic fields. Appl Phys Lett 2008, 92: 112507.

[68] Yi HL, Mao XJ, Zhou GH, et al. Crystal plane evolution of grain oriented alumina ceramics with high transparency. Ceram Int 2012, 38: 5557-5561.

[69] Yang ZG, Yu JB, Li CJ, et al. Preparation of textured porous $\mathrm{Al}_{2} \mathrm{O}_{3}$ ceramics by slip casting in a strong magnetic field and its mechanical properties. Cryst Res Technol 2015, 50: 645-653.

[70] Niu B, Cai DL, Yang ZH, et al. Anisotropies in structure and properties of hot-press sintered h-BN-MAS composite ceramics: Effects of raw h-BN particle size. J Eur Ceram Soc 2019, 39 : 539-546.

[71] Imamura H, Hirao K, Brito ME, et al. Further improvement in mechanical properties of highly anisotropic silicon nitride ceramics. J Am Ceram Soc 2000, 83: 495-500.

[72] Sitzman SD. Introduction to EBSD analysis of micro- to nanoscale microstructures in metals and ceramics. In: Testing, Reliability, and Application of Micro- and Nano-Material Systems II. Meyendorf N, Baaklini GY, Michel B, Eds. Bellingham: Spie-Int Soc Optical Engineering, 2004: 78-90.

[73] Guilmeau E, Henrist C, Suzuki T, et al. Texture of alumina by neutron diffraction and SEM-EBSD. Mater Sci Forum 2005, 495-497: 1395-1400.

[74] Schwarzer RA. Automated crystal lattice orientation mapping using a computer-controlled SEM. Micron 1997, 28: 249-265.

[75] Koblischka MR, Koblischka-Veneva A, Reddy ES, et al. Analysis of the microstructure of superconducting YBCO foams by means 
of AFM and EBSD. $J$ Adv Ceram 2014, 3: 317-325.

[76] Pérez-Arantegui J, Larrea A. Electron backscattering diffraction as a complementary analytical approach to the microstructural characterization of ancient materials by electron microscopy. TrAC Trends Anal Chem 2015, 72: 193-201.

[77] Liang HQ, Zeng YP, Zuo KH, et al. Mechanical properties and thermal conductivity of $\mathrm{Si}_{3} \mathrm{~N}_{4}$ ceramics with $\mathrm{YF}_{3}$ and $\mathrm{MgO}$ as sintering additives. Ceram Int 2016, 42: 15679-15686.

[78] Wenk HR, Houtte PV. Texture and anisotropy. Rep Prog Phys 2004, 67: 1367-1428.

[79] Ni DW, Zhang GJ, Kan YM, et al. Textured h-BN ceramics prepared by slip casting. J Am Ceram Soc 2011, 94: 1397-1404.

[80] Seabaugh MM, Vaudin MD, Cline JP, et al. Comparison of texture analysis techniques for highly oriented $\alpha-\mathrm{Al}_{2} \mathrm{O}_{3} . J \mathrm{Am}$ Ceram Soc 2000, 83: 2049-2054.

[81] Suzuki TS, Uchikoshi T, Sakka Y. Effect of sintering conditions on microstructure orientation in $\alpha$-SiC prepared by slip casting in a strong magnetic field. J Eur Ceram Soc 2010, 30: 2813-2817.

[82] Alkoy S, Dursun S. Processing and properties of textured potassium strontium niobate $\left(\mathrm{KSr}_{2} \mathrm{Nb}_{5} \mathrm{O}_{15}\right)$ ceramic fibersTexture development. J Am Ceram Soc 2012, 95: 937-945

[83] Wei M, Zhi D, Brandon DG. Microstructure and texture evolution in gel-cast $\alpha$-alumina/alumina platelet ceramic composites. Scripta Mater 2005, 53: 1327-1332.

[84] Zhang L, Vleugels J, van der Biest O. Slip casting of alumina suspensions in a strong magnetic field. J Am Ceram Soc 2010, 93: 3148-3152.

[85] Information on https://www.ccdc.cam.ac.uk.

[86] Requena J, Moreno R, Moya JS. Alumina and alumina/zirconia multilayer composites obtained by slip casting. J Am Ceram Soc 1989, 72: 1511-1513.

[87] Steinlage G, Roeder R, Trumble K, et al. Preferred orientation of BSCCO via centrifugal slip casting. J Mater Res 1994, 9: 833-836

[88] Ning JL, Jiang DM, Shim KB. Preparation of textured zinc oxide ceramics by extrusion and spark plasma sintering. Adv Appl Ceram 2006, 105: 265-269.

[89] Rocha-Rangel E, Moreno-Guerrero MS, Hernández RT, et al. Direct extrusion production of monolithic ceramics with different cross section. Mater Sci Forum 2006, 509: 205-210.

[90] Ning JL, Jiang DM, Kim KH, et al. Influence of texture on electrical properties of $\mathrm{ZnO}$ ceramics prepared by extrusion and spark plasma sintering. Ceram Int 2007, 33: 107-114.

[91] Habelitz S, Carl G, Rüssel C, et al. Oriented mica glass-ceramic by extrusion and subsequent heat treatment. Glastech Ber Glass Sci Technol 1997, 70: 86-92.

[92] Ning JL, Jiang DM, Shim KB. Preparation of textured zinc oxide ceramics by extrusion and spark plasma sintering. Adv Appl Ceram 2006, 105: 265-269.

[93] Chen HB, Fu F, Zhai JW. Fabrication and piezoelectric property of highly textured $\mathrm{CaBi}_{2} \mathrm{Nb}_{2} \mathrm{O}_{9}$ ceramics by tape casting. Jpn $J$ Appl Phys 2011, 50: 050207.

[94] Liu HT, Zhang GJ. Textured $\mathrm{ZrB}_{2}$-based ceramics by tape casting from rod-like $\mathrm{ZrB}_{2}$ starting powders. J Ceram Soc Jpn 2013, 121: $327-330$
[95] Hong RZ, Gao F, Liu JJ, et al. Fabrication of $(\mathrm{BiNa})_{0.5} \mathrm{TiO}_{3}-$ $\mathrm{BaTiO}_{3}$ textured ceramics by tape casting. J Mater Sci 2008, 43: 6126-6131.

[96] Chen HB, Fu F, Zhai JW. Fabrication and piezoelectric property of highly textured $\mathrm{CaBi}_{2} \mathrm{Nb}_{2} \mathrm{O}_{9}$ ceramics by tape casting. Jpn $J$ Appl Phys 2011, 50: 050207.

[97] Jabbari M, Bulatova R, Tok AIY, et al. Ceramic tape casting: A review of current methods and trends with emphasis on rheological behaviour and flow analysis. Mat Sci Eng B 2016, 212: 39-61.

[98] Chantaramee N, Tanaka S, Takahashi T, et al. Evolution of discontinuity in particle orientation in ceramic tape casting. $J \mathrm{Am}$ Ceram Soc 2008, 91: 3181-3184.

[99] Yamada H, Suzuki TS, Uchikoshi T, et al. Analysis of abnormal grain growth of oriented $\mathrm{LiCoO}_{2}$ prepared by slip casting in a strong magnetic field. J Eur Ceram Soc 2013, 33: 3059-3064.

[100] Vriami D, Beaugnon E, Erauw JP, et al. Texturing of 3Y-TZP zirconia by slip casting in a high magnetic field of 17.4T. $J$ Eur Ceram Soc 2015, 35: 3959-3967.

[101] Suzuki TS, Uchikoshi T, Sakka Y. Texture development in anatase and rutile prepared by slip casting in a strong magnetic field. J Ceram Soc Jpn 2011, 119: 334-337.

[102] Suzuki TS, Uchikoshi T, Sakka Y. Effect of sintering additive on crystallographic orientation in AlN prepared by slip casting in a strong magnetic field. J Eur Ceram Soc 2009, 29: 2627-2633.

[103] Suzuki TS, Sakka Y, Kitazawa K. Preferred orientation of the texture in the $\mathrm{SiC}$ whisker-dispersed $\mathrm{Al}_{2} \mathrm{O}_{3}$ ceramics by slip casting in a high magnetic field. $J$ Ceram Soc Jpn 2001, 109 886-890.

[104] Suzuki TS, Sakka Y. Preparation of oriented bulk $5 \mathrm{wt} \%$ $\mathrm{Y}_{2} \mathrm{O}_{3}-\mathrm{AlN}$ ceramics by slip casting in a high magnetic field and sintering. Scripta Mater 2005, 52: 583-586.

[105] Suzuki TS, Sakka Y. Fabrication of textured titania by slip casting in a high magnetic field followed by heating. Jpn J Appl Phys 2002, 41: L1272-L1274.

[106] Özen M, Mertens M, Snijkers F, et al. Texturing of hydrothermally synthesized $\mathrm{BaTiO}_{3}$ in a strong magnetic field by slip casting. Ceram Int 2016, 42: 5382-5390.

[107] Miwa Y, Kawada S, Kimura M, et al. Textured lead titanate ceramics fabricated by slip casting under a high magnetic field. $J$ Ceram Soc Jpn 2011, 119: 60-64.

[108] Miwa Y, Kawada S, Kimura M, et al. Textured $\mathrm{PbTiO}_{3}$ based ceramics fabricated by slip casting in a high magnetic field. Key Eng Mater 2010, 421-422: 395-398.

[109] Kimura M, Shiratsuyu K, Ando A, et al. Layer structure of textured $\mathrm{CaBi}_{4} \mathrm{Ti}_{4} \mathrm{O}_{15}$ ceramics fabricated by slip casting in high magnetic field. J Am Ceram Soc 2007, 90: 1463-1466.

[110] Hagio T, Yamauchi K, Kohama T, et al. Beta tricalcium phosphate ceramics with controlled crystal orientation fabricated by application of external magnetic field during the slip casting process. Mat Sci Eng C 2013, 33: 2967-2970.

[111] Gao F, Hong RZ, Liu JJ, et al. Grain growth kinetics of textured $0.92 \mathrm{Na}_{0.5} \mathrm{Bi}_{0.5} \mathrm{TiO}_{3}-0.08 \mathrm{BaTiO}_{3}$ ceramics by tape casting with $\mathrm{Bi}_{2.5} \mathrm{Na}_{3.5} \mathrm{Nb}_{5} \mathrm{O}_{18}$ templates. $J$ Electroceram 2010, 24: 145-152.

[112] Palizdar M, Fancher CM, Comyn TP, et al. Characterization of 
thick bismuth ferrite-lead titanate films processed by tape casting and templated grain growth. J Eur Ceram Soc 2015, 35: 4453-4458.

[113] Kan YM, Wang PL, Li YX, et al. Fabrication of textured bismuth titanate by templated grain growth using aqueous tape casting. $J$ Eur Ceram Soc 2003, 23: 2163-2169.

[114] Takeuchi T, Tani T, Saito Y. Unidirectionally textured $\mathrm{CaBi}_{4} \mathrm{Ti}_{4} \mathrm{O}_{15}$ ceramics by the reactive templated grain growth with an extrusion. Jpn J Appl Phys 2000, 39: 5577-5580.

[115] Dharmendra C, Rao KP, Prasad YVRK, et al. Hot working mechanisms and texture development in $\mathrm{Mg}-3 \mathrm{Sn}-2 \mathrm{Ca}-0.4 \mathrm{Al}$ alloy. Mater Chem Phys 2012, 136: 1081-1091.

[116] Semiatin SL, Bieler TR. Effect of texture and slip mode on the anisotropy of plastic flow and flow softening during hot working of Ti-6Al-4V. Metall Mater Trans A 2001, 32: 1787-1799.

[117] Xie RJ, Mitomo M, Kim W, et al. Preferred orientation of betaphase and its mechanisms in a fine-grained silicon-nitride-based ceramic. J Mater Res 2001, 16: 590-596.

[118] Ehre D, Gutmanas EY, Chaim R. Densification of nanocrystalline $\mathrm{MgO}$ ceramics by hot-pressing. J Eur Ceram Soc 2005, 25: 3579-3585.

[119] Fedrizzi A, Pellizzari M, Zadra M, et al. Microstructural study and densification analysis of hot work tool steel matrix composites reinforced with $\mathrm{TiB}_{2}$ particles. Mater Charact 2013, 86: 69-79.

[120] Chamberlain AL, Fahrenholtz WG, Hilmas GE. Low-temperature densification of zirconium diboride ceramics by reactive hot pressing. J Am Ceram Soc 2006, 89: 3638-3645.

[121] Felten EJ. Hot-pressing of alumina powders at low temperatures. J Am Ceram Soc 1961, 44: 381-385.

[122] Nishimura Y, Hashimoto S, Honda S, et al. Dielectric breakdown and thermal conductivity of textured alumina from platelets. $J$ Ceram Soc Jpn 2010, 118: 1032-1037.

[123] Duan XM, Shen L, Jia DC, et al. Synthesis of high-purity, isotropic or textured $\mathrm{Cr}_{2} \mathrm{AlC}$ bulk ceramics by spark plasma sintering of pressure-less sintered powders. J Eur Ceram Soc 2015, 35: 1393-1400.

[124] Carman A, Pereloma E, Cheng YB. Hot forging of a textured alpha-sialon ceramic. J Am Ceram Soc 2006, 89: 478-483.

[125] Chen HB, Xu JB, Zhai JW. Fabrication and piezoelectric property of textured bismuth layered structure ceramics by hot pressing technique. Key Eng Mater 2013, 547: 11-18.

[126] Liu J, Shen ZJ, Nygren M, et al. SPS processing of bismuth-layer structured ferroelectric ceramics yielding highly textured microstructures. J Eur Ceram Soc 2006, 26: 3233-3239.

[127] Kusunose T, Sekino T. Thermal conductivity of hot-pressed hexagonal boron nitride. Scripta Mater 2016, 124: 138-141.

[128] Kondo N, Suzuki Y, Miyajima T, et al. High-temperature mechanical properties of sinter-forged silicon nitride with ytterbia additive. J Eur Ceram Soc 2003, 23: 809-815.

[129] Xie RJ, Mitomo M, Kim W, et al. Texture development in silicon nitride-silicon oxynitride in situ composites via superplastic deformation. J Am Ceram Soc 2000, 83: 3147-3152.

[130] Venkatachari KR, Raj R. Enhancement of strength through sinter forging. J Am Ceram Soc 1987, 70: 514-520.
[131] Hu CF, Sakka Y, Grasso S, et al. Tailoring $\mathrm{Ti}_{3} \mathrm{SiC}_{2}$ ceramic via a strong magnetic field alignment method followed by spark plasma sintering. J Am Ceram Soc 2011, 94: 742-748.

[132] Uchikoshi T, Suzuki TS, Sakka Y. Crystalline orientation of alumina ceramics prepared by electrophoretic deposition under a high magnetic field. J Mater Sci 2006, 41: 8074-8078.

[133] Li SQ, Sassa K, Asai S. Textured crystal growth of $\mathrm{Si}_{3} \mathrm{~N}_{4}$ ceramics in high magnetic field. Mater Lett 2005, 59: 153-157.

[134] Fei WD. Solid State Physics. Harbin: Harbin Institute of Technology Press, 2014.

[135] Suvaci E, Oh KS, Messing GL. Kinetics of template growth in alumina during the process of templated grain growth (TGG). Acta Mater 2001, 49: 2075-2081.

[136] Shoji T, Yoshida Y, Kimura T. Mechanism of texture development in $\mathrm{Bi}_{0.5}(\mathrm{Na}, \mathrm{K})_{0.5} \mathrm{TiO}_{3}$ templated by platelike $\mathrm{Al}_{2} \mathrm{O}_{3}$ particles. $J \mathrm{Am}$ Ceram Soc 2008, 91: 3883-3888.

[137] Jones JL, Iverson BJ, Bowman KJ. Texture and anisotropy of polycrystalline piezoelectrics. J Am Ceram Soc 2007, 90: 2297-2314.

[138] Kimura T, Yi Y, Sakurai F. Mechanisms of texture development in lead-free piezoelectric ceramics with perovskite structure made by the templated grain growth process. Materials 2010, 3: 49654978.

[139] Vriami D, Damjanovic D, Vleugels J, et al. Textured $\mathrm{BaTiO}_{3}$ by templated grain growth and electrophoretic deposition. $J$ Mater Sci 2015, 50: 7896-7907.

[140] Sabolsky EM, Maldonado L, Seabaugh MM, et al. Textured$\mathrm{Ba}(\mathrm{Zr}, \mathrm{Ti}) \mathrm{O}_{3}$ piezoelectric ceramics fabricated by templated grain growth (TGG). J Electroceram 2010, 25: 77-84.

[141] Özen M, Mertens M, Snijkers F, et al. Texturing of hydrothermally synthesized $\mathrm{BaTiO}_{3}$ in a strong magnetic field by slip casting. Ceram Int 2016, 42: 5382-5390.

[142] Gao F, Hong RZ, Liu JJ, et al. Effect of different templates on microstructure of textured $\mathrm{Na}_{0.5} \mathrm{Bi}_{0.5} \mathrm{TiO}_{3}-\mathrm{BaTiO}_{3}$ ceramics with RTGG method. J Eur Ceram Soc 2008, 28: 2063-2070.

[143] Gao F, Yang SJ, Li JJ, et al. Fabrication, dielectric, and thermoelectric properties of textured $\mathrm{SrTiO}_{3}$ ceramics prepared by RTGG method. Ceram Int 2015, 41: 127-135.

[144] $\mathrm{Su} \mathrm{S,} \mathrm{Zuo} \mathrm{RZ.} \mathrm{Fabrication} \mathrm{and} \mathrm{electrical} \mathrm{properties} \mathrm{of}$ $0.94 \mathrm{Na}_{0.5} \mathrm{Bi}_{0.5} \mathrm{TiO}_{3}-0.06 \mathrm{BaTiO}_{3}$ textured ceramics by RTGG method using micrometer sized $\mathrm{BaTiO}_{3}$ plate-like templates. $J$ Alloys Compd 2012, 525: 133-136.

[145] Hussain A, Ahn CW, Lee HJ, et al. Anisotropic electrical properties of $\mathrm{Bi}_{0.5}\left(\mathrm{Na}_{0.75} \mathrm{~K}_{0.25}\right)_{0.5} \mathrm{TiO}_{3}$ ceramics fabricated by reactive templated grain growth (RTGG). Curr Appl Phys 2010, 10: 305-310.

[146] Hirao K. Microstructure control of silicon nitride ceramics by seeding and their enhanced mechanical and thermal properties. $J$ Ceram Soc Jpn 2006, 114: 665-671.

[147] Takao KN, Tanemoto K, Kubo H. Hot-pressed BN-AlN ceramic composites of high thermal conductivity. Jpn J Appl Phys 1990, 29: 683-687.

[148] Bai WF, Li H, Xi JH, et al. Effect of different templates and texture on structure evolution and strain behavior of $<001>$ textured lead-free piezoelectric BNT-based ceramics. $J$ Alloys Compd 2016, 656: 13-23. 
[149] Deville S, Saiz E, Tomsia AP. Ice-templated porous alumina structures. Acta Mater 2007, 55: 1965-1974.

[150] Deville S. Freeze-casting of porous biomaterials: Structure, properties and opportunities. Materials 2010, 3: 1913-1927.

[151] Zhang JJ, Chao MJ, Liang EJ, et al. Synthesis and dielectric properties of textured $\mathrm{SrBi}_{2} \mathrm{Nb}_{2} \mathrm{O}_{9}$ ceramics via laser rapid solidification. J Alloys Compd 2012, 521: 150-154.

[152] Harimkar SP, Dahotre NB. Crystallographic and morphological textures in laser surface modified alumina ceramic. J Appl Phys 2006, 100: 024901 .

[153] Zhang JJ, Yu JM, Chao MJ, et al. Textured $\mathrm{BaTi}_{2} \mathrm{O}_{5}$ ceramic synthesized by laser rapid solidification method and its dielectric properties. J Mater Sci 2012, 47: 1554-1558.

[154] Rutkowski P, Stobierski L, Zientara D, et al. The influence of the graphene additive on mechanical properties and wear of hotpressed $\mathrm{Si}_{3} \mathrm{~N}_{4}$ matrix composites. J Eur Ceram Soc 2015, 35: 8794.

[155] Hubáček M, Sato T, Ueki M. Copper-boron nitride interaction in hot-pressed ceramics. J Mater Res 1997, 12: 113-118.

[156] Snel MD, van Hoolst J, de Wilde AM, et al. Influence of tape cast parameters on texture formation in alumina by templated grain growth. J Eur Ceram Soc 2009, 29: 2757-2763.

[157] Park D-S, Kim C-W. A modification of tape casting for aligning the whiskers. J Mater Sci 1999, 34: 5827-5832.

[158] German RM, Suri P, Park SJ. Review: Liquid phase sintering. $J$ Mater Sci 2009, 44: 1-39.

[159] Marion JE, Hsueh CH, Evans AG. Liquid-phase sintering of ceramics. J Am Ceram Soc 1987, 70: 708-713.

[160] Kim Y-W, Lee S-G, Mitomo M. Microstructural development of liquid-phase-sintered silicon carbide during annealing with uniaxial pressure. J Eur Ceram Soc 2002, 22: 1031-1037.

[161] Guo SQ, Nishimura T, Kagawa Y. Low-temperature hot pressing of $\mathrm{ZrB}_{2}$-based ceramics with $\mathrm{ZrSi}_{2}$ additives. Int $J$ Appl Ceram Technol 2011, 8: 1425-1435.

[162] Seabaugh MM, Kerscht IH, Messing GL. Texture development by templated grain growth in liquid-phase-sintered $\alpha$-alumina. $J$ Am Ceram Soc 1997, 80: 1181-1188.

[163] Song H, Coble RL. Origin and growth kinetics of platelike abnormal grains in liquid-phase-sintered alumina. J Am Ceram Soc 1990, 73: 2077-2085.

[164] Seabaugh MM, Messing GL, Vaudin MD. Texture development and microstructure evolution in liquid-phase-sintered $\alpha$-alumina ceramics prepared by templated grain growth. J Am Ceram Soc 2000, 83: 3109-3116.

[165] Suzuki TS, Uchikoshi T, Sakka Y. Texture development in alumina composites by slip casting in a strong magnetic field. $J$ Ceram Soc Jpn 2006, 114: 59-62.

[166] Suzuki TS, Uchikoshi T, Sakka Y. Control of texture in alumina by colloidal processing in a strong magnetic field. Sci Technol Adv Mater 2006, 7: 356-364.

[167] Szudarska A, Mizerski T, Sakka Y, et al. Fabrication of textured alumina by magnetic alignment via gelcasting based on low-toxic system. J Eur Ceram Soc 2014, 34: 3841-3848.

[168] Wiecinska P, Sakka Y, Suzuki TS, et al. Fabrication of textured $\alpha$-alumina in high magnetic field via gelcasting with the use of glucose derivative. J Ceram Soc Jpn 2013, 121: 89-94.

[169] Uchikoshi T, Suzuki TS, Okuyama H, et al. Fabrication of textured alumina by electrophoretic deposition in a strong magnetic field. J Mater Sci 2004, 39: 861-865.

[170] Xue JX, Liu JX, Xie BH, et al. Pressure-induced preferential grain growth, texture development and anisotropic properties of hot pressed hexagonal boron nitride ceramics. Scripta Mater 2011, 65: 966-969.

[171] Szudarska A, Sakka Y, Suzuki TS, et al. Magnetic field alignment in highly concentrated suspensions for gelcasting process. Ceram Int 2016, 42: 294-301.

[172] Xing YQ, Deng JX, Zhao J, et al. Cutting performance and wear mechanism of nanoscale and microscale textured $\mathrm{Al}_{2} \mathrm{O}_{3} / \mathrm{TiC}$ ceramic tools in dry cutting of hardened steel. Int $J$ Refract Met Hard Mater 2014, 43: 46-58.

[173] Zhou ZY, Liang RH, Li YC, et al. Enhanced electrical resistivity of $\mathrm{Al}_{2} \mathrm{O}_{3}$ addition modified $\mathrm{Na}_{0.5} \mathrm{Bi}_{2.5} \mathrm{Nb}_{2} \mathrm{O}_{9}$ high-temperature piezoceramics. J Am Ceram Soc 2015, 98: 3925-3929.

[174] Zhang $\mathrm{K}$, Li W, Lin H-X. Effect of $\mathrm{MgO} / \mathrm{Eu}_{2} \mathrm{O}_{3}$ co-doping on the microwave dielectric properties of $\mathrm{Al}_{2} \mathrm{O}_{3}$ ceramics. J Inorg Mater 2015, 30: 984-988.

[175] Ma XX, Liang W, Zhao XG, et al. Effect of $\mathrm{Al}_{2} \mathrm{O}_{3}$ layer on improving high-temperature oxidation resistance of siliconized TiAl-based alloy. Mater Lett 2006, 60: 1651-1653.

[176] Li J, Zuo KH, Liu WJ, et al. Porous $\mathrm{Al}_{2} \mathrm{O}_{3}$ prepared via freeze casting and its biocompatibility. In: Ceramic Materials and Components for Energy and Environmental Applications. Jiang D, Zeng Y, Singh M, et al., Eds. John Wiley \& Sons, Inc., 2010: 537-543.

[177] Pravarthana D, Chateigner D, Lutterotti L, et al. Growth and texture of spark plasma sintered $\mathrm{Al}_{2} \mathrm{O}_{3}$ ceramics: A combined analysis of X-rays and electron back scatter diffraction. $J$ Appl Phys 2013, 113: 153510 .

[178] Becher PF, Sun EY, Plucknett KP, et al. Microstructural design of silicon nitride with improved fracture toughness: I, effects of grain shape and size. J Am Ceram Soc 1998, 81: 2821-2830.

[179] Muscat D, Pugh MD, Drew RAL, et al. Microstructure of an extruded $\beta$-silicon nitride whisker-reinforced silicon nitride composite. J Am Ceram Soc 1992, 75: 2713-2718.

[180] Rutkowski P, Piekarczyk W, Stobierski L, et al. Anisotropy of elastic properties and thermal conductivity of $\mathrm{Al}_{2} \mathrm{O}_{3} / \mathrm{h}-\mathrm{BN}$ composites. J Therm Anal Calorim 2014, 115: 461-466.

[181] Shen H, Guo J, Wang H, et al. Bioinspired modification of h-BN for high thermal conductive composite films with aligned structure. ACS Appl Mater Interfaces 2015, 7: 5701-5708.

[182] Shen HJ. Thermal-conductivity and tensile-properties of BN, SiC and Ge nanotubes. Comput Mater Sci 2009, 47: 220-224

[183] Monteverde F, Bellosi A, Scatteia L. Processing and properties of ultra-high temperature ceramics for space applications. $\mathrm{Mat} \mathrm{Sci}$ Eng A 2008, 485: 415-421.

[184] Fahrenholtz WG, Hilmas GE. Ultra-high temperature ceramics: Materials for extreme environments. Scripta Mater 2017, 129 94-99.

[185] Barsoum MW. The $\mathrm{M}_{N+1} \mathrm{AX}$ phases: A new class of solids: Thermodynamically stable nanolaminates. Prog Solid State Chem 
2000, 28: 201-281.

[186] Barsoum MW, Radovic M. Elastic and mechanical properties of the MAX phases. Annu Rev Mater Res 2011, 41: 195-227.

[187] Haftani M, Saeedi Heydari M, Baharvandi HR, et al. Studying the oxidation of $\mathrm{Ti}_{2} \mathrm{AlC}$ MAX phase in atmosphere: A review. Int $J$ Refract Met Hard Mater 2016, 61: 51-60.

[188] Hu CF, Li FZ, He LF, et al. In situ reaction synthesis, electrical and thermal, and mechanical properties of $\mathrm{Nb}_{4} \mathrm{AlC}_{3} . J \mathrm{Am}$ Ceram Soc 2008, 91: 2258-2263.

[189] Barsoum MW, Radovic M. Mechanical properties of the MAX phases. In: Encyclopedia of Materials: Science and Technology. Jürgen Buschow KH, Cahn RW, Flemings MC, et al., Eds. Elsevier, 2004: 1-16.

[190] Kingery WD, Bowen HK, Uhlmann DR. Introduction to Ceramics, 2nd edn. Beijing: Higher Education Press, 2010. (in Chinese)

[191] Chikh H, SI Ahmed F, Afir A, et al. In-situ X-ray diffraction study of alumina $\alpha-\mathrm{Al}_{2} \mathrm{O}_{3}$ thermal behavior under dynamic vacuum and constant flow of nitrogen. $J$ Alloys Compd 2016, 654: 509-513.

[192] Carisey T, Leviri I, Brandon DG. Micro structure and mechanical properties of textured $\mathrm{Al}_{2} \mathrm{O}_{3}$. J Eur Ceram Soc 1995, 15: 283-289.

[193] Pavlacka RJ, Messing GL. Processing and mechanical response of highly textured $\mathrm{Al}_{2} \mathrm{O}_{3}$. J Eur Ceram Soc 2010, 30: 2917-2925.

[194] Yang ZG, Yu JB, Deng K, et al. Fabrication of textured $\mathrm{Si}_{3} \mathrm{~N}_{4}$ ceramics with $\beta-\mathrm{Si}_{3} \mathrm{~N}_{4}$ powders as raw material by gel-casting under strong magnetic field. Mater Lett 2014, 135: 218-221.

[195] Suzuki TS, Uchikoshi T, Okuyama H, et al. Mechanical properties of textured, multilayered alumina produced using electrophoretic deposition in a strong magnetic field. $J$ Eur Ceram Soc 2006, 26: 661-665.

[196] Sakka Y, Suzuki TS, Uchikoshi T. Fabrication and some properties of textured alumina-related compounds by colloidal processing in high-magnetic field and sintering. $J$ Eur Ceram Soc 2008, 28: 935-942.

[197] Uchikoshi T, Suzuki TS, Okuyama H, et al. Electrophoretic deposition of alumina suspension in a strong magnetic field. $J$ Eur Ceram Soc 2004, 24: 225-229.

[198] Mao LB, Gao HL, Yao HB, et al. Synthetic nacre by predesigned matrix-directed mineralization. Science 2016, 354: 107-110.

[199] Jackson AP, Vincent JFV, Turner RM. The mechanical design of nacre. Proc R Soc Lond B Biol Sci 1988, 234: 415-440.

[200] Ritchie RO. The conflicts between strength and toughness. Nat Mater 2011, 10: 817-822.

[201] Rutkowski P, Stobierski L, Górny G. Thermal stability and conductivity of hot-pressed $\mathrm{Si}_{3} \mathrm{~N}_{4}$-graphene composites. $J$ Therm Anal Calorim 2014, 116: 321-328.

[202] Li SQ, Sassa K, Asai S. Fabrication of textured $\mathrm{Si}_{3} \mathrm{~N}_{4}$ ceramics by slip casting in a high magnetic field. J Am Ceram Soc 2004, 87: 1384-1387.

[203] Hampshire S, Pomeroy MJ. Silicon nitride-grain boundary oxynitride glass interfaces: Deductions from glass bulk properties. Int J Appl Ceram Technol 2013, 10: 747-755.

[204] Hirao K, Watari K, Hayashi H, et al. High thermal conductivity silicon nitride ceramic. MRS Bull 2001, 26: 451-455.

[205] Kim H-D, Han B-D, Park D-S, et al. Novel two-step sintering process to obtain a bimodal microstructure in silicon nitride. $J \mathrm{Am}$ Ceram Soc 2004, 85: 245-252.

[206] Zhou Y, Hyuga H, Kusano D, et al. A tough silicon nitride ceramic with high thermal conductivity. Adv Mater 2011, 23: 4563-4567.

[207] Hirata T, Akiyama K, Morimoto T. Synthesis of $\beta-\mathrm{Si}_{3} \mathrm{~N}_{4}$ particles from $\alpha-\mathrm{Si}_{3} \mathrm{~N}_{4}$ particles. $J$ Eur Ceram Soc 2000, 20: 1191-1195.

[208] Urakami R, Sato Y, Ogushi M, et al. Phase transformation and interface segregation behavior in $\mathrm{Si}_{3} \mathrm{~N}_{4}$ ceramics sintered with $\mathrm{La}_{2} \mathrm{O}_{3}-\mathrm{Lu}_{2} \mathrm{O}_{3}$ mixed additive. $J$ Am Ceram Soc 2017, 100 1231-1240.

[209] Kitayama M, Hirao K, Kanzaki S. Effect of rare earth oxide additives on the phase transformation rates of $\mathrm{Si}_{3} \mathrm{~N}_{4}$. J Am Ceram Soc 2006, 89: 2612-2618.

[210] Yu FL, Bai Y, Han PD, et al. Spark plasma sintering of $\alpha / \beta \mathrm{Si}_{3} \mathrm{~N}_{4}$ ceramics with $\mathrm{MgO}-\mathrm{Al}_{2} \mathrm{O}_{3}$ and $\mathrm{MgO}-\mathrm{Y}_{2} \mathrm{O}_{3}$ as sintering additives. J Mater Eng Perform 2016, 25: 5220-5224.

[211] Liang Z-H, Zhang H-L, Gui L-C, et al. Effects of whisker-like $\beta-\mathrm{Si}_{3} \mathrm{~N}_{4}$ seeds on phase transformation and mechanical properties of $\alpha / \beta \mathrm{Si}_{3} \mathrm{~N}_{4}$ composites using $\mathrm{MgSiN}_{2}$ as additives. Ceram Int 2013, 39: 2743-2751.

[212] Dai JH, Li JB, Chen YJ. The phase transformation behavior of $\mathrm{Si}_{3} \mathrm{~N}_{4}$ with single $\mathrm{Re}_{2} \mathrm{O}_{3}(\mathrm{Re}=\mathrm{Ce}, \mathrm{Nd}, \mathrm{Sm}, \mathrm{Eu}, \mathrm{Gd}, \mathrm{Dy}, \mathrm{Er}, \mathrm{Yb})$ additive. Mater Chem Phys 2003, 80: 356-359.

[213] Bae BC, Park DS, Kim YW, et al. Texture in silicon nitride seeded with silicon nitride whiskers of different sizes. $J \mathrm{Am}$ Ceram Soc 2003, 86: 1008-1013.

[214] Park DS, Roh TW, Han BD, et al. Microstructural development of silicon nitride with aligned $\beta-\mathrm{Si}_{3} \mathrm{~N}_{4}$ whiskers. $J$ Eur Ceram Soc 2000, 20: 2673-2677.

[215] Yang ZG, Yu JB, Li CJ, et al. Effect of seed particles content on texture formation of $\mathrm{Si}_{3} \mathrm{~N}_{4}$ ceramics by gel-casting in a strong magnetic field. Adv Manuf 2015, 3: 193-201.

[216] Jiang QG, Guo WM, Liu W, et al. Influence of powder characteristics on hot-pressed $\mathrm{Si}_{3} \mathrm{~N}_{4}$ ceramics. Sci Sinter 2017, 49: 81-89.

[217] Iskoe JL, Lange FF, Diaz ES. Effect of selected impurities on the high temperature mechanical properties of hot-pressed silicon nitride. J Mater Sci 1976, 11: 908-912.

[218] Lange FF. Fracture toughness of $\mathrm{Si}_{3} \mathrm{~N}_{4}$ as a function of the initial a-phase content. J Am Ceram Soc 1979, 62: 428-430.

[219] Zhu XW, Sakka Y, Zhou Y, et al. A strategy for fabricating textured silicon nitride with enhanced thermal conductivity. $J$ Eur Ceram Soc 2014, 34: 2585-2589.

[220] Hirao K, Watari K, Brito ME, et al. High thermal conductivity in silicon nitride with anisotropie microstructure. J Am Ceram Soc 1996, 79: 2485-2488.

[221] Watari K, Hirao K, Brito ME, et al. Hot isostatic pressing to increase thermal conductivity of $\mathrm{Si}_{3} \mathrm{~N}_{4}$ ceramics. $J$ Mater Res 1999, 14: 1538-1541.

[222] Shen ZJ, Peng H, Pettersson P, et al. Self-reinforced $\alpha$-SiAlON ceramics with improved damage tolerance developed by a new processing strategy. J Am Ceram Soc 2002, 85: 2876-2878. 
[223] Yi XM, Niu J, Akiyama T, et al. Spark plasma sintering behavior of combustion-synthesized (Y,Ca)- $\alpha$-SiAlON. Ceram Int 2016, 42: 15687-15693.

[224] Alcalá MD, Criado JM, Gotor FJ, et al. $\beta$-SiAlON obtained from carbothermal reduction of kaolinite employing sample controlled reaction temperature (SCRT). J Mater Sci 2006, 41: 1933-1938.

[225] Zhu XW, Suzuki TS, Uchikoshi T, et al. Highly texturing $\beta$-sialon via strong magnetic field alignment. J Am Ceram Soc 2008, 91: 620-623.

[226] Liu J, Ma CY, Du HL, et al. The preparation and oxidation behavior of Ca-doped $\alpha$-SiAlON ceramic with elongated grains. $J$ Alloys Compd 2017, 722: 400-405.

[227] Zhu XW, Suzuki TS, Uchikoshi T, et al. Texturing Ca- $\alpha-S i A l O N$ via strong magnetic field alignment. J Ceram Soc Jpn 2007, 115: 701-705.

[228] Liu GH, Chen KX, Zhou HP, et al. Shape deformation and texture development of consolidated $\mathrm{Ca} \alpha$-SiAlON ceramics prepared by hot-forging. Mater Res Bull 2008, 43: 425-430.

[229] Cinar A, Baskut S, Seyhan AT, et al. Tailoring the properties of spark plasma sintered SiAlON containing graphene nanoplatelets by using different exfoliation and size reduction techniques: Anisotropic mechanical and thermal properties. J Eur Ceram Soc 2018, 38: 1299-1310.

[230] Song L, Ci LJ, Lu H, et al. Large scale growth and characterization of atomic hexagonal boron nitride layers. Nano Lett 2010, 10: 3209-3215.

[231] Golberg D, Bando Y, Huang Y, et al. Boron nitride nanotubes and nanosheets. ACS Nano 2010, 4: 2979-2993.

[232] Eichler J, Uibel K, Lesniak C. Boron nitride (BN) and boron nitride composites for applications under extreme conditions. $A d v$ Sci Technol 2010, 65: 61-69.

[233] Zhang Z, Duan XM, Qiu BF, et al. Anisotropic properties of textured h-BN matrix ceramics prepared using $3 \mathrm{Y}_{2} \mathrm{O}_{3}-$ $5 \mathrm{Al}_{2} \mathrm{O}_{3}(-4 \mathrm{MgO})$ as sintering additives. J Eur Ceram Soc 2019, 39: 1788-1795.

[234] Newnham RE. Properties of Materials: Anisotropy, Symmetry, Structure. Xi'an: Xi'an Jiaotong University Press, 2009.

[235] Xiao L, He WJ, Yin YS. First-principles calculations of structural and elastic properties of hexagonal boron nitride. Adv Mater Res 2009, 79-82: 1337-1340.

[236] Duan XM, Yang ZH, Chen L, et al. Review on the properties of hexagonal boron nitride matrix composite ceramics. J Eur Ceram Soc 2016, 36: 3725-3737.

[237] Tang SF, Hu CL. Design, preparation and properties of carbon fiber reinforced ultra-high temperature ceramic composites for aerospace applications: A review. J Mater Sci Technol 2017, 33: $117-130$.

[238] Jin XC, Fan XL, Lu CS, et al. Advances in oxidation and ablation resistance of high and ultra-high temperature ceramics modified or coated carbon/carbon composites. J Eur Ceram Soc 2018, 38: $1-28$.

[239] Dub SN, Sichkar SM, Belous VA, et al. Mechanical properties of single crystals of transition metals diborides TMB2 $(\mathrm{TM}=\mathrm{Sc}, \mathrm{Hf}$, $\mathrm{Zr}$, Ti). Experiment and theory. J Superhard Mater 2017, 39: $308-318$
[240] Kou HB, Li WG, Cheng TB, et al. Thermal shock resistance of ultra-high temperature ceramics under active cooling condition including the effects of external constraints. Appl Therm Eng 2017, 110: 1247-1254.

[241] Levine SR, Opila EJ, Halbig MC, et al. Evaluation of ultra-high temperature ceramics foraeropropulsion use. J Eur Ceram Soc 2002, 22: 2757-2767.

[242] Bellosi A, Monteverde F, Sciti D. Fast densification of ultra-high-temperature ceramics by spark plasma sintering. Int $J$ Appl Ceram Technol 2006, 3: 32-40.

[243] Fahrenholtz WG, Hilmas GE. Oxidation of ultra-high temperature transition metal diboride ceramics. Int Mater Rev 2012, 57: 61-72.

[244] Ran SL, van der Biest O, Vleugels J. ZrB $\mathrm{Zr}_{2}-\mathrm{SiC}$ composites prepared by reactive pulsed electric current sintering. $J$ Eur Ceram Soc 2010, 30: 2633-2642.

[245] Ran SL, van der Biest O, Vleugels J. $\mathrm{ZrB}_{2}-\mathrm{SiC}$ composites prepared by reactive pulsed electric current sintering. J Eur Ceram Soc 2010, 30: 2633-2642.

[246] Fahrenholtz WG, Hilmas GE, Talmy IG, et al. Refractory diborides of zirconium and hafnium. J Am Ceram Soc 2007, 90: 1347-1364.

[247] Yang ZG, Yu JB, Deng K, et al. Preparation of c-axis textured $\mathrm{TiB}_{2}$ ceramics by a strong magnetic field of $6 \mathrm{~T}$ assisted slip-casting process. Mater Lett 2018, 217: 96-99.

[248] Ran SL, Zhang L, van der Biest O, et al. Pulsed electric current, in situ synthesis and sintering of textured $\mathrm{TiB}_{2}$ ceramics. J Eur Ceram Soc 2010, 30: 1043-1047.

[249] Wu WW, Wang Z, Zhang GJ, et al. $\mathrm{ZrB}_{2}-\mathrm{MoSi}_{2}$ composites toughened by elongated $\mathrm{ZrB}_{2}$ grains via reactive hot pressing. Scripta Mater 2009, 61: 316-319.

[250] Liu HT, Zou J, Ni DW, et al. Textured and platelet-reinforced $\mathrm{ZrB}_{2}$-based ultra-high-temperature ceramics. Scripta Mater 2011, 65: $37-40$.

[251] Wu WW, Sakka Y, Estili M, et al. Microstructure and hightemperature strength of textured and non-textured $\mathrm{ZrB}_{2}$ ceramics. Sci Technol Adv Mater 2014, 15: 014202.

[252] Haggerty JS, Lee DW. Plastic deformation of $\mathrm{ZrB}_{2}$ single crystals. J Am Ceram Soc 1971, 54: 572-576.

[253] Ni DW, Zhang GJ, Kan YM, et al. Textured $\mathrm{HfB}_{2}$-based ultrahigh- temperature ceramics with anisotropic oxidation behavior. Scripta Mater 2009, 60: 913-916.

[254] Ni DW, Zhang GJ, Kan YM, et al. Highly textured $\mathrm{ZrB}_{2}$-based ultrahigh temperature ceramics via strong magnetic field alignment. Scripta Mater 2009, 60: 615-618.

[255] Sun M. Progress in research and development on MAX phases: A family of layered ternary compounds. Int Mater Rev 2011, 56: 143-166.

[256] Rampai T, Lang CI, Sigalas I. Investigation of MAX phase/c-BN composites. Ceram Int 2013, 39: 4739-4748.

[257] Magnuson M, Mattesini M. Chemical bonding and electronicstructure in MAX phases as viewed by X-ray spectroscopy and density functional theory. Thin Solid Films 2017, 621: 108-130.

[258] Hu CF, Zhang HB, Li FZ, et al. New phases' discovery in MAX family. Int J Refract Met Hard Mater 2013, 36: 300-312. 
[259] Liu B, Wang JY, Zhang J, et al. Theoretical investigation of A-element atom diffusion in $\mathrm{Ti}_{2} \mathrm{AC}(\mathrm{A}=\mathrm{Sn}, \mathrm{Ga}, \mathrm{Cd}, \mathrm{In}$, and $\mathrm{Pb})$. Appl Phys Lett 2009, 94: 181906.

[260] Farle A-S, Kwakernaak C, van der Zwaag S, et al. A conceptual study into the potential of $\mathrm{M}_{n+1} \mathrm{AX}_{n}$-phase ceramics for self-healing of crack damage. J Eur Ceram Soc 2015, 35: 37-45.

[261] Greil P. Generic principles of crack-healing ceramics. $J A d v$ Ceram 2012, 1: 249-267.

[262] Mishra M, Sakka Y, Szudarska A, et al. Textured $\mathrm{Ti}_{3} \mathrm{SiC}_{2}$ by gelcasting in a strong magnetic field. J Ceram Soc Jpn 2012, 120: 544-547.

[263] Mizuno Y, Sato K, Mrinalini M, et al. Fabrication of textured $\mathrm{Ti}_{3} \mathrm{AlC}_{2}$ by spark plasma sintering and their anisotropic mechanical properties. J Ceram Soc Jpn 2013, 121: 366-369.

[264] Hu CF, Sakka Y, Tanaka H, et al. Fabrication of textured $\mathrm{Nb}_{4} \mathrm{AlC}_{3}$ ceramic by slip casting in a strong magnetic field and spark plasma sintering. J Am Ceram Soc 2011, 94: 410-415.

[265] Sato K, Mishra M, Hirano H, et al. Fabrication of textured $\mathrm{Ti}_{3} \mathrm{SiC}_{2}$ ceramic by slip casting in a strong magnetic field and pressureless sintering. J Ceram Soc Jpn 2014, 122: 817-821.

[266] Zhang $\mathrm{HB}, \mathrm{Hu} \mathrm{CF}$, Sato $\mathrm{K}$, et al. Tailoring $\mathrm{Ti}_{3} \mathrm{AlC}_{2}$ ceramic with high anisotropic physical and mechanical properties. $J$ Eur Ceram Soc 2015, 35: 393-397.

[267] Xu LD, Zhu DG, Grasso S, et al. Effect of texture microstructure on tribological properties of tailored $\mathrm{Ti}_{3} \mathrm{AlC}_{2}$ ceramic. $J A d v$ Ceram 2017, 6: 120-128.

[268] Hu CF, Sakka Y, Nishimura T, et al. Physical and mechanical properties of highly textured polycrystalline $\mathrm{Nb}_{4} \mathrm{AlC}_{3}$ ceramic. Sci Technol Adv Mater 2011, 12: 044603.

[269] Bouhemadou A. First-principles study of structural, electronic and elastic properties of $\mathrm{Nb}_{4} \mathrm{AlC}_{3}$. Braz J Phys 2010, 40: 52-57.

[270] Zhou YC, Wang XH, Sun ZM, et al. Electronic and structural properties of the layered ternary carbide $\mathrm{Ti}_{3} \mathrm{AlC}_{2}$. J Mater Chem 2001, 11: 2335-2339.

[271] Noviyanto A, Han S-W, Yu H-W, et al. Rare-earth nitrate additives for the sintering of silicon carbide. J Eur Ceram Soc 2013, 33: 2915-2923.

[272] Kim T-E, Khishigbayar K-E, Cho KY. Effect of heating rate on the properties of silicon carbide fiber with chemical-vapor-cured polycarbosilane fiber. J Adv Ceram 2017, 6: 59-66.

[273] Schulz U. Phase transformation in EB-PVD yttria partially stabilized zirconia thermal barrier coatings during annealing. $J$ Am Ceram Soc 2000, 83: 904-910.

[274] Moshtaghioun BM, Cumbrera-Hernández FL, Gómez-García D, et al. Effect of spark plasma sintering parameters on microstructure and room-temperature hardness and toughness of fine-grained boron carbide (B ${ }_{4}$ C). J Eur Ceram Soc 2013, 33: 361-369.

[275] Yang ZG, Yu JB, Ren ZM, et al. Preparation of c-axis textured $\mathrm{SiC}$ ceramics by a strong magnetic field of $6 \mathrm{~T}$ assisted gel-casting process. Ceram Int 2016, 42: 6168-6177.

[276] Xie RJ, Mitomo M, Kim W, et al. Phase transformation and texture in hot-forged or annealed liquid-phase-sintered silicon carbide ceramics. J Am Ceram Soc 2002, 85: 459-465.

[277] Sacks MD, Scheiffele GW, Staab GA. Fabrication of textured silicon carbide via seeded anisotropic grain growth. J Am Ceram Soc 1996, 79: 1611-1616.

[278] Roh MH, Kim W, Kim YW, et al. Effect of hot-forging on mechanical properties of silicon carbide sintered with $\mathrm{Al}_{2} \mathrm{O}_{3}-\mathrm{Y}_{2} \mathrm{O}_{3}-\mathrm{MgO}$. Met Mater Int 2010, 16: 891-894.

[279] Lee SH, Lee YI, Kim YW, et al. Mechanical properties of hot-forged silicon carbide ceramics. Scripta Mater 2005, 52: $153-156$.

[280] Vriami D, Beaugnon E, Vanmeensel K, et al. Texturing of 3Y-TZP zirconia by electrophoretic deposition in a high magnetic field of 17.4T. J Eur Ceram Soc 2014, 34: 3879-3885.

[281] Zhang L, Vleugels J, Darchuk L, et al. Magnetic field oriented tetragonal zirconia with anisotropic toughness. J Eur Ceram Soc 2011, 31: 1405-1412.

[282] Werheit H, Leithe-Jasper A, Tanaka T, et al. Some properties of single-crystal boron carbide. J Solid State Chem 2004, 177: 575-579.

[283] Grasso S, Hu CF, Vasylkiv O, et al. High-hardness $\mathrm{B}_{4} \mathrm{C}$ textured by a strong magnetic field technique. Scripta Mater 2011, 64: 256-259.

[284] Poorteman M, Descamps P, Cambier F, et al. Anisotropic properties in hot pressed silicon nitride-silicon carbide platelet reinforced composites. J Eur Ceram Soc 1999, 19: 2375-2379.

[285] Wilk A, Rutkowski P, Zientara D, et al. Aluminium oxynitridehexagonal boron nitride composites with anisotropic properties. $J$ Eur Ceram Soc 2016, 36: 2087-2092.

Open Access This article is licensed under a Creative Commons Attribution 4.0 International License, which permits use, sharing, adaptation, distribution and reproduction in any medium or format, as long as you give appropriate credit to the original author(s) and the source, provide a link to the Creative Commons licence, and indicate if changes were made.

The images or other third party material in this article are included in the article's Creative Commons licence, unless indicated otherwise in a credit line to the material. If material is not included in the article's Creative Commons licence and your intended use is not permitted by statutory regulation or exceeds the permitted use, you will need to obtain permission directly from the copyright holder.

To view a copy of this licence, visit http://creativecommons.org/licenses/by/4.0/. 